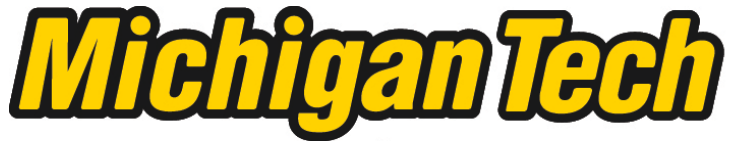 \\ Michigan Technological University Create the Future Digital Commons @ Michigan Tech
}

2014

\section{IMPROVEMENTS IN SUSTAINABILITY OF GRAVITY-FED WATER SYSTEMS IN THE COMARCA NGÄBE-BUGLÉ, PANAMA: SPRING CAPTURES AND CIRCUIT RIDER MODEL}

Erica Kathryn Jones

Michigan Technological University

Follow this and additional works at: https://digitalcommons.mtu.edu/etds

Part of the Environmental Engineering Commons

Copyright 2014 Erica Kathryn Jones

Recommended Citation

Jones, Erica Kathryn, "IMPROVEMENTS IN SUSTAINABILITY OF GRAVITY-FED WATER SYSTEMS IN THE COMARCA NGÄBE-BUGLÉ, PANAMA: SPRING CAPTURES AND CIRCUIT RIDER MODEL", Master's report, Michigan Technological University, 2014.

https://doi.org/10.37099/mtu.dc.etds/763

Follow this and additional works at: https://digitalcommons.mtu.edu/etds

Part of the Environmental Engineering Commons 


\title{
IMPROVEMENTS IN SUSTAINABILITY OF GRAVITY-FED WATER SYSTEMS IN THE COMARCA NGÄBE-BUGLÉ, PANAMA: SPRING CAPTURES AND CIRCUIT RIDER MODEL
}

\author{
By \\ Erica Kathryn Jones
}

\begin{abstract}
A REPORT
Submitted in partial fulfillment of the requirements for the degree of MASTER OF SCIENCE

In Environmental Engineering
\end{abstract}

MICHIGAN TECHNOLOGICAL UNIVERSITY

(C) 2014 Erica Kathryn Jones 
This report has been approved in partial fulfillment of the requirements for the Degree of MASTER OF SCIENCE in Environmental Engineering

Department of Civil and Environmental Engineering

\author{
Report Advisor: $\quad$ Dr. David Watkins
}

Committee Member: Dr. John Gierke

Committee Member: $\quad$ Dr. Richelle Winkler

Department Chair: $\quad$ Dr. David Hand 


\section{Table of Contents}

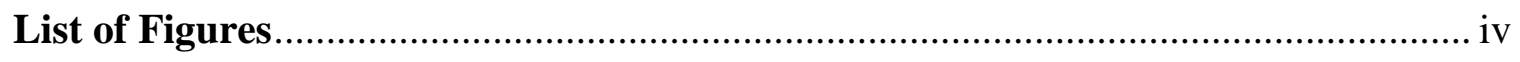

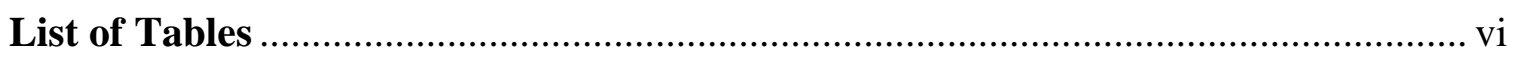

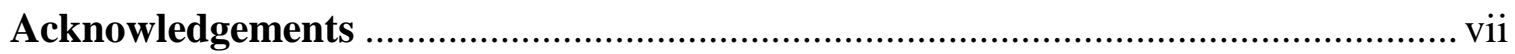

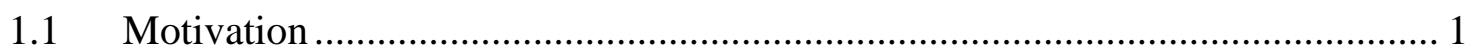

1.2 Study Setting: Comarca Ngäbe-Buglé ……………......................................... 2

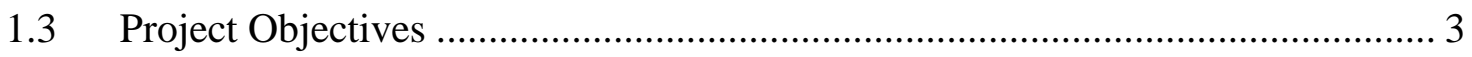

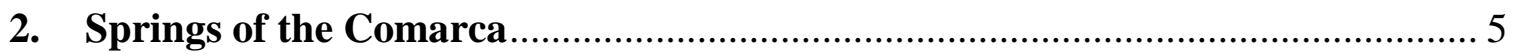

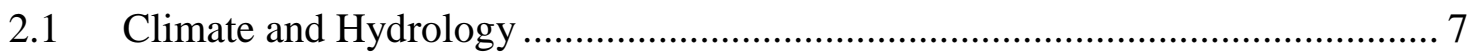

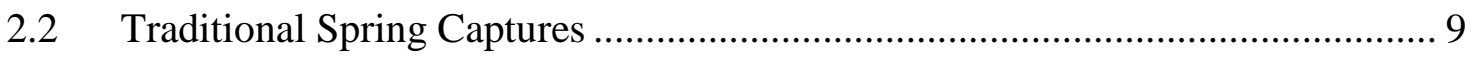

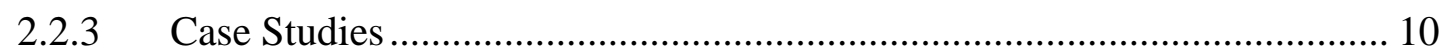

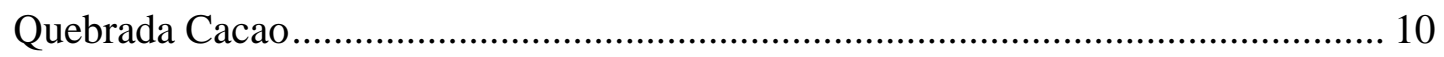

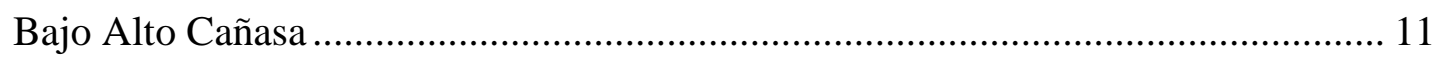

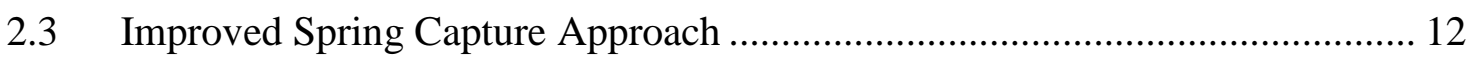

2.3.1 Design and Construction ...................................................................... 13

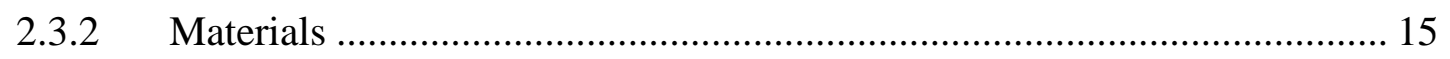

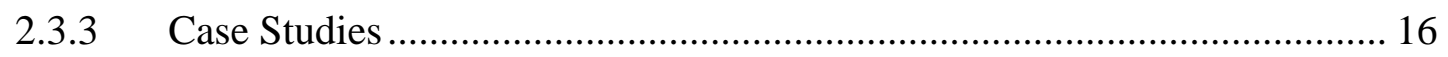

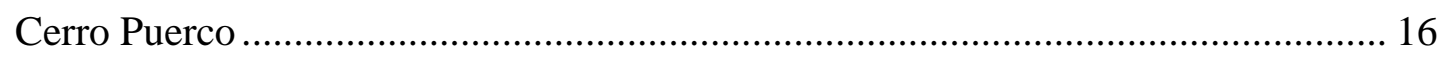

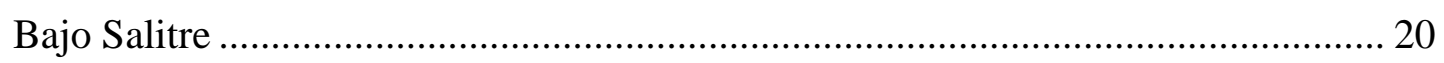

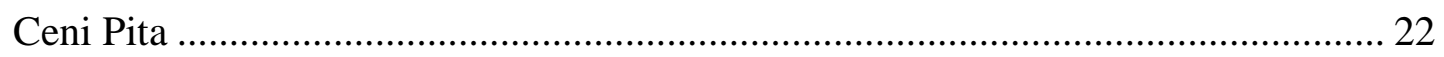

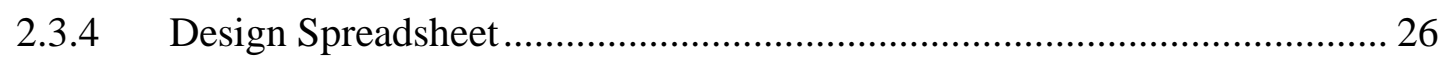

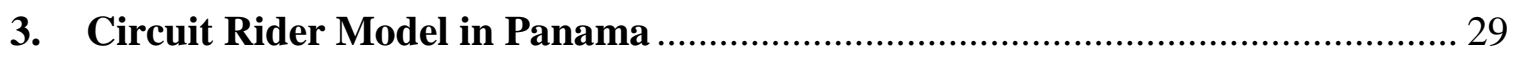

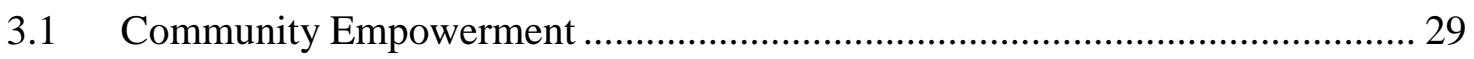

3.2 Rural Water System Maintenance in the Comarca Ngäbe-Buglé ....................... 30

3.2.1 Peace Corps Circuit Riders ................................................................. 30

3.2.2 Panamanian Agencies Working in the Comarca Ngabe-Buglé ................... 31

3.2.3 Connections and Overlap in Water System Maintenance Entities ............. 32

3.3 The Development of a Circuit Rider Model with PASAP …………………..... 33

3.3.1 Circuit Rider Model in Honduras .............................................................. 34

3.4 Case Study of Circuit Rider Influence: Cerro Iglesias One …………………... 36

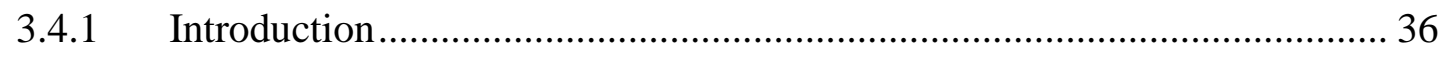

3.4.2 Role of the Volunteer Circuit Rider and Community Participants ............. 38

3.4.3 Case Study Outcomes and Conclusion ....................................................... 39

3.5 Recommendations for Panama Circuit Rider Program ........................................ 39 
3.5.1 Training Circuit Riders for the Comarca Ngäbe-Buglé ............................. 40

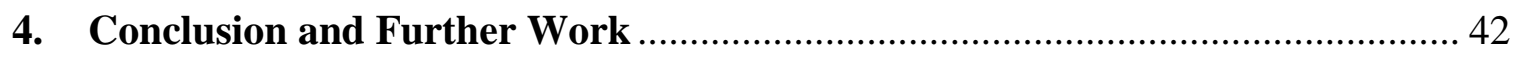

Appendix A - Precipitation and Flow Data ................................................................ 45 


\section{List of Figures}

Figure 1. Regions of the Comarca Ngäbe-Buglé (Used with permission from Nacho

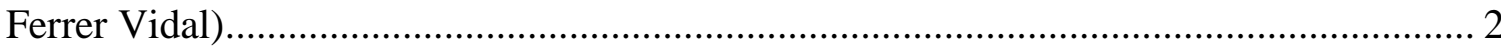

Figure 2. Mountainous terrain of the Comarca Ngäbe-Buglé (photo by author)............... 5

Figure 4. Spring on basalt bedrock (photo by author) ............................................... 6

Figure 5. Spring on impermeable clay (photo by author) ........................................... 6

Figure 6. Dense vegetation surrounding spring sources in Comarca Ngäbe-Buglé (photo

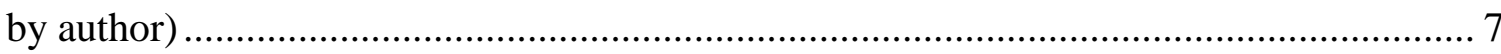

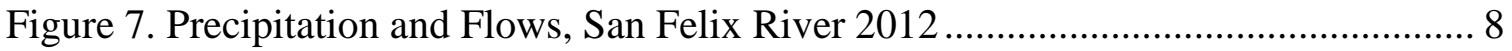

Figure 8. San Felix River Spring flow and precipitation ........................................ 8

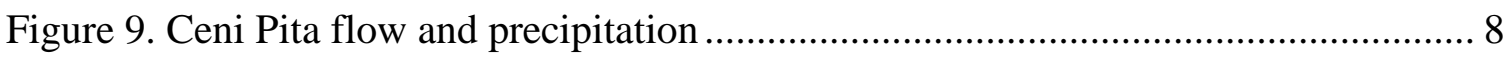

Figure 10. Total yearly precipitation at San Felix station, 2003-2013 _......................... 9

Figure 11. Deep watertight wall forming the front of a traditional spring capture (spring

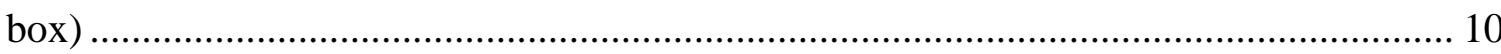

Figure 12. Quebrada Cacao spring capture, const. 1992 (photos by author)................... 11

Figure 13. Bajo Alto Cañasa old spring box (photo by author) .................................... 11

Figure 14. Cerro Puerco spring capture constructed in 1994 (photo by author).............. 12

Figure 15.Spring Capture (Used with Permission from Christopher Kingsley) ............... 13

Figure 16.Cerro Puerco, 8.348723N, -81.771179W (Google Maps) .............................. 16

Figure 17. Cerro Puerco water system prior to August 2013 renovations ...................... 17

Figure 18. Cerro Puerco water system after August 2013 renovations .......................... 17

Figure 19. Cerro Puerco old spring box and escaping water (photo by author) .............. 18

Figure 20. Puerco improved spring capture, including old spring box (middle right of

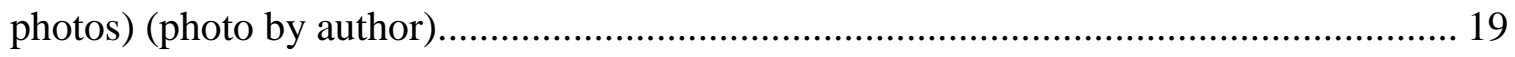

Figure 21. Cerro Puerco spring flows before and after spring capture improvements,

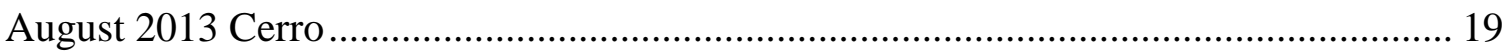

Figure 22. Bajo Salitre, 8.444701 N, -81.727222 W (Google Maps) ............................ 20

Figure 23. Bajo Salitre completes spring captures (photo by author) ............................ 21

Figure 24. Bajo Salitre improved spring capture completed view with access tank (photo

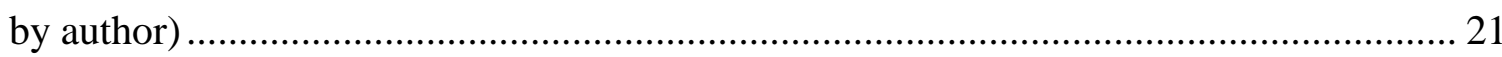


Figure 25. Bajo Salitre stone masonry collection tank (photo by author)

Figure 26. Cross section of improved spring capture. Arrows indicate flow direction of

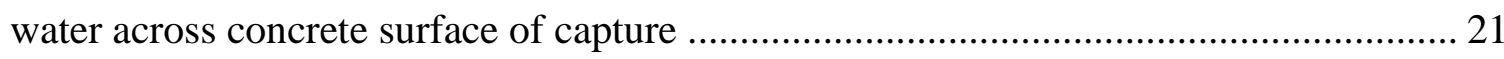

Figure 27. Bajo Salire spring flows from November 2012-September 2013 .................. 22

Figure 28. Map showing Ceni Pita, 8.353390 N, -81.755074 W (Google Maps) ............ 22

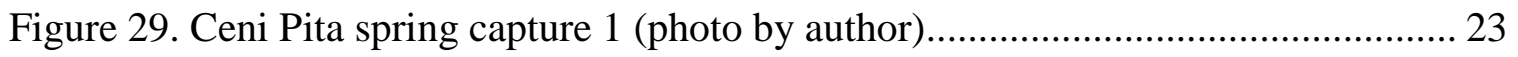

Figure 30 Ceni Pita spring capture 2 (photo by author) ............................................. 23

Figure 31. Ceni Pita improved spring capture 1(photo by author) ................................ 24

Figure 32 Ceni Pita 1 Spring Flow, August 2012 - October 2013 ............................... 25

Figure 33 Ceni Pita improved spring capture 2 (photo by author) .............................. 25

Figure 34. Spring Capture Design Spreadsheet, Spring Dimensions section .................. 26

Figure 35. Spring Capture Design Spreadsheet, Front Wall section ............................ 27

Figure 36. Spring Capture Design Spreadsheet, Volume of Materials section ............... 27

Figure 37. Spring Capture Design Spreadsheet, Flow Data section and graph ............... 28

Figure 38. Venn diagram illustrating connections between water system entities in the

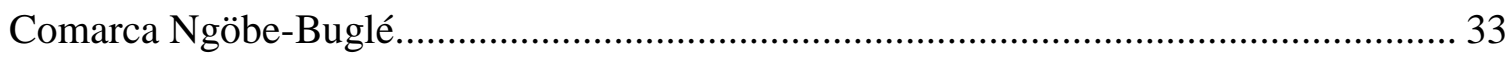

Figure 39. Map indicating Cerro Iglesias One in the Comarca Ngöbe-Buglé (GPS

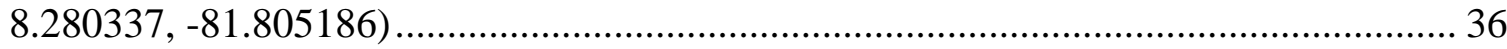

Figure 40. Schematic of Cerro Iglesias water system, un-functioning and water not

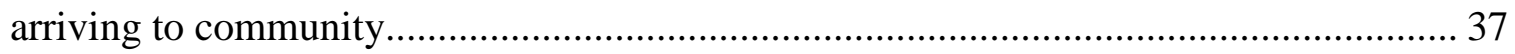

Figure 41. Schematic of Cerro Iglesias water system, improved ................................ 38 


\section{List of Tables}

Table 1. Common $\mathrm{pH}$ range of water from different sources ..................................... 6

Table 2. Traditional vs. Improved Spring Capture Materials and Costs ........................ 15

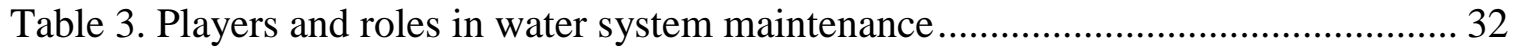

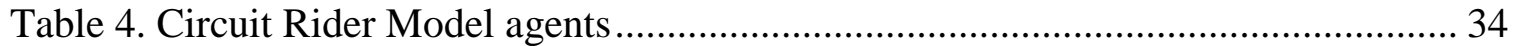

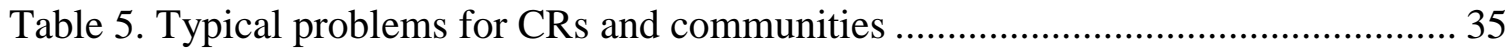




\section{Acknowledgements}

I was always told throughout my time in the Peace Corps to trust the process. I didn't always. As a critical thinker, when there was something I didn't understand - I fought against it until it proved itself to me. This worked for and against me, as you can imagine. The evolution of the project for which this report represents was a struggle. The struggle was against heat, public transportation, muddy hills, missing tubes, bad calculations, and bags of cement carried on the backs of men. It was a process. It proved itself.

Thanks to my fans at home, always equal parts amazed and concerned about my endeavors. My parents, Paul and Cynthia Jones, all my family, and my wonderful friends.

I recognize with sincere appreciation the Peace Corps Panama staff and Waterlines Volunteers. You gave me freedom to roam and trust to allow me to make mistakes and maybe, just maybe, a difference. My fellow Peace Corps Panama Volunteers who really know what this report is about: Chet Hopp, Emma Luther, and Christopher Kingsley for your contributions to the work this report approaches and for letting me document it all.

Without the support of Michigan Tech, particularly my advisor Dave Watkins, this report, this affirmation of the past two years of my life, would not have taken form. Thank you for encouraging attitudes and words, they have sustained me through this process.

My greatest acknowledgment is to my Ngobes. Not the poor, impoverished, in need ones you always hear about. My fellow human ones, with whom I ate and laughed, joked and worked. The ones that took tools out of my hands and looked to me for advice, and then forgave me when I was wrong. Thank you for your friendship and for being the unknowing subjects of my self-explorative research project. You gave me the opportunity to learn about myself and you are an aura of light shining out of me always. 


\begin{abstract}
Gravity-flow aqueducts are used to bring clean water from mountain springs in the Comarca Ngäbe-Buglé, Panama, to the homes of the indigenous people who reside there. Spring captures enclose a spring to direct the flow of water into the transmission line. Seepage contact springs are most common, with water appearing above either hard basalt bedrock or a dense clay layer. Spring flows vary dramatically during wet and dry seasons, and discharge points of springs can shift, sometimes enough to impact the capture structure and its ability to properly collect all of the available water.

Traditionally, spring captures are concrete boxes. The spring boxes observed by the author were dilapidated or out of alignment with the spring itself, only capturing part of the discharge. An improved design approach was developed that mimics the terrain surrounding the spring source to address these issues. Over the course of a year, three different spring sites were evaluated, and spring captures were designed and constructed based on the new approach. Spring flow data from each case study demonstrate increased flow capture in the improved structures.

Rural water systems, including spring captures, can be sustainably maintained by the Circuit Rider model, a technical support system in which technical assistance is provided for the operation of the water systems. During 2012-2013, the author worked as a Circuit Rider and facilitated a water system improvement project while exploring methods of community empowerment to increase the capacity for system maintenance. Based on these experiences, recommendations are provided to expand the Circuit Rider model in the Comarca Ngäbe-Buglé under the Panamanian Ministry of Health's Water and Sanitation Project (PASAP)
\end{abstract}




\section{Introduction}

\subsection{Motivation}

As the target year approaches for the United Nations (UN) Millennium Development Goal (MDG) 7C, to "halve, by 2015, the proportion of the population without sustainable access to safe drinking water and basic sanitation", accolades are given for providing 2.1 billon more people with in-home access to clean drinking water since 1990, which exceeds the MDG (United Nations, Department of Public Information 2013). Through cooperation between the UN and local government, Panama has been the recipient of nine community water systems in the Comarca Ngäbe-Buglé (United Nations, Department of Information 2013). As observed by the author serving as a United States Peace Corps Volunteer (PCV) in Panama from 2011 until 2013, working in the Comarca Ngäbe-Buglé, development was extensive: from road improvements to latrine and water-system construction. The Environmental Health (EH) sector of work in Peace Corps Panama falls directly under and is responsible for implementing strategies aimed at achieving MDG 7, contributing towards rural clean water access and training. A PCV has a unique perspective, however, from living with local people for two years, eating what they eat, and sharing their struggles. Meeting an MDG target becomes less abstract and more about ensuring that your friend next door won't lose any more of her children to preventable illness and that you yourself won't get sick either. When the development target is met for a typical aid organization, such as the UN, and the focus is shifted, a PVC continues to work with compassion until conditions are improved in every corner of their immediate world.

Many different methods to increase access to clean water have been employed in rural parts of Panama. In the Comarca Ngäbe-Buglé, Panamanian government agencies such as the Project for Water and Sanitation in Panama (PASAP) and the Panamanian Institute for Municipal Development (IPADEM) have been created to collaborate with international organizations such as the World Bank, the United Nations, and the Government of Spain to carry out projects in water infrastructure. Religious organizations, university students, and other non-governmental organizations (NGOs), as well as the Peace Corps, work for varying amounts of time and intensity using methods of community partnership, economic infusions, and cultural exchange. The Peace Corps uses a behavioral change model of development work with the understanding that through facilitation, training, and influence over a significant amount of time, good habits for health and sanitation can be promoted (Peace Corps, 2005). In terms of water systems, the Peace Corps focuses on capacity building of community members, key community leaders, and local government agencies to ensure sustainability of water projects. Capacity building comes through formal events such as project management and leadership seminars, as well as informal personal relations.

The motivation for this report is to promote a more sustainable approach to water system construction and maintenance in order to continue to increase access to clean water. While working in the Comarca Ngäbe-Buglé, the first major issue encountered by the author regarding water systems was inadequate protection of the water sources. Secondly, there was a lack of maintenance methods for water systems, on both a community and regional 
level. Spring captures constructed in a more sustainable way, along with increased community involvement and technical support for maintenance, can contribute to increased rates of clean water access in this region.

\subsection{Study Setting: Comarca Ngäbe-Buglé}

Located in the western half of Panama (Figure 1), the Comarca Ngäbe-Buglé is home to two distinct people groups, the Ngäbe and the Buglé, who live harmoniously and share the same culture, yet have distinct languages. The Ngäbe-Buglé is the focus of world-wide attention because it is one of the most populous indigenous groups and also one of the poorest (ECLAC, 2006). The incidence of poverty among indigenous people in Panama is ninety-five percent (World Bank, 1999), access to clean water in the house or community is just forty-two percent, and only ten percent have uninterrupted service (Encalada, 2013). The Comarca became designated land in 1997 from the provinces of Bocas Del Toro and Chiriquí.

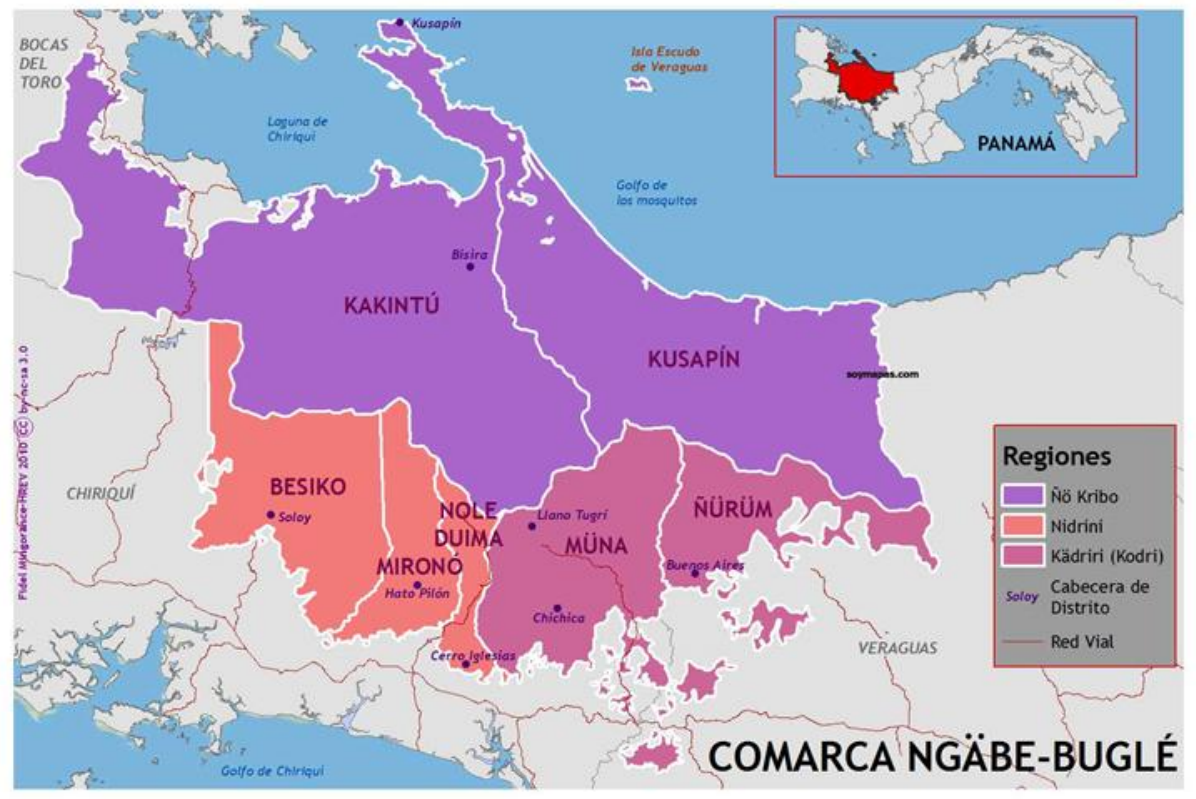

Figure 1. Regions of the Comarca Ngäbe-Buglé (Used with permission from Nacho Ferrer Vidal)

The indigenous group settled in this mountainous, infertile region of Panama after the arrival of Spain in the early $16^{\text {th }}$ century. Rodrigo de Bastidas, Christopher Columbus, and Vasco Balboa were the first Spaniards to settle Panama, where approximately 500,000 indigenous people of different tribes resided (Meditz and Hanratty, 1987). The people currently live in extended family groups in either traditional grass and bamboo huts, made of rough cut timber or cement block and with corrugated zinc roofs. The diet of the NgäbeBuglé consists mainly of locally grown rice, yucca, plantains, and beans.

One sustainable model of infrastructure projects in developing areas involves generating economic activity among the population to be served in order to provide capital 
investments for project materials, construction, and maintenance. This type of development creates community ownership and motivation to maintain the infrastructure because of personal investment. When approaching development work in low-income areas, however, social, economic, and technical issues must be considered. For example, income generation is culturally irrelevant for some, as most rural indigenous Panamanians are subsistence farmers with cultural motivations to maintain their lifestyle inside the Comarca. Thus, external funding sources are needed to construct systems large enough to meet the basic needs of the community.

With very little funding for design and construction of water systems, communities cannot contract design work nor hire skilled laborers to meet their water needs. The indigenous in Panama are not the beneficiaries of a proportional amount of the country's gross domestic product (GDP). The gross national income (GNI) for Panama is \$8,510 (2012), while $27.6 \%$ of Panamanians are below the national poverty line, and $19 \%$ of those are indigenous Panamanians (The World Bank, 2014). The income gap creates a non-viable local economy and unskilled demographic without funding for capital projects but great basic infrastructure needs.

Initial investment in a water project is generally needed from foreign countries or organizations. System design is usually done by government technicians specializing in water projects. Most of the menial labor is done by community members, while technical work is contracted out to skilled laborers or knowledgeable persons related to the project. After the project is completed, regular maintenance and periodic upgrades are necessary. However, most communities do not have the knowledge and skills to follow through with project maintenance on their own. To address this shortcoming, the Panamanian Ministry of Health (MINSA) provides technicians for each township of the Comarca. The Project of Water and Sanitation of Panama (PASAP) is a subsector of MINSA that manages the technicians. PASAP is funded partially through national funds and partially through contributions from other nations and world organizations.

Figure 1 shows the seven townships that comprise the Comarca, of which the population is over 154,000 residents (Ferrer, 2012). PASAP provides approximately one technician per township, which means each technician is responsible for approximately 66 water systems in 44 communities. Many communities are very remote with no vehicle access. This is why community-based maintenance is critical.

\subsection{Project Objectives}

The overall goal of this report is to provide recommendations for the improvement of gravity-fed water systems in the Comarca Ngäbe-Buglé. It investigates the most relevant topics affecting system performance, as observed during the author's two-year Peace Corps service. As specific objectives, the report aims to provide the following:

An in-depth knowledge of spring sources in the Comarca and examples demonstrating the lack of success of traditional spring boxes for gravity-fed water systems. 
$>$ An improved method of spring capture design specifically developed for the geology of the Comarca Ngäbe-Buglé, along with three case studies showing the development of specific designs.

A new tool for future PCVs that can facilitate design of spring captures and aid selection of a spring source.

A description of current water system monitoring in the Comarca NgäbeBuglé, both by Peace Corps and the Panamanian government.

$>$ Recommendations for a Circuit Rider model of water system maintenance, based on a successful model used in Honduras and the author's own participant experience working in the Comarca Ngäbe-Buglé.

The following chapters will support these objectives with illustrative case studies and analysis. Chapter 2 will describe the issues encountered with traditional spring captures and the method developed to resolve those issues, and case studies that support the improved method. Chapter 3 will discuss the sustainability of water system maintenance in the Comarca Ngöbe-Buglé and propose the Circuit Rider model for technical assistance and community empowerment, based on the author's experience. 


\section{Springs of the Comarca}

Residents of the Comarca Ngäbe-Buglé obtain water from spring sources, naturally filtered of microbes and sediments by thick layers of earth. In the hilly landscape (Figure 2), springs are found on hillsides and in ravines, recharged during the rainy season and flowing into creeks and rivers towards the nearby Pacific Ocean (Figure 3).

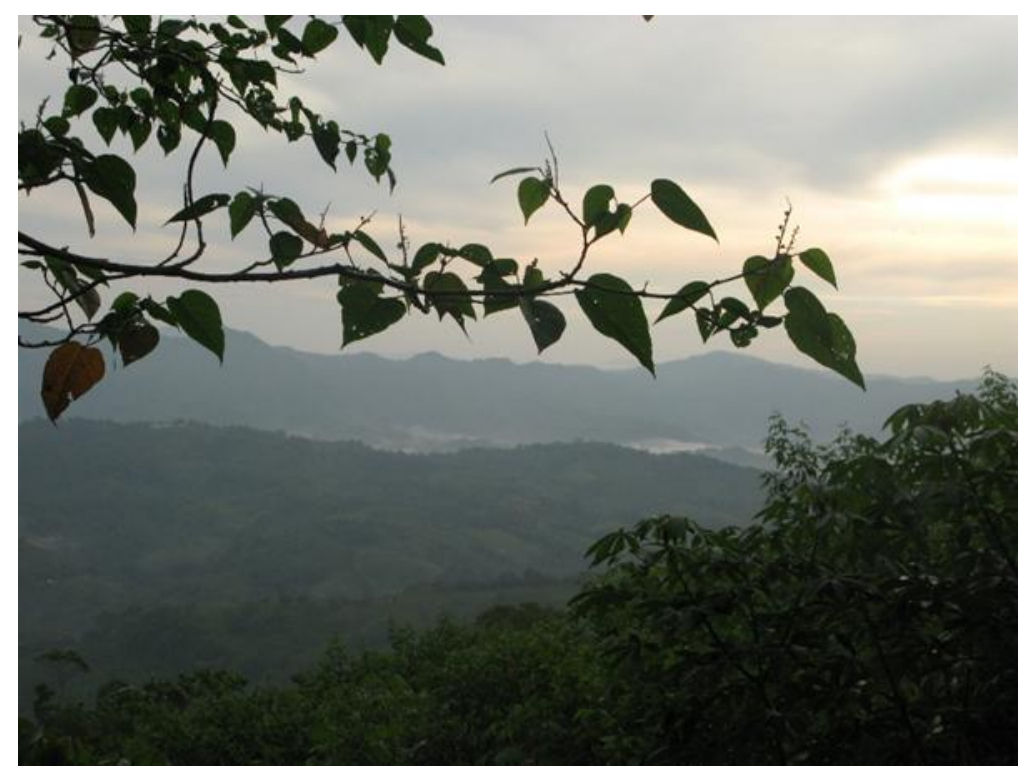

Figure 2. Mountainous terrain of the Comarca Ngäbe-Buglé (photo by author)

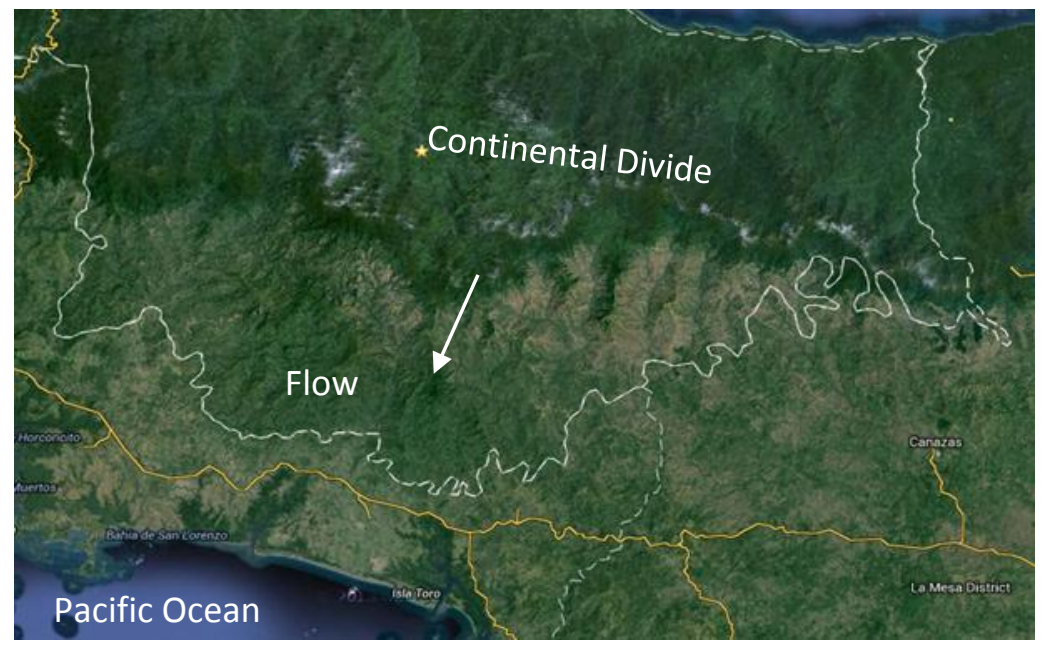

Figure 3. Satellite map of Comarca Ngäbe-Buglé (Google maps) 
The springs in this region are contact springs. Water leaves the ground at the ojo de agua or eye of the spring, when it comes in contact with an impermeable layer after flowing through permeable material in the local aquifer. The impermeable layer is either bedrock of volcanic basalt (Figure 4) or clay (Figure 5).
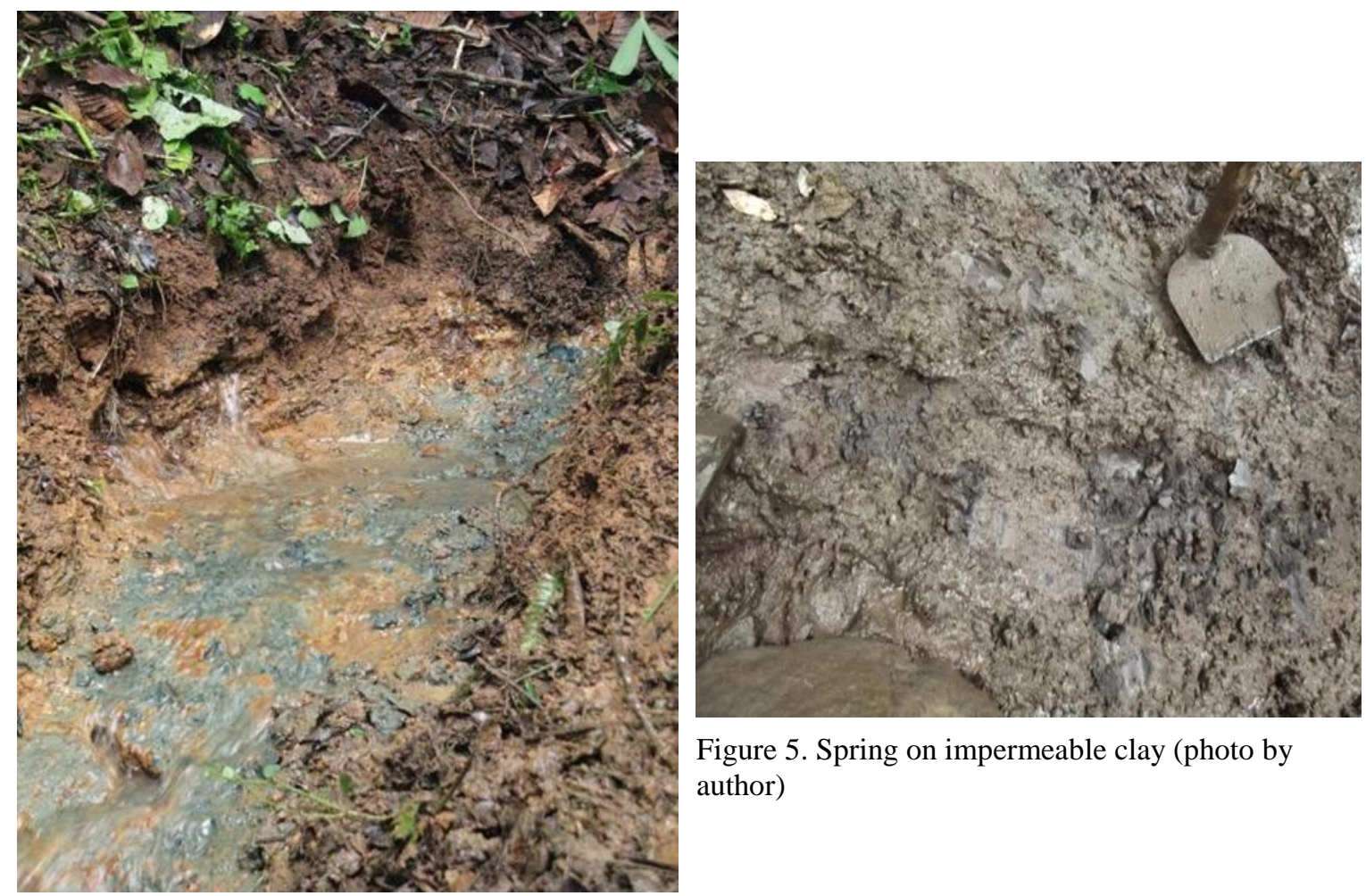

Figure 5. Spring on impermeable clay (photo by author)

Figure 4. Spring on basalt bedrock (photo by author)

Geomorphology affects spring sources in the Comarca Ngäbe-Buglé. Several factors in Panama lead to weathering in a tropical environment, including high temperature, high precipitation, dense vegetation (Figure 6), rock type and texture, and seasonal variations in climate (Thomas, 1974, p. 14). In addition, groundwater tends to have a higher $\mathrm{pH}$ than rainfall, as shown in Table 2, which contributes to acidic reactions of silica rock and clays found in tropical locations such as the Comarca Ngäbe-Buglé (Thomas, 1974, p. 24). The weathering of the impermeable layers affects spring structure, flow, and the location of the contact with the impermeable layer within a wet-dry cycle and over multiple years. These are all important considerations in spring capture design and construction.

Table 1.Common $\mathrm{pH}$ range of water from different sources

\begin{tabular}{|c|c|}
\hline Source of Water & Common pH range \\
\hline Rainfall & $5.1-7.4$ \\
\hline Runoff - streams & $4.8-7.6$ \\
\hline Groundwater - superficial & $5.8-8.6$ \\
\hline
\end{tabular}




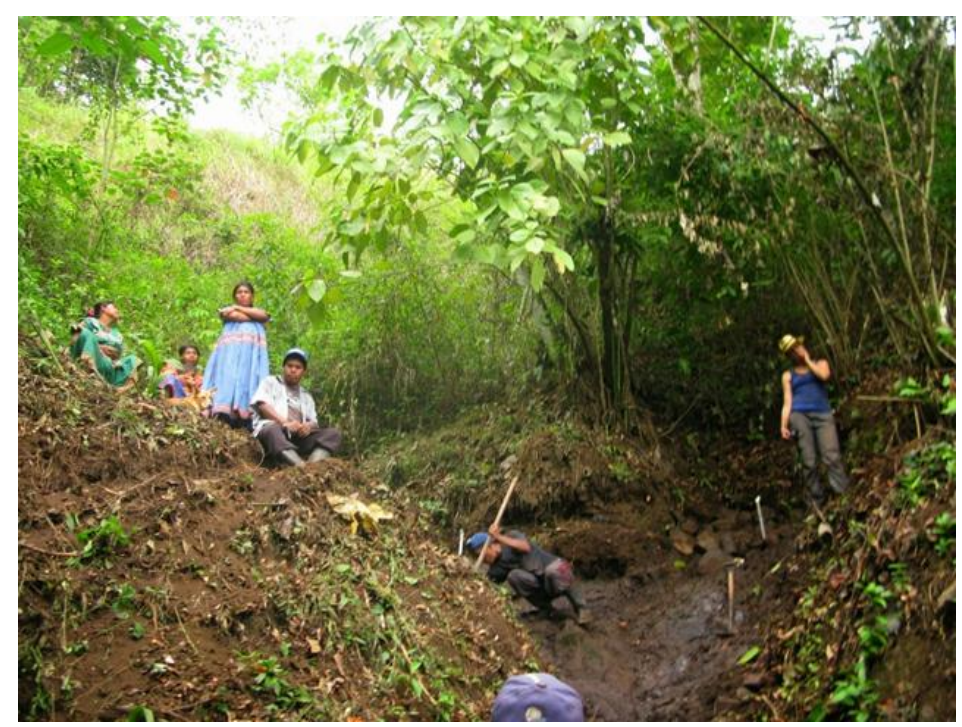

Figure 6. Dense vegetation surrounding spring sources in Comarca Ngäbe-Buglé (photo by author)

\subsection{Climate and Hydrology}

There are distinct wet and dry seasons in this region. The dry season begins in December and lasts until April or May, when rainstorms begin to occur regularly. Figures 7 and 8 show the relationship between monthly precipitation and the flow of the San Felix River, the culminating river in the San Felix area watershed. The graphs demonstrate a lag of increased flow at the end of the dry season (April), where precipitation significantly increases. During this period, the dry earth is recharging its store of water, and as soils become more saturated, flow corresponds more directly with precipitation (JulyNovember).The pronounced dry season in Panama affects water supply quantities and will affect the selection and planning of a spring capture. The dry season does not typically begin to affect springs until March, when water flows decrease over time. Some springs dry completely, and others decrease flow by varying amounts. For example, measurements in 2013 at the Ceni Pita spring (Figure 9) showed sustained flows of 0.4-0.5 liter/s until May, when the flow dropped to less than 0.2 liter/s. Following the dry season, it sometimes takes weeks of rain before the aquifers are recharged again and springs flow with more consistency. The strong seasonal relationship between rainfall and spring flows suggests a shallow local flow system. Figure 8 shows the San Felix River flows over the same time frame. 


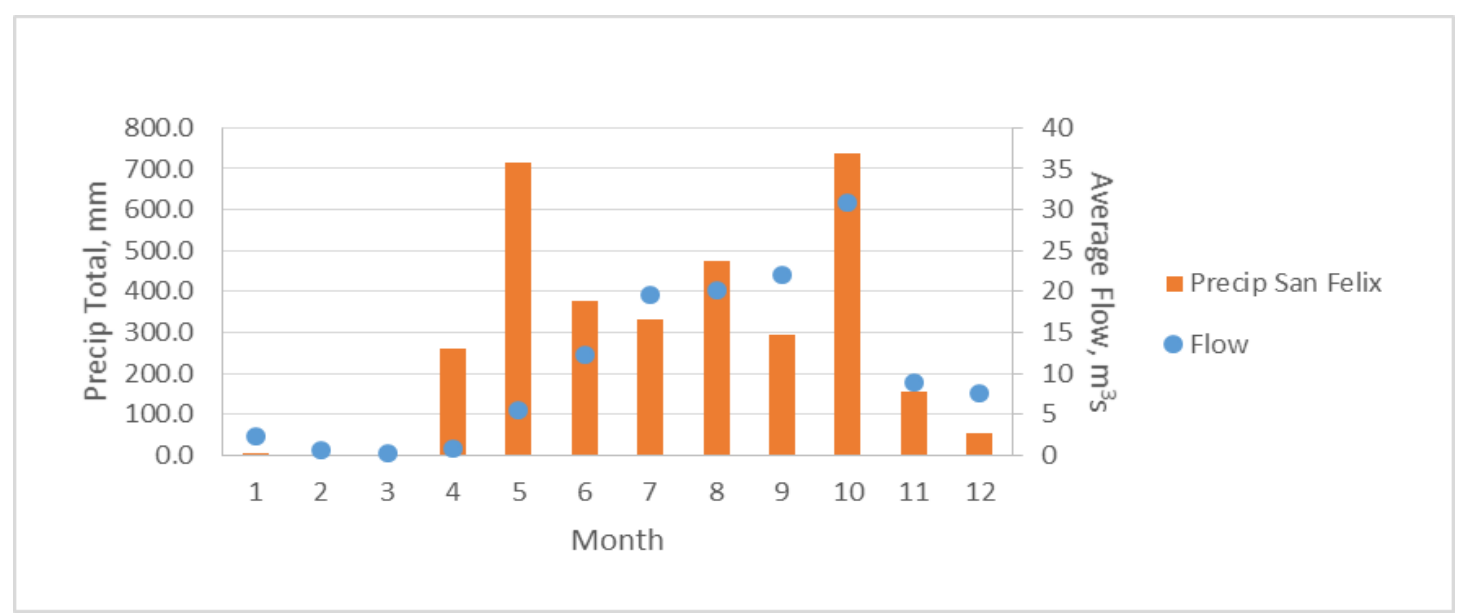

Figure 7. Precipitation and Flows, San Felix River 2012

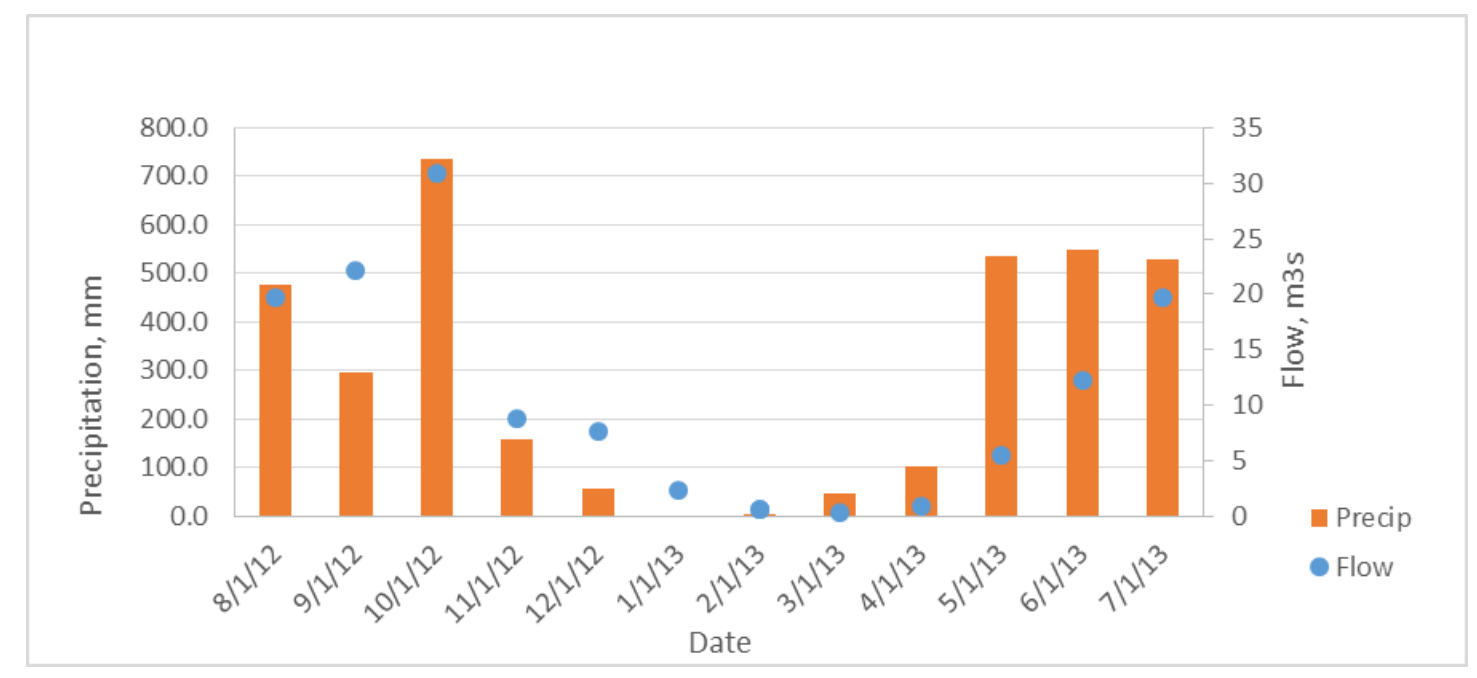

Figure 8. Precipitation and Flows, San Felix River, August 2012-July 2013

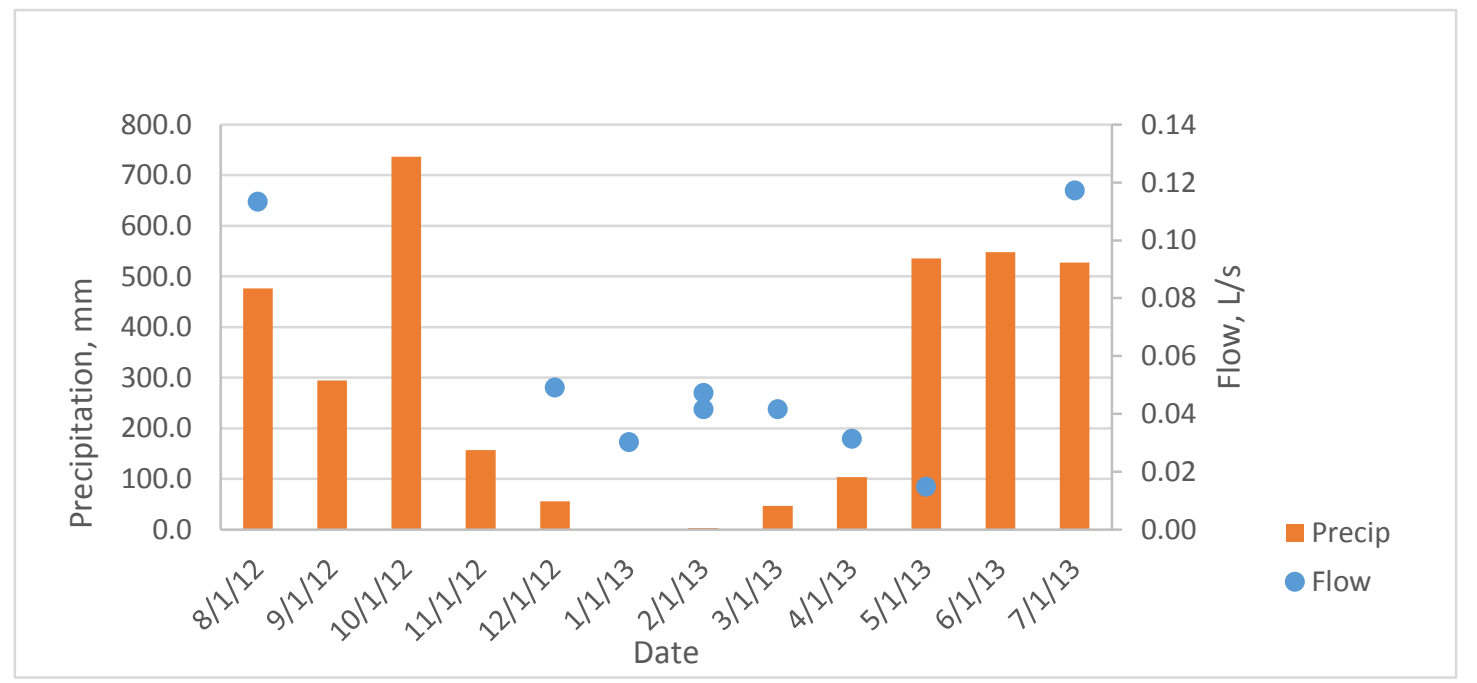

Figure 9. Precipitation and Flows, Ceni Pita Spring, August 2012-July 2013 
Figure 10 illustrates inter-annual precipitation variability, based on rainfall measurement at San Felix. This ten year period exhibits a downward trend in total precipitation from 2003 until 2013, and low-rainfall years were especially noted by the author during the 2011-2013 period.

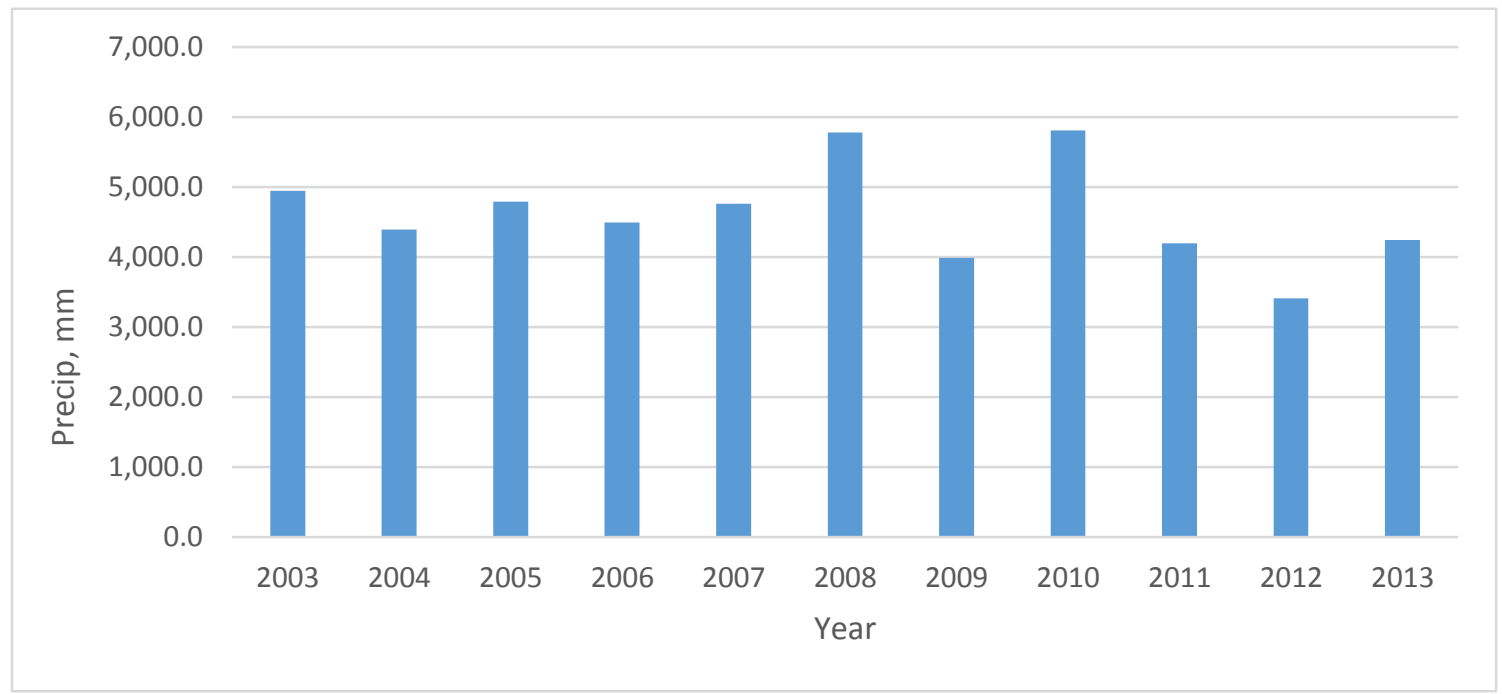

Figure 10. Total yearly precipitation at San Felix station, 2003-2013

In this study, spring flows were measured using the volume-time method with appropriatesized containers. Flows from spring captures were measured through the outflow tube. Any water flowing outside of the spring capture was measured by channeling the flow into a single stream with banana leaves, split lengths of bamboo shoots, and soft clay earth material. Three measurements were taken of each flow and the mean flow was used.

\subsection{Traditional Spring Captures}

\subsubsection{Design Theory}

Thomas Jordan describes in the book A Handbook of Gravity-Flow Water Systems that the source is where water is collected at an intake and channeled into a pipeline, and is the first point of flow in a water system (Jordan, 2006, p. 99). For traditional spring captures, deep, watertight walls are constructed to cut off seepage flow around the spring (Figure 11). Spring flows tend to carry little sediment material, and generally do not require a large collection tank for sedimentation purposes. Any sediment that may be present is primarily settled out or filtered by the aggregate in the spring. Spring capture cleaning is recommended once a year to remove sediment buildup on the screen. The lifetime of a spring capture is limited by the durability of materials and affected by the exposure to weathering. With yearly cleaning and maintenance to repair any degradation to concrete work, spring captures can typically function for up to twenty years. 


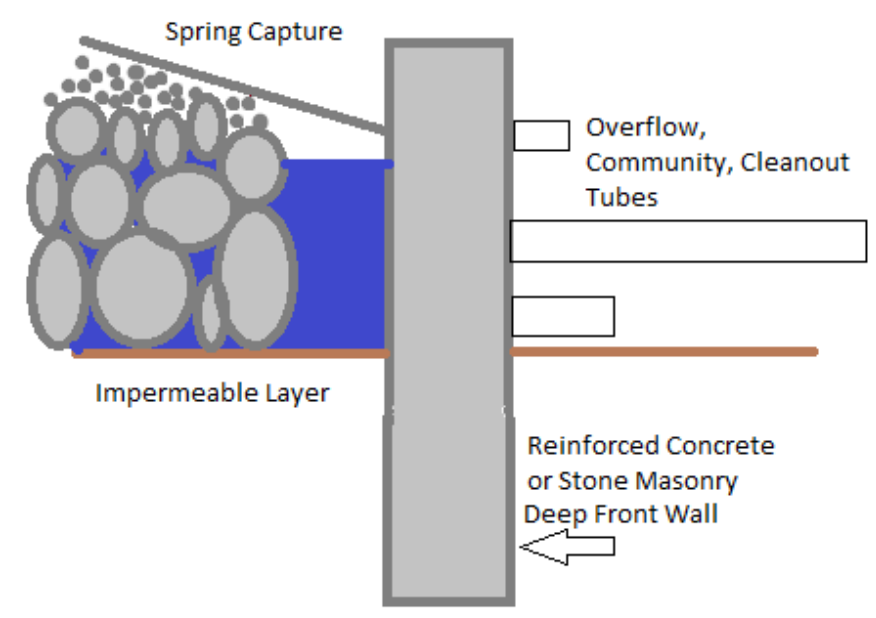

Figure 11. Deep watertight wall forming the front of a traditional spring capture (spring box)

\subsubsection{Failure Modes}

Most of the spring boxes of the Comarca Ngäbe-Buglé include sedimentation tanks and lack deep, watertight walls. The following three cases are failing spring captures in the Comarca. All are over ten years old and were constructed by government contractors. All have major construction faults, and the worst one lacks a deep watertight wall. Currently, water seeps from underneath, and the capture loses large quantities of water during the dry season. It is almost impossible to fix this problem without having to rebuild the entire capture.

\subsubsection{Case Studies}

\section{Quebrada Cacao}

The photos displayed in Figure 12 from Quebrada Cacao show a spring capture in which an extreme amount of materials was used without a purpose. The original spring was located on the side of an eroded hillside. A wall at least seven feet high was constructed between soft dirt sidewalls, and a poorly constructed roof is now collapsing from lack of reinforcement. The tall front wall serves no purpose as a settling box. It also has no potential to be water tight, as the edges of the walls are against soft earth material. Currently, most of the water flows into the outflow line to the community water storage tank, while part of it seeps out from underneath the front wall. This spring capture has also been poorly maintained by the community. One day was spent with the community sealing the failing roof to prevent the introduction of organic material and contamination. Fortunately, the spring provides sufficient water flow that the small community it serves is not affected by the flow loss. 

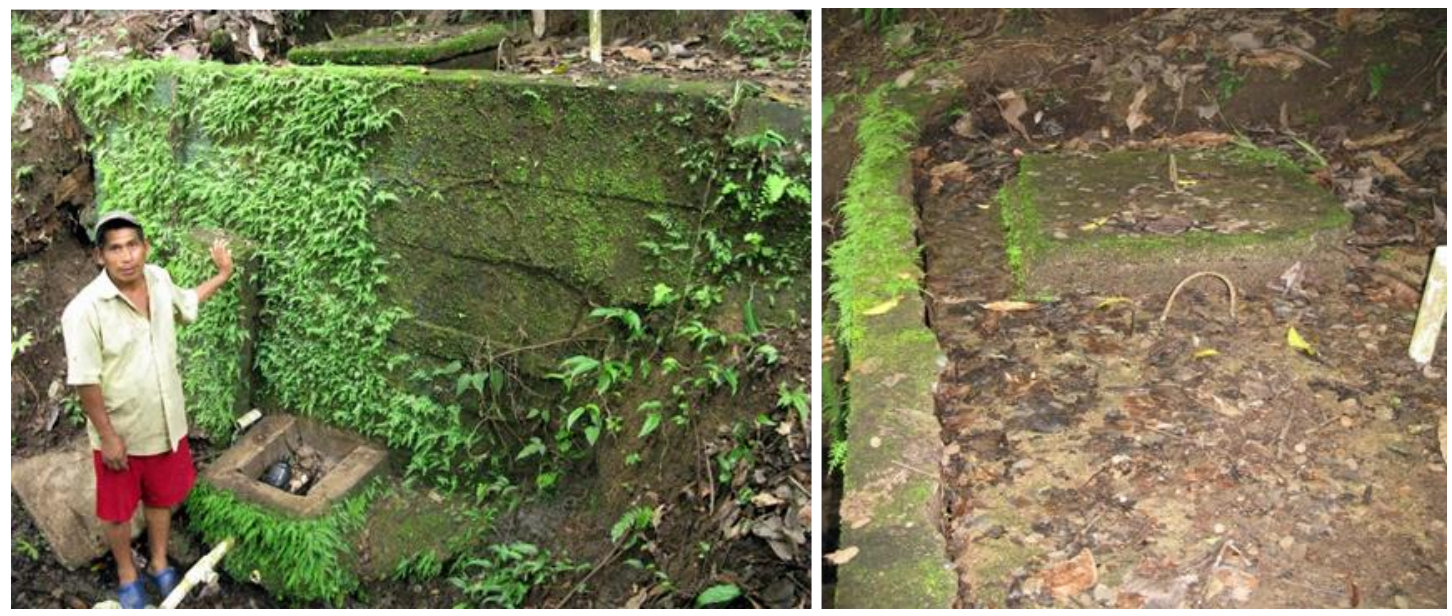

Figure 12. Quebrada Cacao spring capture, const. 1992 (photos by author)

\section{Bajo Alto Cañasa}

The community of Bajo Alto Cañasa has two spring captures that serve a community of sixteen houses. The two spring captures are 50 feet apart and located at the base of one slope and before the land begins to slope downhill again. The springs are both from the same immediate watershed. The community has misguidedly been maintaining the immediate watershed, approximately 100 feet radially, clear of vegetation. This is suspected to have increased surface runoff and decreased the flow of groundwater into the springs. The spring captures themselves have no deep front wall, and water bypasses the outflow tube to the community (Figure 13).

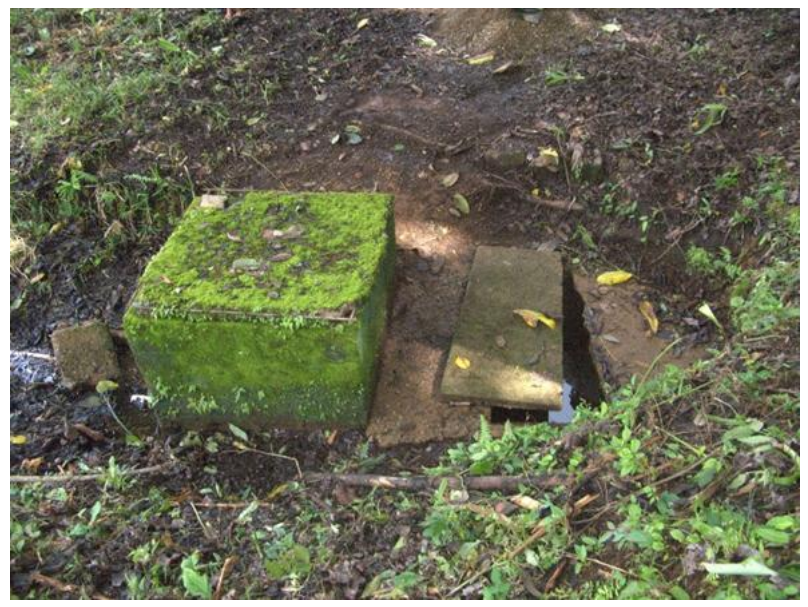

Figure 13. Bajo Alto Cañasa old spring box (photo by author) 


\section{Cerro Puerco}

In Cerro Puerco, two spring captures were constructed to provide water to over 600 residents and an elementary and high school. The spring capture in Figure 14 was constructed in 1994 by contractors funded by the Panamanian Ministry of Health. The spring is located in a ravine on a mixture of hard clay and granite rock, covered in very soft earth material. Water discharge points in the spring can be easily manipulated in the low density earth material within a twenty foot radius. If the water is blocked at one section, it will begin to flow in another area.

This spring does not stop flowing in the dry months and is a permanent water source for the community. However, construction of the spring capture is poor. Like the spring capture in Quebrada Cacao, this spring capture was constructed without a deep front wall to back up any seeping water. Seepage inside of the collection box eventually eroded away channels around the concrete wall, and now a large percentage of the flow seeps from beneath the front wall and out of the front right side of the box.

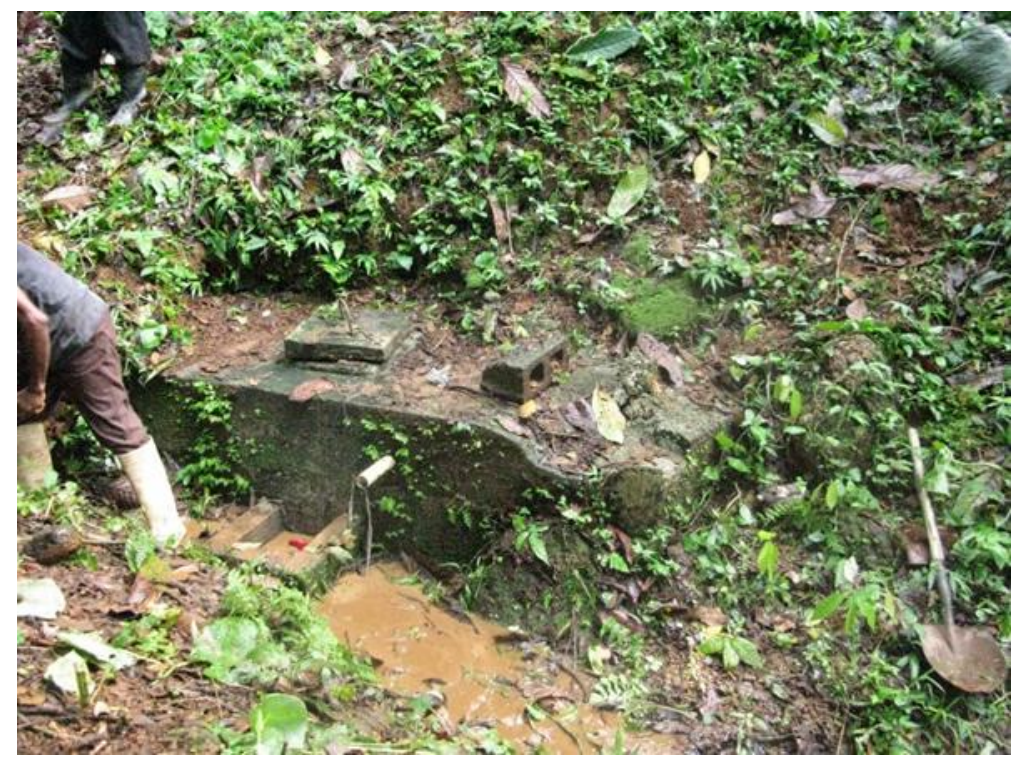

Figure 14. Cerro Puerco spring capture constructed in 1994 (photo by author)

\subsection{Improved Spring Capture Approach}

The examples of the three spring captures above are not unique. Time, environmental stress, and weather exposure negatively affect spring captures. Every spring capture will need basic maintenance annually and more serious maintenance when necessary. Poorly constructed spring captures can misuse scarce materials and lose their ability to capture water almost immediately. Most poor construction is irreversible. For example, when water starts to seep from beneath a front wall, it becomes extremely difficult to repair it.

In response to these problems, a new theory of spring captures in the Comarca NgäbeBuglé has developed among technically skilled constructors and among PCVs working in EH. In a technical brief from the collection Running Water (Shaw, 1999), spring boxes are 
described, and an alternative design is presented. The alternative can be used if water can be protected and collected without a spring box, if no sedimentation is needed, and if no storage box is required (Shaw, 1999, p. 5). The technical brief describes the essential parts to protecting a spring without a spring box, including site selection, excavation, and construction of the headwall. The approach that has been developed in the Comarca NgäbeBuglé includes many of the principles of spring protection and applies to the site-specific environment of the Comarca. This approach, shown in Figure 15, has been applied in the Comarca Ngäbe-Buglé over the past five years, started by a Panamanian technician and now replicated by PCVs.

The new approach is a way to protect the spring as it naturally flows, accounting for shifts in geology through time and capturing the full amount of water, while using the most practical amount of materials. There is no specialized skill involved with the construction of these spring captures. Community members can easily replicate the design once the concept is well understood.

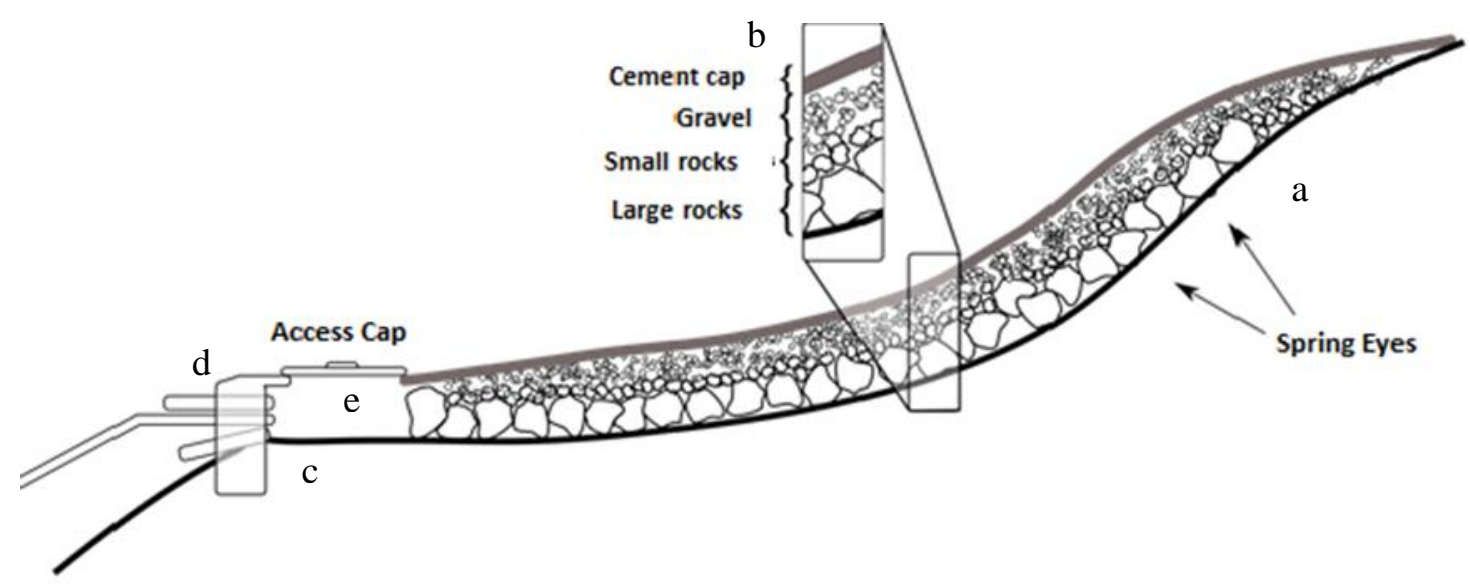

Figure 15.Spring Capture (Used with Permission from Christopher Kingsley)

\subsubsection{Design and Construction}

\section{$\underline{\text { Step One }}$}

As with any other spring capture, an appropriate spring source must be selected. This involves knowing the water demand of the population the system will serve and knowing the seasonal flows of the spring. Typically, a community will know the seasonal variations in flow in general terms, but it is best to have recorded monthly flows from throughout the year.

Quantities of water flowing over a poorly defined channel of mud and rocks may be difficult to measure. The best approach is to channel the water into one path and measure a single stream. In the jungle of the Comarca Ngäbe-Buglé, employ the use of banana leaves and large bamboo shoots to direct water. Clay may also be helpful to secure the banana leaves. 


\section{$\underline{\text { Step Two }}$}

The next step is to prepare the site. Excavate material (Figure 15, a) along the flow path from where the spring appears until a natural change in structure is observed. As material is removed, it may become obvious that the spring is appearing in different locations. There should be a balance between removing too much material and not enough material to clearly see where the water is originating. Ideally, excavate until soft material is removed and the spring source is obvious. Be aware when excavating that in the following steps the excavated area should be filled and covered with concrete, and the joint of the concrete with the surrounding earth should be flush.

Water should be diverted away from the construction area, especially the deep front wall. A common effective method is to dam the water at one point and connect a drainage pipe that directs the water below the site. Every site will have to be evaluated for the most appropriate method of water diversion.

\section{Step Three}

The excavated volume should be filled with sorted rocks, starting with clean, small boulders, around one foot in diameter (Figure 15, b). The floor of the excavated area should be covered, so that the spring water is draining around the larger rocks. Then cover the large rocks with clean medium-sized gravel. Ideally, the gravel should not fall though the small boulders, but rather fill the visible cracks between them. When the water is directed into the capture, it should flow between the boulders, and there should only be enough gravel so that the tops of the small boulders show, leaving a uniform surface adjacent to the surrounding earth.

\section{$\underline{\text { Step Four }}$}

A trench should be excavated in the front of the new spring capture area (Figure 15, c). The trench should be deep enough to avoid erosion of soil beneath the wall, approximately one foot below the surface of the impermeable layer; and wide enough to block any spring flow downhill, approximately one foot wider than the natural water channel.

\section{Step Five}

Ventilation tubes should be placed in the spring capture area. They should provide an exit for air moving around the flowing water, so the tubes should extend into the rock fill. They should be covered with screening material or bent over so that nothing can enter the spring capture.

\section{$\underline{\text { Step Six }}$}

The deep front wall should be reinforced with rebar or built using stone masonry. Rebar should be placed at half-foot intervals. Stones should be layered and fitted around concrete mix until the desired height is reached. The top should be flush with the spring capture above it. Cleanout, outflow, and overflow pipe sections should be placed in the wall.

The outflow pipes should be treated as in any other spring capture (Figure 15, d). The cleanout should be fitted with a threaded cap or valve. The outflow pipe to the community 
storage tank should be fitted with a shutoff valve. Metal valves are preferred over plastic valves. The overflow pipe should be left un-capped in case of overflow.

\section{$\underline{\text { Step Seven }}$}

The filled in capture area should be covered with a mortar (mixture of sand and cement, with no large aggregate). A waterproofing admixture, such as SIKA® (commonly found in Panama) should be used as well. The cover should be just thick enough to cover all of the gravel. The breather tubes should be sealed tightly in place. The edges of the spring capture should round up towards the joint with the earth so as to reduce the likelihood of erosion and to encourage rain to run off over top of the capture structure.

Between the wall and the capture area, around the location of the outflow tubes, a space should be left open, free of boulders and the other fill materials (Figure 15, e). This space is for settling, collection, and cleaning. A lid should be constructed and sealed in place on top of the open space, so no foreign material can enter.

\subsubsection{Materials}

In comparison to traditional spring box construction, the alternative method of spring capture uses less construction materials, reduces disturbance of the spring, and better ensures that the spring capture stays structurally sound and continuously collects clean water, free of sediment. In addition, the improved spring capture is less expensive and does not require technical skills for building forms, which can be prohibitive to construction. Table 2 displays a comparison of the materials and costs.

Table 2. Traditional vs. Improved Spring Capture Materials and Costs

\begin{tabular}{|c|c|c|c|c|}
\hline \multirow{2}{*}{ Material } & \multicolumn{2}{|c|}{ Traditional Spring Box } & \multicolumn{2}{c|}{$\begin{array}{c}\text { Improved Spring } \\
\text { Capture }\end{array}$} \\
\cline { 2 - 5 } & $\begin{array}{c}\text { Average } \\
\text { Qty* }\end{array}$ & Cost \$ & $\begin{array}{c}\text { Average } \\
\text { Qty* }\end{array}$ & Cost \$ \\
\hline Tube (PVC) & N/A & N/A & 1 10-ft length & 4 \\
\hline Small boulders & N/A & N/A & & - \\
\hline Gravel & N/A & N/A & 15 bags & 5 \\
\hline Cement & 1000 & 100 & 500 lbs & 50 \\
\hline Sand & 30 bags & 5 & 15 bags & 2 \\
\hline $\begin{array}{c}\text { Waterproofing } \\
\text { admixture }\end{array}$ & 4 gallons & 40 & 2 gallons & 20 \\
\hline Rebar & 150 feet & 30 & $<30$ feet & 6 \\
\hline $\begin{array}{c}\text { Forms (cut } \\
\text { boards, nails) }\end{array}$ & 192 feet & 115 & N/A & N/A \\
\cline { 2 - 5 } & Total & $\mathbf{\$ 2 9 0}$ & Total & $\mathbf{\$ 8 8}$ \\
\cline { 2 - 5 } & & & & \\
\hline
\end{tabular}

*Based on median size of spring capture: 4'x3'x3' box for traditional and $60 \mathrm{ft}^{2}$ area for improved. 


\subsubsection{Case Studies}

To better understand how this new method of spring capture improves the condition of water flow for the communities that it serves, three case studies will be presented. Two cases are of spring captures that already exist, but were poorly constructed, and the study will assess the improvement in the quality of the capture though application of the new method. The other is a completely new design for an undeveloped spring. These case studies will describe the previous situation of the spring, and how the design was approached, as well as demonstrate the improvement of the spring as a water source.

\section{Cerro Puerco}

The Cerro Puerco (Figure 16) aqueduct has a relatively long history. In 1999, a spring capture, tank, and distribution system were constructed. The spring is located in the hills above Cerro Puerco about an hour walk from Cerro Puerco central. In 2005, a PCV and a local expert reconstructed the original spring capture along. The spring capture was built using the improved method and continues to capture ample water. Then in 2009, a private constructor built another spring box, joined the pipes to bring the water from both springs to the tank, and then constructed a second tank on the south side of Cerro Puerco, below the school, to be filled directly from the higher tank. This second tank would serve the community of Quebrada Gato, as shown in Figure 17.

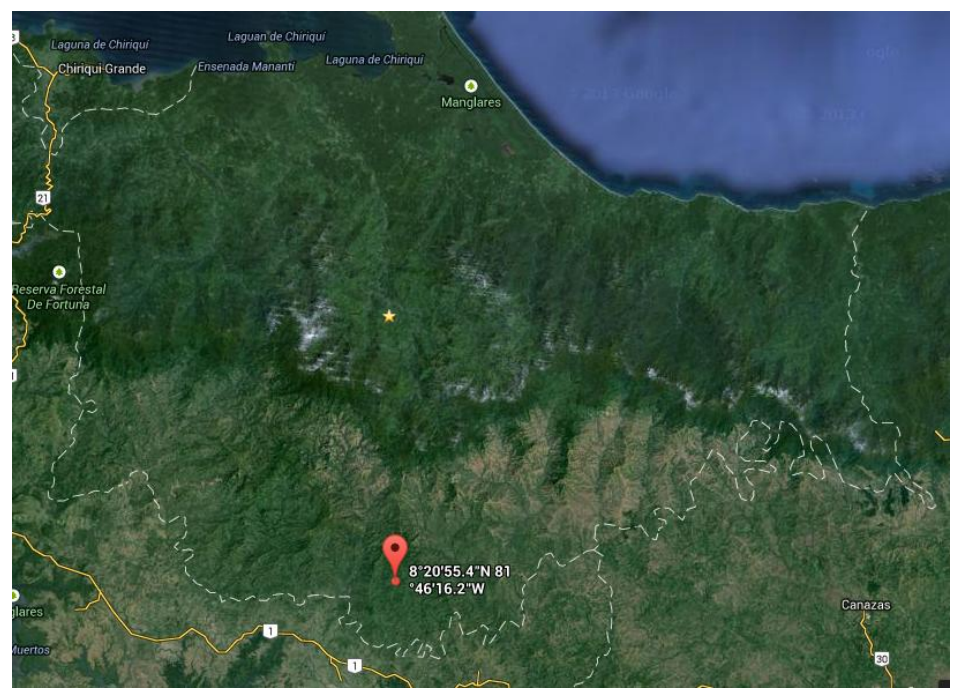

Figure 16. Cerro Puerco, 8.348723N, -81.771179W (Google Maps) 


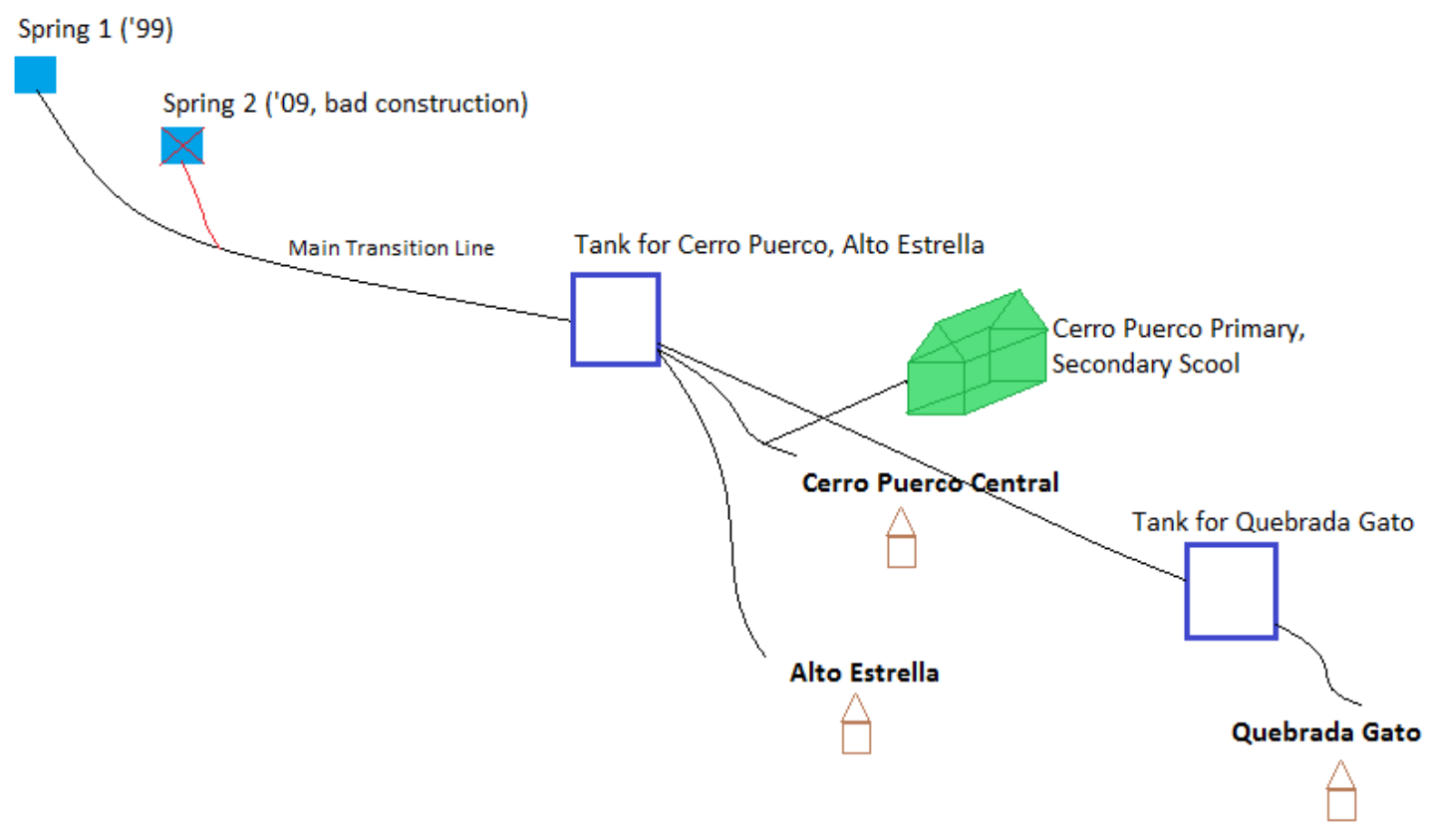

Figure 17. Cerro Puerco water system prior to August 2013 renovations

The second spring box was poorly constructed without a clear understanding of how the eye (initial outflow) of the spring may shift and how erosion might affect the box structure (Figure 19). The spring box at the time of inspection only captured approximately half of the spring water during the dry season, and a very small amount during the wet season. The community decided to rebuild the spring capture and give it a separate line directly to the second tank, creating a separate system, as shown in Figure 18.

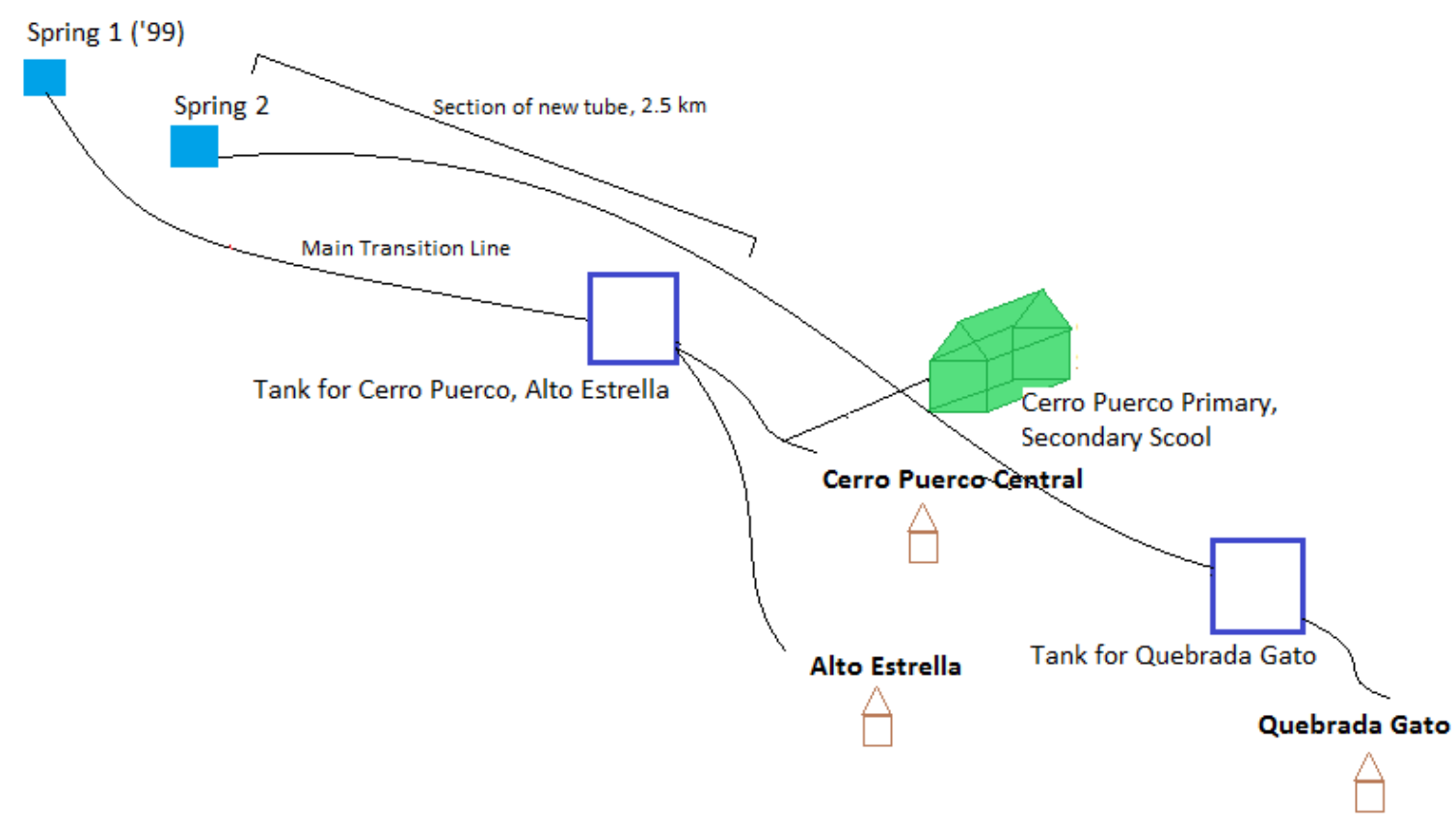

Figure 18. Cerro Puerco water system after August 2013 renovations 
The traditional construction time of the year is the dry season, when there is less water to interfere with the concrete work. It was proposed that the construction work be done in the wet season so that an accurate location of the spring could be determined. This added to the challenge of water diversion, and led to shorter work days due to afternoon rainstorms, but the result was the location of the capture at the obvious location of eye of the spring.

Most of the challenges encountered in construction were related to the diversion of the spring water around the construction site, especially during the pouring and setting of the concrete for the deep front wall. Diversion methods were used to channel the water into tubes bypassing the work site, yet some water continued to flow through the work site. A dry cement mixture was used in the base of the deep front wall to absorb the pooled water, and a normal mix was added above that layer.

The spring capture was constructed as per the improved spring capture method, including the area around the previous spring box. The improved spring capture included additional eyes of the spring source (Figure 20), the escaping water from the old capture, and the contents of the old spring capture, as indicated by spring flow data from before and after the improvements (Figure 21).

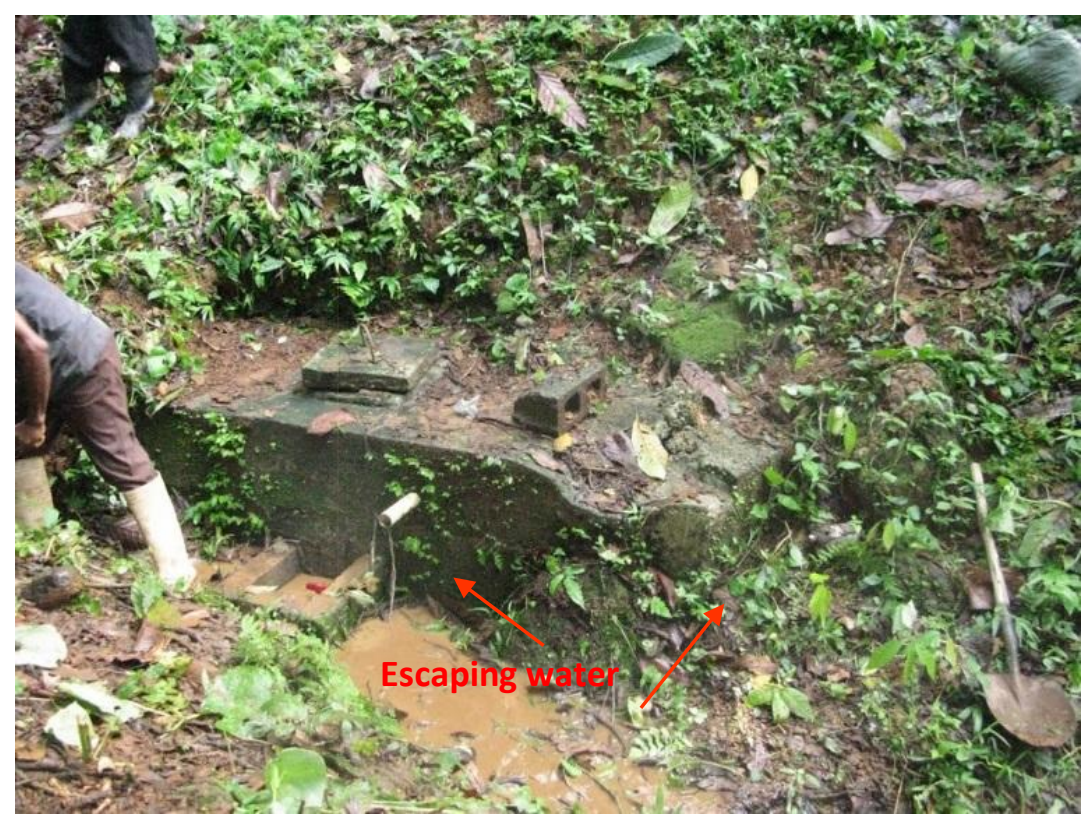

Figure 19. Cerro Puerco old spring box and escaping water (photo by author) 

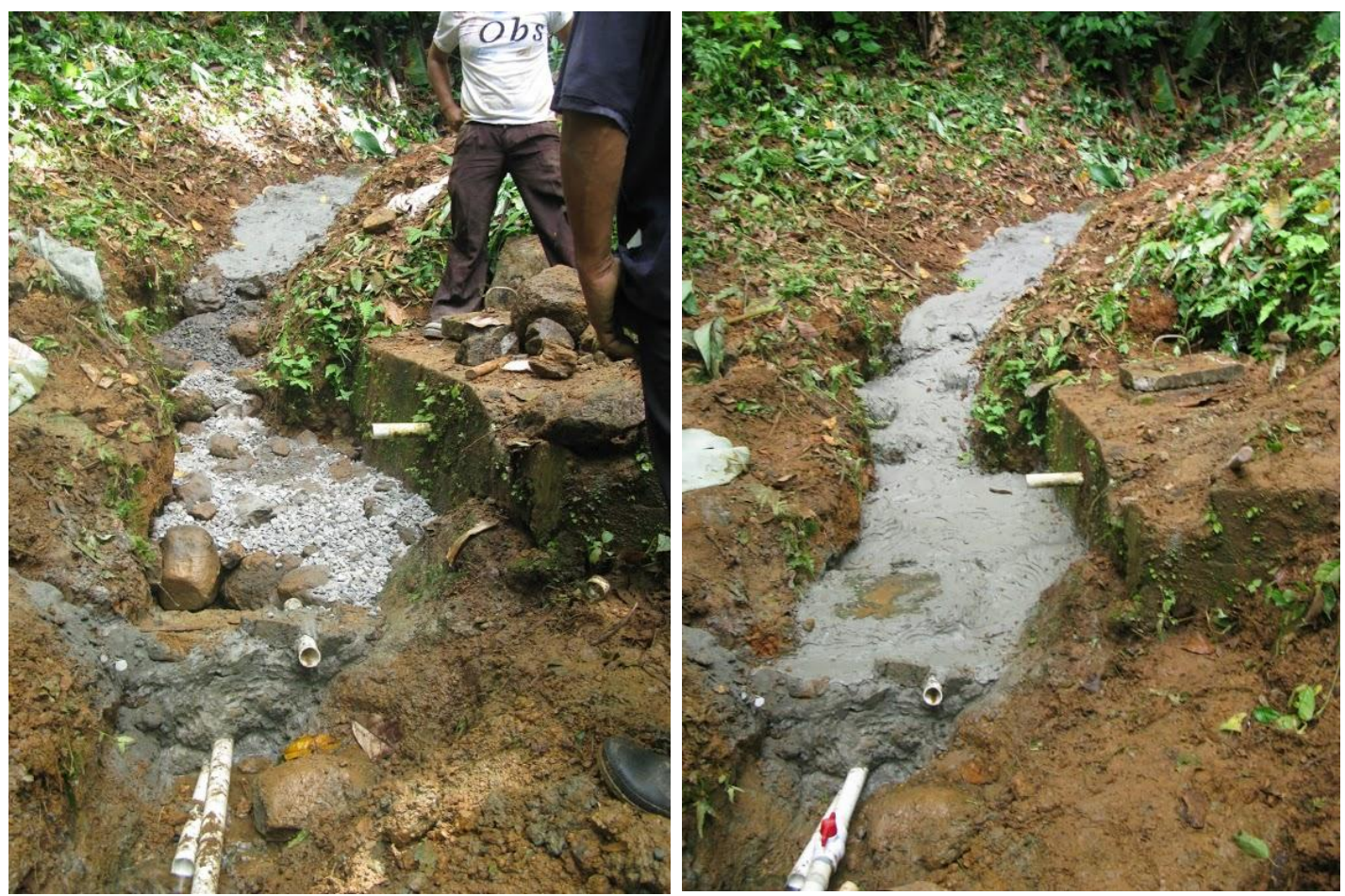

Figure 20. Puerco improved spring capture, including old spring box (middle right of photos) (photo by author).

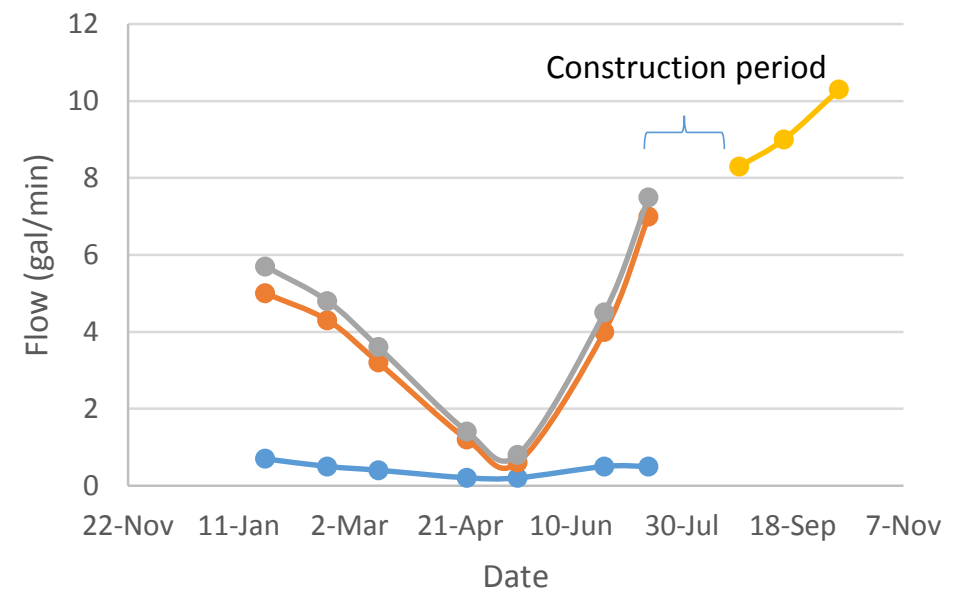

- Old Spring Capture

- Spring Soure Outside Capture

- - Spring Source Total

Figure 21. Cerro Puerco spring flows before and after spring capture improvements, August 2013 Cerro 


\section{Bajo Salitre}

The community of Bajo Salitre is located in the Müna district in the Pena Blanca Township of the Comarca Ngäbe-Buglé, as shown in Figure 22. The community had no previous water system, but there were nearby springs for gathering water. With the design assistance of the PCV in the area and government funding, the community was able to construct a spring capture and water distribution system. The construction of the spring capture was done using the improved method.

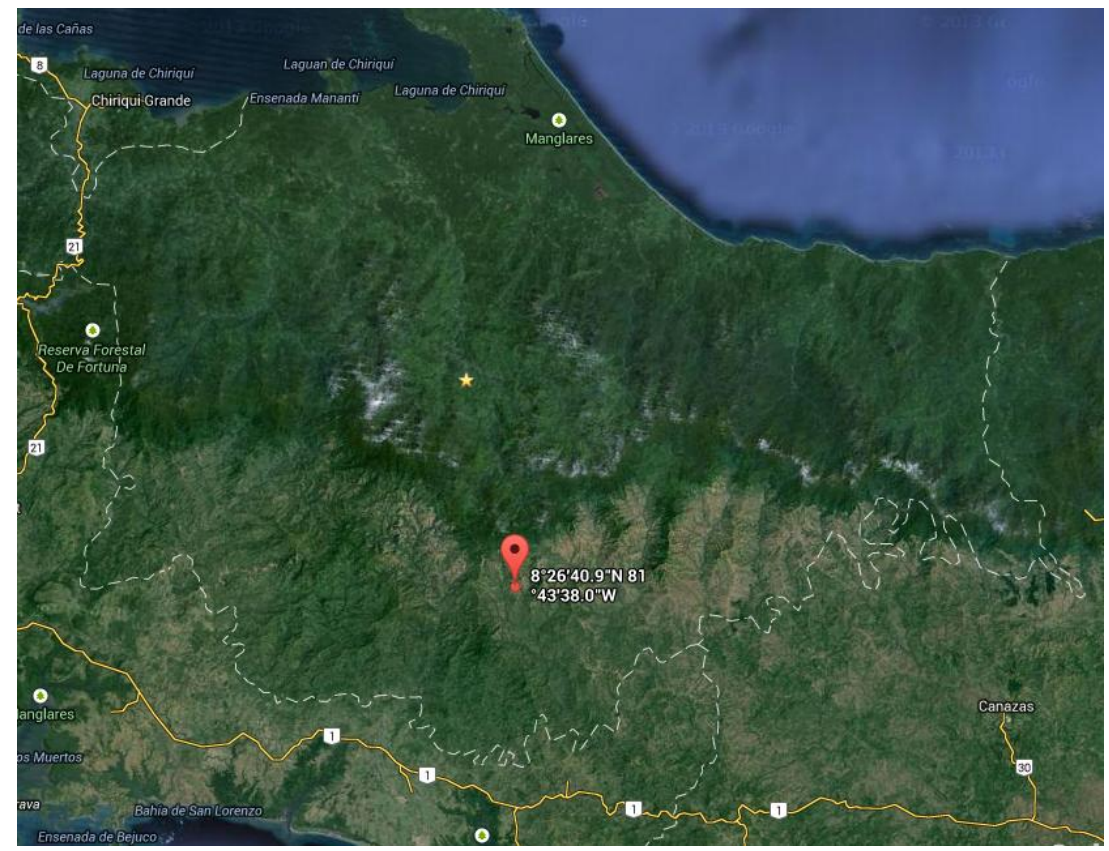

Figure 22. Bajo Salitre, 8.444701 N, -81.727222 W (Google Maps)

The water source for the new system included two springs, located very near to each other. Both springs were contact springs, one on bedrock and the other on impermeable clay (Figure 23). The collection tank just below the spring captures was constructed to provide for local access, as shown in Figure 24. The tank was constructed using stone masonry (Figure 25), eliminating the need for formwork and rebar. The capture cover conveys surface water over the capture structure, diminishing the potential for erosion around edges of the structure. This was done by carefully forming the mortar cover near the surrounding soil so that it channels the runoff on top of the cover and not along the edge (Figure 26). Figure 27 shows spring flows measured before and after construction of the capture. 


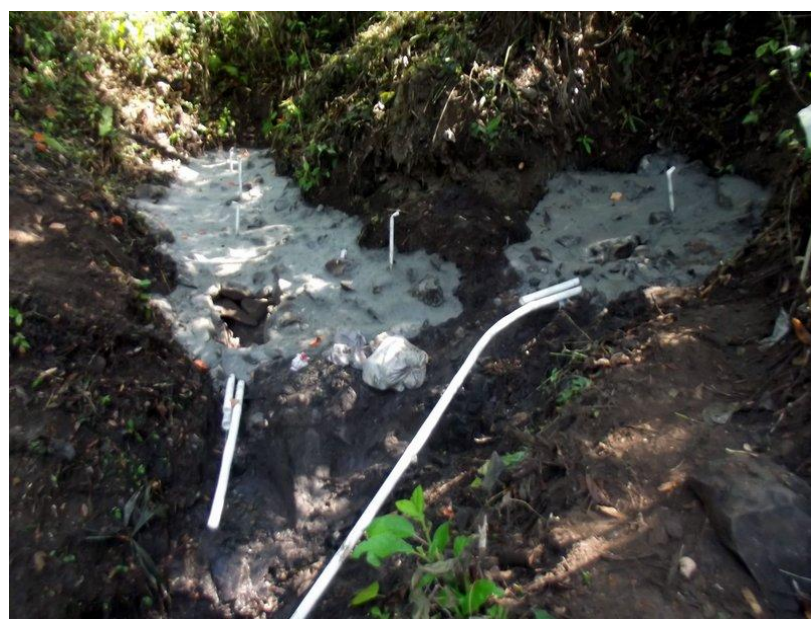

Figure 23. Bajo Salitre completes spring captures (photo by author)

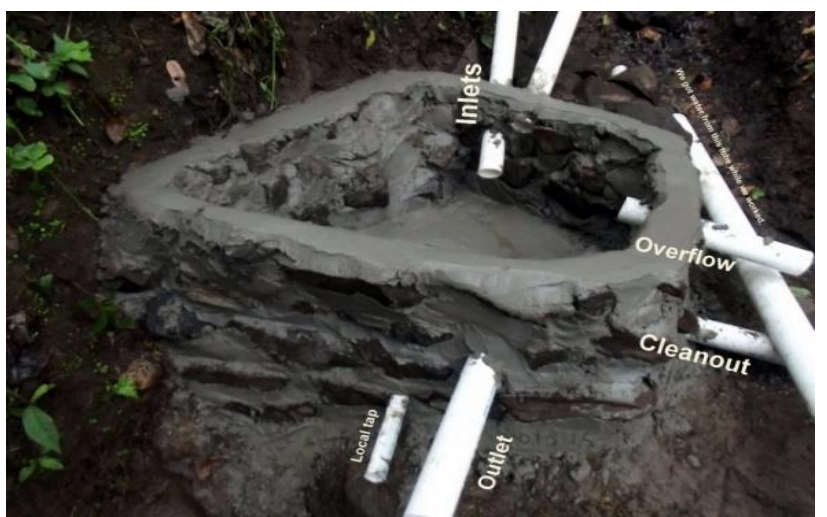

Figure 25. Bajo Salitre stone masonry collection tank (photo by author)

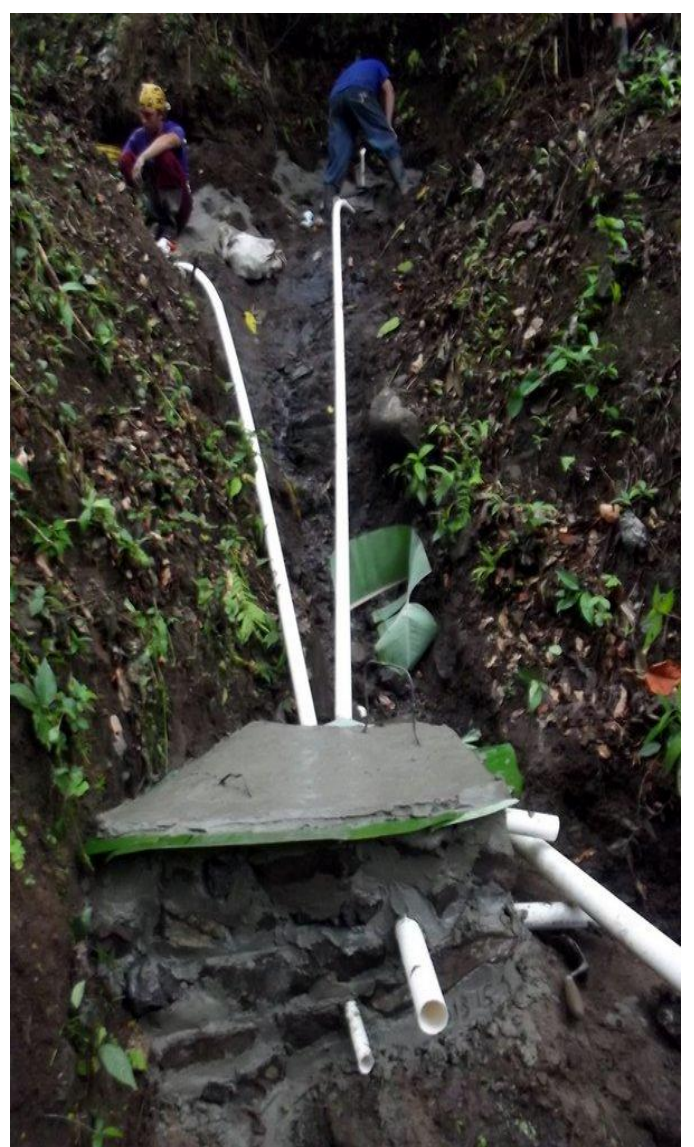

Figure 24. Bajo Salitre improved spring capture completed view with access tank (photo by author)

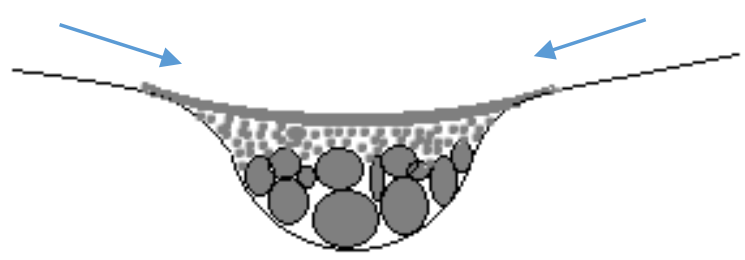

Figure 26. Cross section of improved spring capture. Arrows indicate flow direction of water across concrete surface of capture 


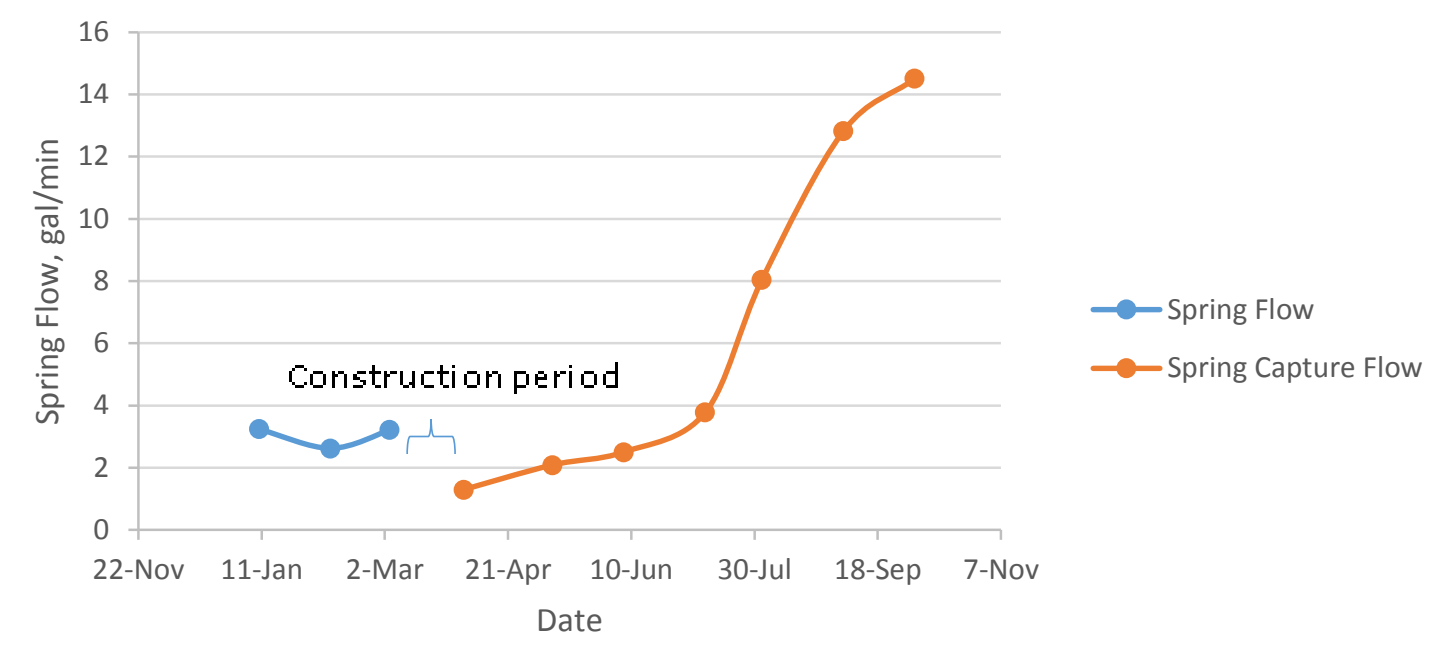

Figure 27. Bajo Salire spring flows from November 2012-September 2013

\section{Ceni Pita}

The community of Ceni Pita is located in the district of Nole Duima in the township of Cerro Puerco, as shown in Figure 28. The community is comprised of 250 residents with two water systems with 18 taps. Two springs provide water to two separate distribution networks. There is a centrally located water tank, but due to poor design the tank is too high to receive water from the source. There are many other issues surrounding the water system in Ceni Pita, but when the PCV in the area analyzed the needs of the community, it was decided that improving the condition of the spring captures was most urgent and feasible given the scope of all of the needs.

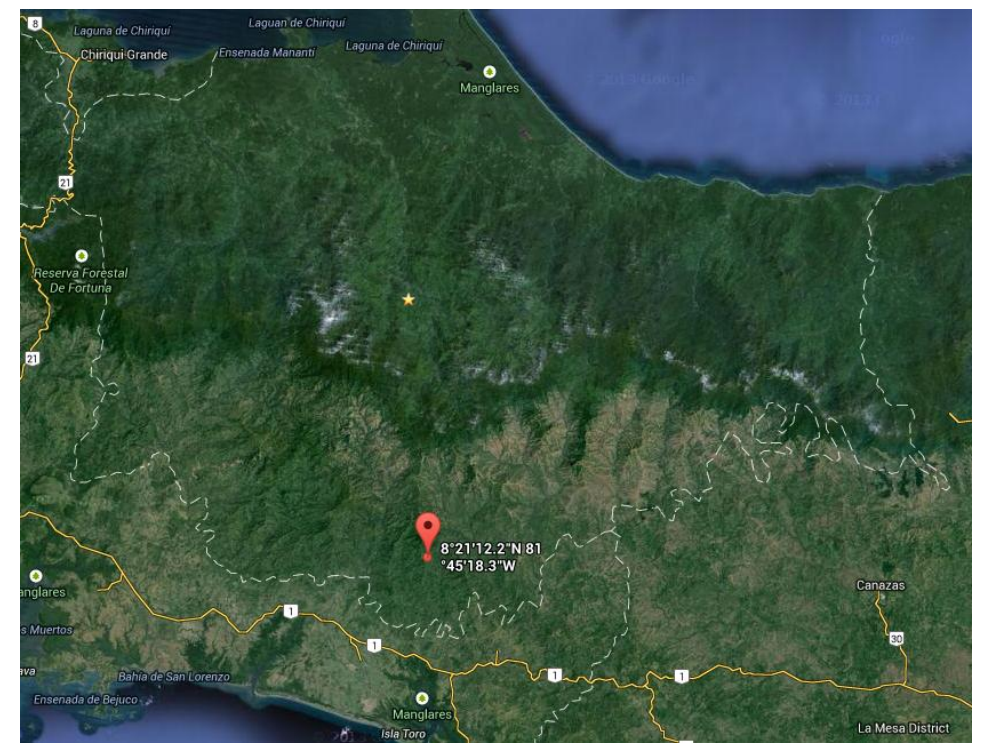

Figure 28. Map showing Ceni Pita, 8.353390 N, -81.755074 W (Google Maps) 
The first spring source in Ceni Pita was protected with a traditional spring box structure (Figure 29). According to the community, the amount of water from this source had diminished greatly over time. Water was found to be escaping around the front wall and flowing outside of the transmission line. The spring source was not located at a great elevation difference from the community, and water was turbid some of the time. This source was connected to the tank, but the tank is located at a higher elevation than the source. The second spring (Figure 30) was located on a hill well above the community, but this spring source was not protected. There was only a retaining box constructed, but no structural support of the spring itself.

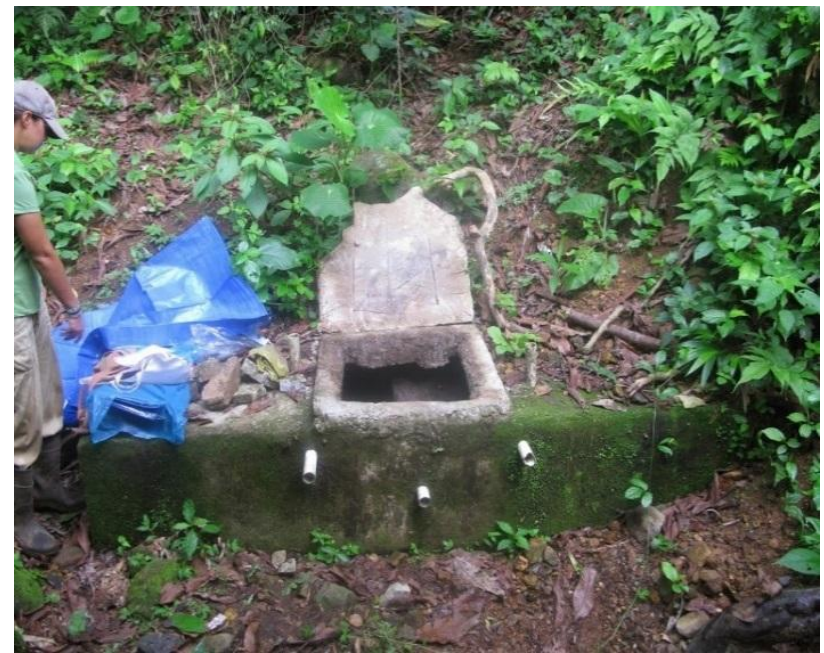

Figure 29. Ceni Pita spring capture 1 (photo by author)

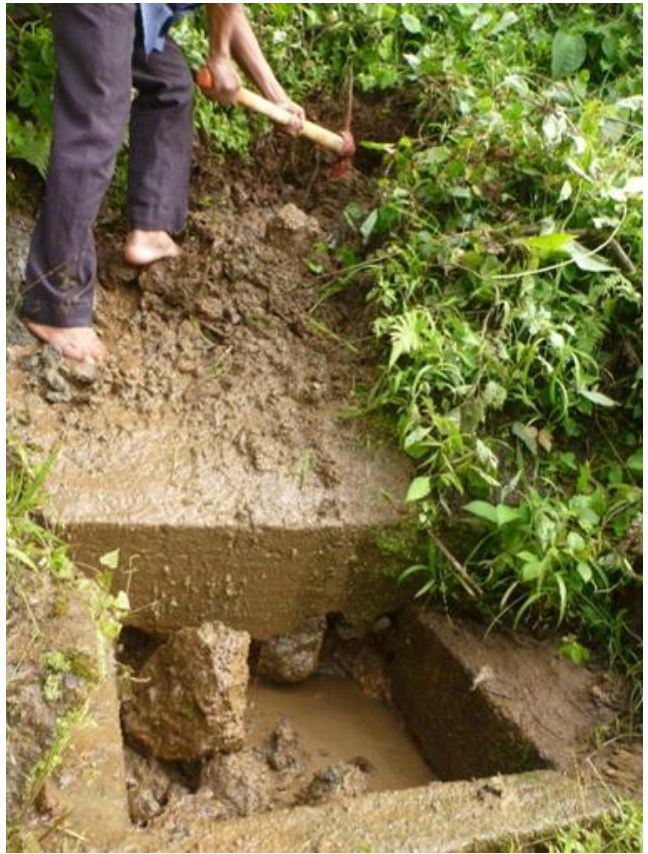

Figure 30 Ceni Pita spring capture 2 (photo by author) 
The PCV in the area worked with the community of Ceni Pita to design a solution and renovate the two spring captures. Spring source one was renovated to capture the escaping water and to provide extra settling for the turbid water. The existing spring box was thoroughly cleaned on the inside.

After the renovation of this spring capture was completed, it became apparent that the chosen method was not the most effective. The PCV chose this method because of the water turbidity, but a more appropriate solution would have been to remove sediment from within the spring box and possibly add a spring capture, using the new approach, in front of the existing box. This design would have utilized the existing spring capture without the difficult work of deconstructing the concrete work. The water would have been clarified by cleaning inside the spring box, rather than the addition of a settling tank. Also, proper cleaning and maintenance techniques would have been demonstrated to the community. Finally, the work would have been simplified by eliminating the need for formwork in creating the new spring box.

The goal for rehabilitation of the second spring source was to increase the flow of water and construct a structurally sound capture. This was achieved by following the procedure for the improved spring capture method and utilizing the existing front wall. This created a well-protected spring capture with more of the water from the spring collected for transmission to the community (Figure 32).

Figure 31 shows the improvements made to the Ceni Pita spring capture one and Figure 32 shows the improvements made to spring capture two. Through these improvements, the spring capture collected practically all of the water from the spring in the months following the project, as shown in Figure 33.

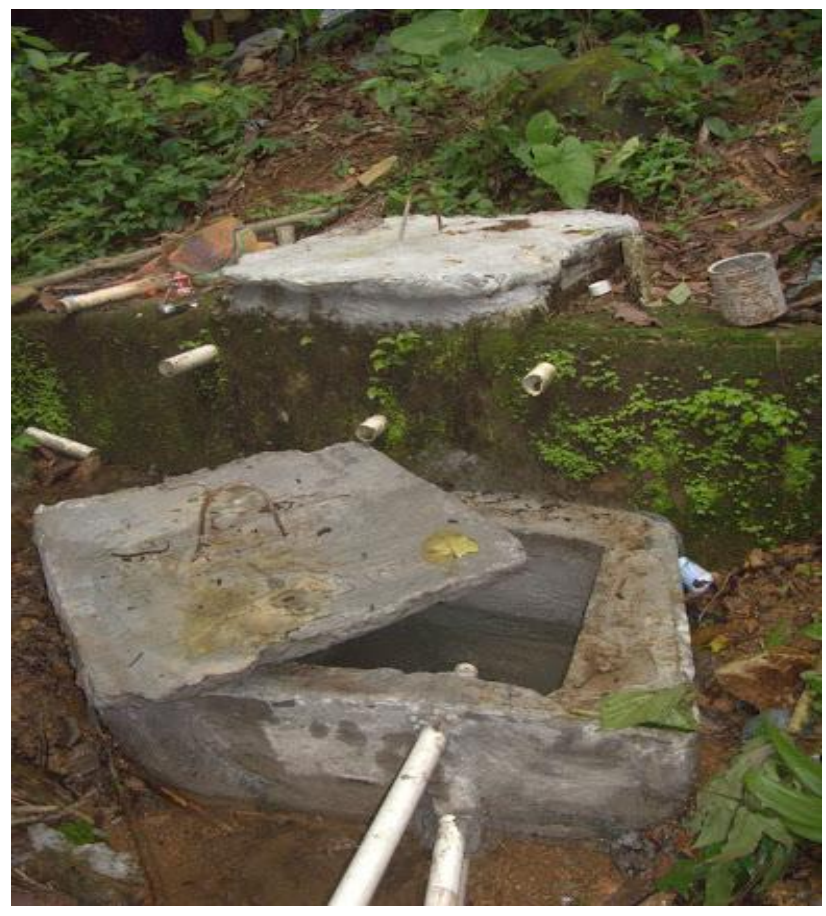

Figure 31. Ceni Pita improved spring capture 1(photo by author) 


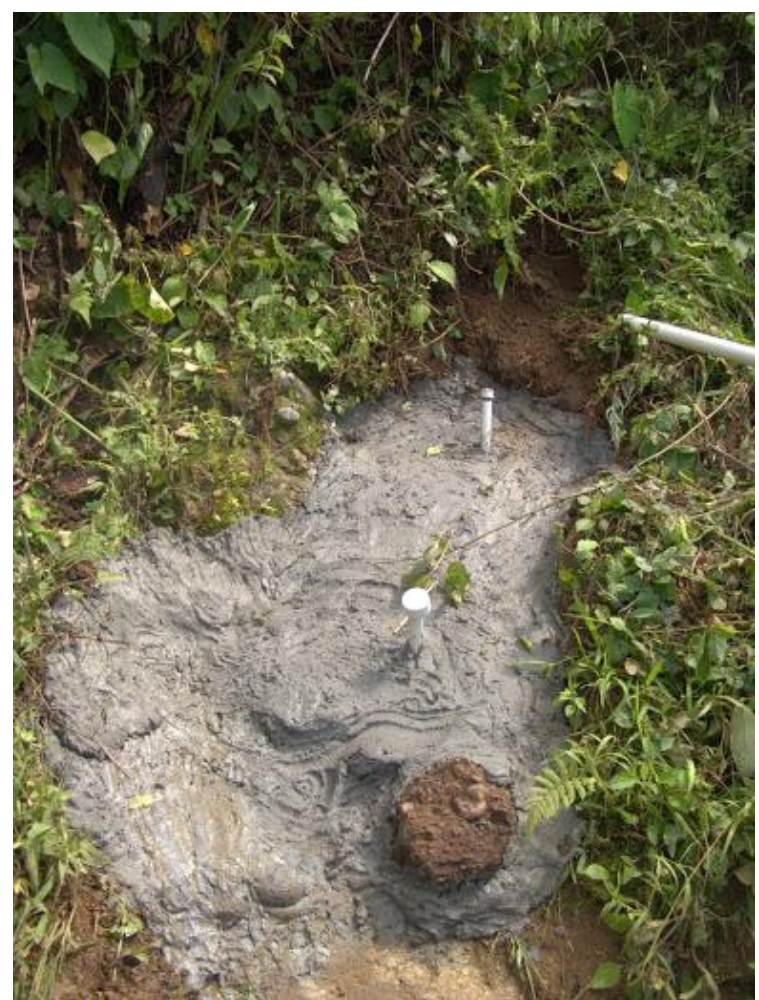

Figure 32 Ceni Pita 1 Spring Flow, August 2012 October 2013

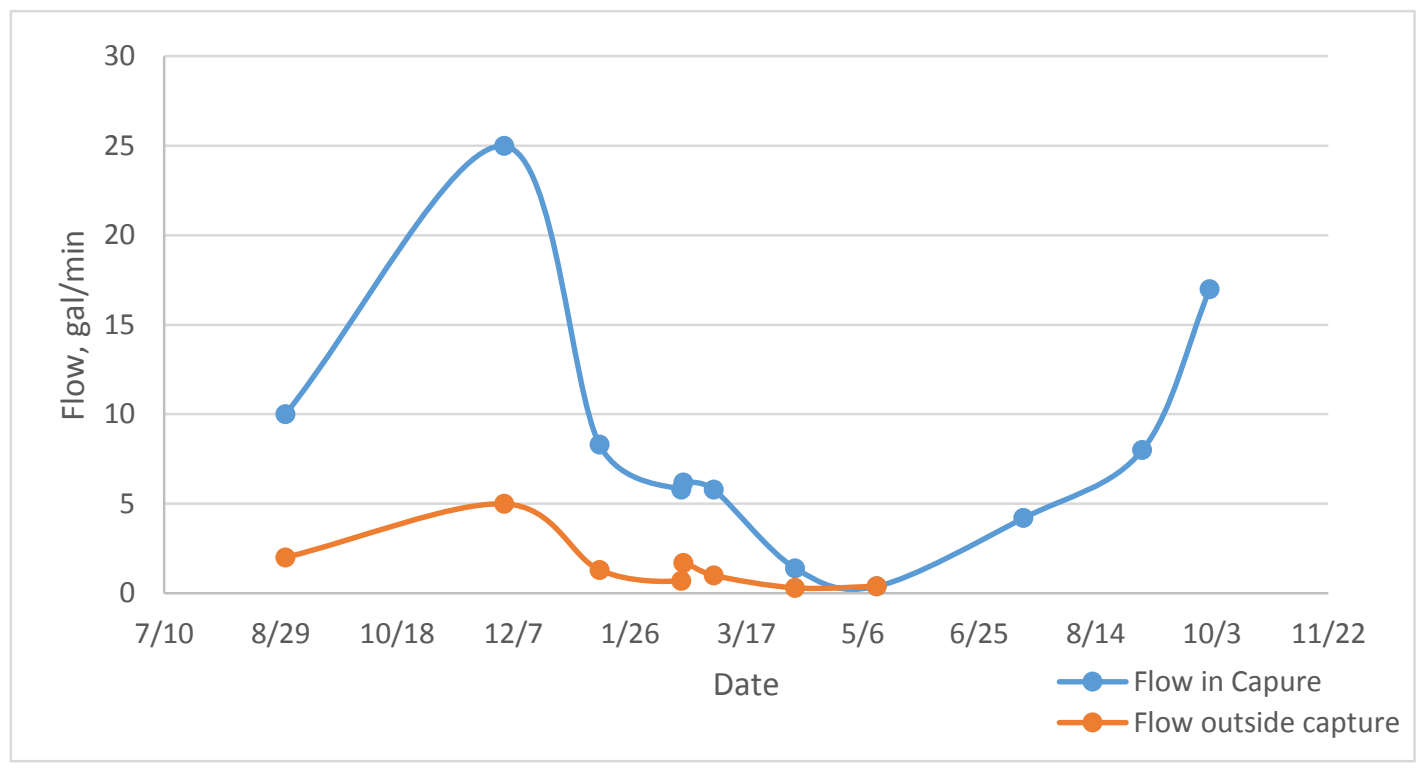

Figure 33 Ceni Pita improved spring capture 2 (photo by author) 


\subsubsection{Design Spreadsheet}

Peace Corps Panama Volunteers from the EH sector start their service with varying backgrounds. Some are engineers, or student engineers, while others have experience with construction work, and still others have no relevant experience. The situations that the volunteers will find in their communities also vary dramatically. EH volunteers are usually placed in the most rural settings, where water and sanitation issues exist, but the focus may be on either water or sanitation, or both. Nevertheless, all EH Volunteers participate in eight weeks of technical training on water and sanitation topics they might encounter in their communities.

To support volunteers, a spring capture design spreadsheet was developed to assist with the design and planning for a spring capture using the improved approach in rural Panama. The following are the components of the spreadsheet and an explanation of how they can be used.

\section{Spring Dimensions}

A proper topographic survey of the desired spring capture area should be done. The survey should consist of cross sections, starting from below the eye of the spring and working uphill until all appropriate area is included. The distance between the cross sections should be measured. At each cross section, a test section of earth should be removed to determine the depth to the impermeable layer (z). Upon entering this information, values for Volume, Total Area, and Volume of Cap will automatically be calculated, as shown in Figure 34.

\section{Front Wall}

\begin{tabular}{|c|c|c|c|}
\hline \multicolumn{4}{|l|}{ Spring Dimensions } \\
\hline $\begin{array}{l}\text { Distance between cross } \\
\text { sections }(\mathrm{m})\end{array}$ & $\begin{array}{l}\text { Width of cross } \\
\text { section }(\mathrm{m})\end{array}$ & $z^{*}(m)$ & $\begin{array}{l}\text { Incremental } \\
\text { Volume }\left(\mathrm{m}^{3}\right)\end{array}$ \\
\hline-- & 2 & 0.5 & -- \\
\hline 1 & 3 & 0.5 & 1.5 \\
\hline 1 & 4 & 0.5 & 2 \\
\hline 1 & 3 & 0.5 & 1.5 \\
\hline 1 & 5 & 0.5 & 2.5 \\
\hline 1 & 4 & 0.5 & 2 \\
\hline 1 & 3 & 0.5 & 1.5 \\
\hline 1 & 2 & 0.5 & 1 \\
\hline 1 & 5 & 0.5 & 2.5 \\
\hline 1 & 5 & 0.5 & 2.5 \\
\hline 1 & 5 & 0.5 & 2.5 \\
\hline *Depth to impermeable layer & & Total Volume $\left(\mathrm{m}^{3}\right)$ & 19.5 \\
\hline \multicolumn{2}{|c|}{ **Volume of Cap based on $5 \mathrm{~cm}$ thickness } & Surface Area $\left(\mathrm{m}^{2}\right)$ & 41 \\
\hline & & Volume of Cap** $\left(\mathrm{m}^{3}\right)$ & 2.05 \\
\hline
\end{tabular}

Figure 34. Spring Capture Design Spreadsheet, Spring Dimensions section 
The design of the front wall includes length, width, and depth, as determined by the user after experience at the spring site (Figure 35). Design criteria from section 3.2.1 should be considered, including constructing the front wall one half foot deeper than the surface of the impermeable layer, and one foot wider on each side than the channel to be excavated for the spring capture.

\begin{tabular}{|l|l|r|}
\hline Front Wall & & \\
\hline length $(\mathrm{m})$ & width $(\mathrm{m})$ & depth $(\mathrm{m})$ \\
\hline & 0.1 & 1 \\
\hline & Total Volume $\left(\mathrm{m}^{3}\right)$ & 0.3 \\
\hline
\end{tabular}

Figure 35. Spring Capture Design Spreadsheet, Front Wall section

\section{Volume of Materials}

The volume of materials is calculated based on the cross sectional and front wall dimensions. The volume of materials is shown in traditional metric units $\left(\mathrm{m}^{3}\right)$, units of cubos (five gallon buckets) which might be used in the community, and local units that might be found in a Panamanian hardware store (Figure 36).

\begin{tabular}{|c|c|c|c|c|}
\hline \multicolumn{3}{|c|}{ Volume of Materials } & \multirow[b]{2}{*}{ Iocal units } & \\
\hline Materials & $\mathrm{m}^{3}$ & cubos & & \\
\hline Boulders & 12.3 & $n / a$ & 410 & rocks \\
\hline Small rocks & 6.15 & 308 & $n / a$ & \\
\hline Gravel & 2.05 & 103 & 103 & saquitos \\
\hline Cement & 0.5125 & 26 & 17 & sacos \\
\hline Sand & 1.5375 & 77 & 77 & saquitos \\
\hline
\end{tabular}

Figure 36. Spring Capture Design Spreadsheet, Volume of Materials section

\section{Flow Data}

This section for flow data of the spring source encourages the user to have a complete set of flow measurements throughout a wet-dry seasonal cycle and gives a visual representation of the data (Figure 37). If more than one spring is being considered, this part of the spreadsheet could be used to determine which spring source has the highest flow with least fluctuation. Flow data from the driest period of the year should be used in design calculations to determine if a source has sufficient flow to serve a community with a given population. 


\begin{tabular}{|l|r|r|}
\hline Flow Data & & Flow $($ gpm) \\
\hline Jan & Date & 2.1 \\
\hline Feb & $2 / 1$ & 1.7 \\
\hline March & $3 / 1$ & 1.3 \\
\hline April & $4 / 1$ & 1.2 \\
\hline May & $5 / 1$ & 1.5 \\
\hline June & $6 / 1$ & 2.1 \\
\hline July & $7 / 1$ & 2.8 \\
\hline August & $8 / 1$ & 3 \\
\hline September & $9 / 1$ & 3 \\
\hline October & $10 / 1$ & 4.5 \\
\hline November & $11 / 1$ & 5 \\
\hline December & $12 / 1$ & 4.1 \\
\hline
\end{tabular}

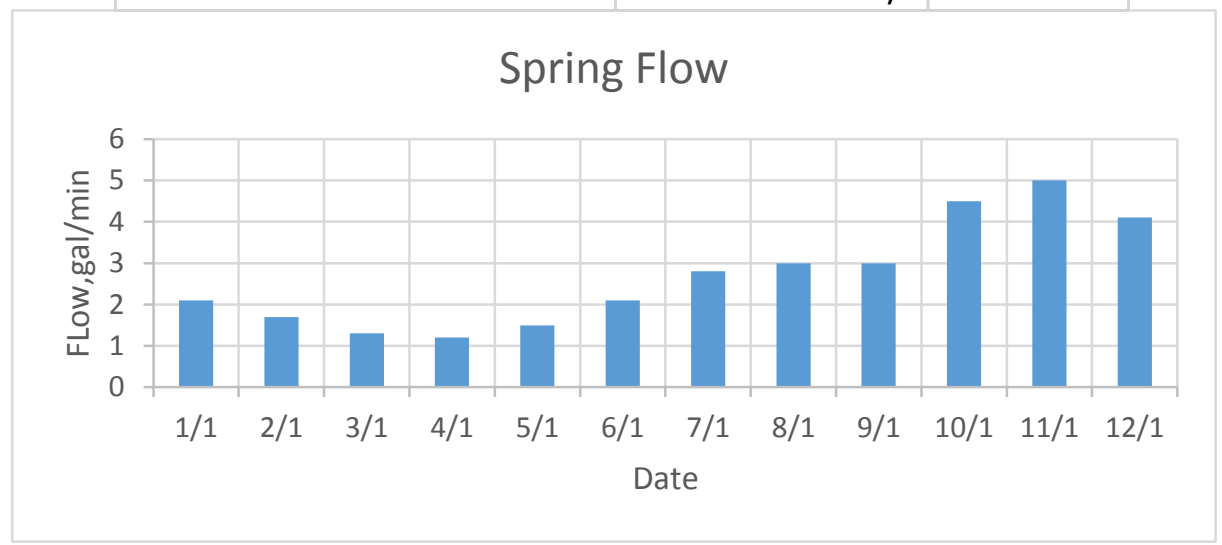

Figure 37. Spring Capture Design Spreadsheet, Flow Data section and graph 


\section{Circuit Rider Model in Panama}

The Circuit Rider model (CRM) for water system maintenance is used in the United States and has been adapted for use in some Latin American countries (USDA, 2014). Since 2010, Peace Corps Panama has supported a Circuit Rider Volunteer to provide technical support to former Peace Corps-funded projects. This section will look at the state of rural water system maintenance across the Comarca Ngäbe-Buglé, including both Panamanian agency maintenance programs and the use of the Peace Corps CRM, and how these entities can be combined using a model similar to one that has been used in Honduras to develop a selfsustaining CRM independent from Peace Corps presence.

A sustainable maintenance program offers technical support by an agency with continual funding and presence in the region, while the community leads day-to-day maintenance. Many entities currently work in the Comarca to build physical water system infrastructure, but not the social infrastructure to support it. However, the Panamanian health ministry PASAP has a network of technicians already in place in the Comarca Ngäbe-Buglé, and Peace Corps Volunteers work at the community level to develop maintenance abilities using empowerment training. Using these empowerment techniques, as explored by the author working as a Circuit Rider and PCV through methods of participant observation, it is evident that empowerment leads to community-based maintenance. Based on the author's analysis and two-year experience, it is recommended that PASAP utilize their technicians for support and community empowerment, as practiced by the Peace Corps.

\subsection{Community Empowerment}

The Peace Corps in Panama promotes community empowerment and community-based management through project and development facilitation. This is done primarily using a method called the Participatory Analysis for Community Action (PACA). PACA is a series of tools that PCVs utilize to develop social infrastructure in any area. It reinforces community-based decision making and needs analysis. The PCV works as a facilitator and participates with them, as a trusted partner, to analyze their needs and draw conclusions from that analysis about development goals.

The PACA method trains PCVs in participatory skills and gives specific tools to use while interacting with the community. The specific skills that are necessary to the PACA method are observing, interviewing, and facilitating (U.S. Peace Corps, 2005). The PCV uses PACA tools to help the community formalize and understand their organizational system and needs, and prioritize the needs into realistic and achievable goals. From there, the PCV works over a two-year period to advance the organizational skills of the community, often through the achievement of a project that meets one of the community goals.

Peace Corps Panama measures their success through PACA methods carried out in communities (U.S. Peace Corps, 2014). The author worked as both a PCV and Circuit Rider, and used PACA methods. The author expanded the PACA methods into an informal 
empowerment program through a water system project and noted results as a participant observer and close friend of community members.

Empowerment does not negate the need for a Circuit Rider for technical assistance, but creates a maintenance model where there is less dependence on an outside entity and more confidence within the community for regular maintenance and non-technical problem solving. A community management model is the structure that empowerment brings, and the CRM has the unique ability to enforce it.

\subsection{Rural Water System Maintenance in the Comarca Ngäbe-Buglé}

The stakeholders in a water system project in the Comarca Ngäbe-Bugle may include the community, the Panamanian government, an outside NGO or governmental organization (ex. the Spanish Government, the United Nations, U.S. Peace Corps), or educational institutions (Anderson, 2010; Brookbanks et al., 2008; Mau, 2006; United Nations, 2013). The goals of these groups can vary, including educational, research, and personal growth goals. After initial investments and project completion, the documentation of these projects also varies within organizations. Peace Corps Panama, for example, reports to the US Federal Government in accordance with Standard Indicator Data Sheets developed by the Peace Corps on the topic of "Constructed and Improved Water and Sanitation Systems" (U.S. Peace Corps, 2014b) in a volunteer reporting system. As there are multiple stakeholders in this region, and all work for different amounts of time and with varying goals, the lack of uniform and available documentation often leads to no clear means for accountability of these projects over time.

The various benevolent groups working in the Comarca Ngäbe-Buglé contribute a significant economical input for water system development, though usually the input is unequally distributed throughout the region based on accessibility. However, the entities are rarely coordinated or focused on sustainability. Often times they do not recognize the long term presence of the Panamanian agencies working in the Comarca Ngäbe-Buglé. Independent of their level of effectiveness, Panamanian agencies are the only real long term presence in the Comarca Ngäbe-Buglé with consistent funding levels.

\subsubsection{Peace Corps Circuit Riders}

In 2010, PCV and Peace Corps Masters International student from Michigan Technological University, Ryu Suzuki, discussed the implementation of a CRM for rural water system maintenance in Panama (Suzuki, 2010). The CRM is based on one implemented by the United State Department of Agriculture (2014) for the same purpose, that is, rural water system technical support. The CRM employs the use of revolving technical support agents for water systems in rural communities. One technician may service 50 community water systems, which are visited by the technician four times yearly. Depending on the specific model, the technician may provide training to community maintenance workers, general water and environmental conservation training, or technical recommendations for repairs. 
Peace Corps Panama started a CRM in the Comarca Ngäbe-Buglé in 2010. Since then, four volunteers have served as Circuit Riders, and another is currently serving. The author's experience as Circuit Rider has been the most recently completed, in October 2013. The Circuit Riders are Peace Corps Response Volunteers, usually those who have worked with the Ngäbe-Buglé people during their two years of regular service. Response Volunteers work in a specialized position after completing their regular service (Peace Corps, 2014a). As the Panama Circuit Rider, their work is closely tied to Waterlines, the American NGO that partners with Peace Corps Panama for water projects all over Panama.

The Peace Corps Circuit Rider has minimal interaction with Panamanian agencies in the Comarca Ngäbe-Buglé, although an underlying goal is to build the connection between the two entities. The reason for this seems to be that, because the Circuit Rider is working with a responsibility to Waterlines, there is little connection back to the agencies - with their own agendas and budgets not related to Circuit Rider projects. Meanwhile, the Panamanian technicians work with few resources and training.

Since the development of the Circuit Rider program in Panama, an internationally adopted community training manual for the maintenance of rural aqueducts has been developed, "El Manejo de Acueductos Rurales" (MAR) (Bansal et al., 2011). While this manual provides useful information for community members and water committees for water system operation and maintenance, Suzuki (2010) recognized the limits of a communitybased maintenance system, where rural, often impoverished and uneducated, Panamanians lack the technical insight to solve their water system issues on their own (Suzuki, 2010). Even with community training, some water system issues require advanced knowledge such as understanding of closed system hydraulics.

The Environmental Health sector of Peace Corps Panama focuses on these technical training seminars in conjunction with PACA tools. The seminar with the MAR manual gives community members the basic knowledge of community mapping, understanding water use, measuring water flow, and basic physical understanding of hydraulic principles, as well as project management and leadership skills training, such as how to run a successful meeting and understanding the roles of the water committee in the community. This seminar employs approaches to facilitation and needs assessment from the PACA method.

\subsubsection{Panamanian Agencies Working in the Comarca Ngabe-Buglé}

The Ministry of Health in Panama (Ministerio de Salud, MINSA) is the federal agency designated to protect the health of the citizens Panama, including in the Comarca NgäbeBuglé. MINSA is responsible for healthcare in the Comarca Ngäbe-Buglé, with their main office located in the town of San Felix in the Province of Chiriquí. Peace Corps Volunteers often coordinate with MINSA for health promotion and projects.

Within the MINSA agency is another organization, The Water and Sanitation Project in Panama (Proyecto de Agua y Saneamiento en Panamá, PASAP). PASAP is funded both by the Panamanian government and the United Nations. The mission of PASAP is to 
improve the access to water and sanitation for participating communities (U.S. Peace Corps, 2005). The main responsibilities of PASAP are to facilitate water and sanitation projects and provide technical assistance. An example of resources provided by PASAP is chlorinators and chlorine tablets, free for communities who can access the main office.

PASAP technicians work in each district of the Comarca Ngäbe-Buglé. The technicians are capable of water system design, construction management, and technical advising for gravity-fed water systems. In the author's experience as Circuit Rider, the exposure to PASAP was minimal. The author made formal introductions and submitted reports, and there was occasional contact with a technician. The author noted that technicians tended to be without resources and only worked in communities long enough to collect data, make recommendations, and sometimes make promises that they could not keep.

\subsubsection{Connections and Overlap in Water System Maintenance Entities}

In order to understand how the CRM fits into the scheme of water system maintenance in the Comarca Ngäbe-Buglé, those entities that work most in the Comarca are analyzed and related. Table 3 lists the four main agents for water system development, their level and function, and their connections to each other. This will help make clear where, in the overlap of missions, there is the strongest potential to make progress in maintaining the water systems.

Figure 38 illustrates the connections between the entities. The connections are important for the efficient utilization of resources. For example, Waterlines may have funds, but the Panamanian government might have better local knowledge of materials and construction procedures, and the Peace Corps Volunteers may have the local connections to the water committee.

Table 3. Players and roles in water system maintenance

\begin{tabular}{|l|l|l|l|l|}
\hline Entity & $\begin{array}{l}\text { Water } \\
\text { Committees } \\
\text { (WC) }\end{array}$ & $\begin{array}{l}\text { Panamanian } \\
\text { Government (G) }\end{array}$ & $\begin{array}{l}\text { Peace Corps Volunteers } \\
(\mathrm{PC})\end{array}$ & Waterlines (W) \\
\hline Level & Community & Regional/National & $\begin{array}{l}\text { Community/Some } \\
\text { regional }\end{array}$ & Community \\
\hline Function & $\begin{array}{l}\text { Use/ } \\
\text { Maintenance }\end{array}$ & $\begin{array}{l}\text { Funding for new } \\
\text { projects/ } \\
\text { recommendations/ } \\
\text { project } \\
\text { management }\end{array}$ & $\begin{array}{l}\text { Facilitation/ } \\
\text { Technical } \\
\text { assistance/training/ } \\
\text { project management }\end{array}$ & $\begin{array}{l}\text { Funding/ } \\
\text { project follow up }\end{array}$ \\
\hline Connections & PC, G & WC, PC & WC, W, G & PC \\
\hline
\end{tabular}




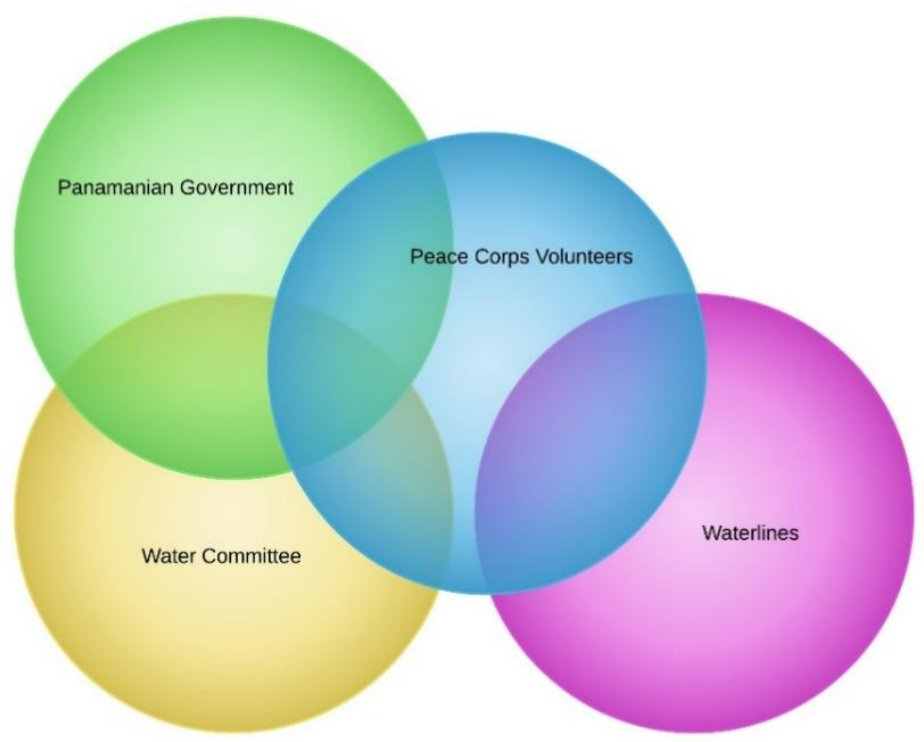

Figure 38. Venn diagram illustrating connections between water system entities in the Comarca Ngöbe-Buglé

With the knowledge that longevity and presence is key to sustainability, it is clear that the Panamanian agencies, specifically PASAP, have the potential to be the most impactful. NGOs and other independent groups have less long-term viability because of their disconnection with the more permanent entities.

\subsection{The Development of a Circuit Rider Model with PASAP}

The number of entities working for the development of water systems in the Comarca Ngäbe-Buglé, along with the demonstrated overlap in goals and outreach, points to the need for one entity working long-term towards the structured and organized maintenance of water systems. This entity must take into account the compelling effects of community empowerment for the proper management of their own water systems. The most effective model in the Comarca, based on the author's experience, is where a community is empowered and has the resources of a competent technician such as a Circuit Rider. The Circuit Rider must work to develop this empowerment within the community while providing technical support. Resources available for a CRM of this magnitude include empowerment techniques, similar to the PACA approach, and the Panamanian agency PASAP. The development of a CRM in Honduras exemplifies the possibilities for this unified system in the Comarca Ngäbe-Buglé. 


\subsubsection{Circuit Rider Model in Honduras}

The CRM is being proliferated in Central America by non-profit organizations such as Waterlines and research organizations such as the Desert Research Institute (DRI). There exist models to different extents in El Salvador, Honduras, and Panama. Erik Toledo, a researcher with DRI in the Center on International Water and Sustainability, has worked in applying the CRM in Honduras.

The model in Honduras provides post construction support for water systems by training operators and managers. The Circuit Rider is a qualified technician that visits 20-40 systems, 4-6 times a year, providing assistance and support (Toledo, 2014). The Circuit Rider provides not only technical support, but also managerial and financial support and community outreach services (Table 4). Technical assistance and training might involve understanding air blocks in a transmission line, sediment cleanouts, or proper chlorination techniques. The focus of this assistance and training is with the "Técnico de Operaciones y Mantenimiento" or Maintenance and Operations Technician (TOM) within the community. An example of managerial assistance and training is how to run meetings, both with the community and within the water system management team (water committee). Community involvement may include organizing a fundraiser, a repair, or a community led information session on water conservation before the dry season.

Table 4.Circuit Rider Model agents

\begin{tabular}{|l|l|}
\hline Circuit Rider & Community \\
\hline Board of Directors & Managerial team (water committee) \\
\hline Director/Coordinator & Skilled operator (TOM) \\
\hline Team of CRs & \\
\hline
\end{tabular}

Legal matters present themselves in community water systems from time to time as well. In areas where land ownership is not well documented, the land surrounding the water source may be contested. Local authorities may need to be involved to present the legal situation to the complaining parties. The Circuit Rider may be a knowledgeable intermediate to assure that legal proceedings are done fairly and in accordance with the local law. Environmental issues, such as land use in the near spring watershed, can also be mediated by the Circuit Rider. Finally, the Circuit Rider agents are available to network with other communities and stakeholders for best management practices and local resources. Other examples of typical problems that Circuit Riders can help solve are found in Table 5. 
Table 5. Typical problems for CRs and communities

\begin{tabular}{|l|l|}
\hline Circuit Rider & Community \\
\hline $\begin{array}{l}\text { Insufficient funds for mobilization and } \\
\text { initial technical assistance }\end{array}$ & Insufficient funding \\
\hline Convincing users to increase service fees & $\begin{array}{l}\text { Lack of qualified staff for operations and } \\
\text { maintenance }\end{array}$ \\
\hline Resistance to disinfection of water & Weak committee governance \\
\hline Donor bias toward construction projects & Lack of community support \\
\hline $\begin{array}{l}\text { Perception that technicians just collect } \\
\text { data }\end{array}$ & Unprotected sources of water \\
\hline
\end{tabular}

Mr. Toledo has suggested that there are several conditions under which the program in Honduras is successful. First, the maximum capacity an individual Circuit Rider may undertake is around 30 water systems. These water systems should be in approximately the same regional area in order to maintain the ability to visit communities, especially in rural settings. Second, subsidization for initial costs of Circuit Rider expenses is needed. Third, ongoing training on construction techniques and relevant scientific principles is critical. Finally, Circuit Riders must comply with local and national regulations and standards to ensure sustainability and continuity over time and space.

In general, the Circuit Riders provide support and training to ensure that the community water systems have the necessary resources to be successful themselves. This includes a structured system for collecting water service fees to cover expenses related to the water system, and an accounting and registration system to properly track beneficiary and water system accounts. With overall technical assistance the Circuit Rider ensures that the water systems have safe and reliable service, a plan for the future, a secure source of water, and legal recognition with local authorities.

Mr. Toledo has found that the program is most effective when rural communities can be clustered together. Additionally, the Circuit Rider should be working in rural or peri-urban areas where there are piped, communal type water systems, ideally with less than 1,000 connections off the distribution network.

There exist many challenges to the CRM in Honduras. A large challenge is the tradition of building systems rather than building social infrastructure. Investors looking to meet goals for clean water access often consider only physical infrastructure, whereas the base for a functioning system must be an organized and motivated community with a sense of ownership of the system. Building this capacity takes time and effort - sometimes years to help the community understand their need, allow leaders to rise in the community, and to build trust with the Circuit Rider that technical advice should be followed.

The author's experience participating in this work during Peace Corps is compiled in the next section. The case study addresses the issue of building social infrastructure through empowerment, and provides the motivation to develop the unified and sustainable CRM for the Comarca Ngäbe-Buglé. 


\subsection{Case Study of Circuit Rider Influence: Cerro Iglesias One}

In the following case study, the author used standard Peace Corps methods for community development and empowerment to ensure the continuation of proper maintenance once there was not Circuit Rider presence in the community. Activities included technical support, leadership development, and the reinforcement of responsibilities.

Over the course of the project the author became friends with the community members, often eating with them after work days. The author socially interacted with community members playing soccer in the community. Conversations and informal questions form the basis of the measurements of the effects of the authors work.

\subsubsection{Introduction}

The community of Cerro Iglesias One is located in the Comarca Ngäbe-Buglé within the district of Nedrini in the township of Nole Duima (Figure 39). The community is easily accessed by public transportation, creating a lot of exposure to the surrounding larger towns and the employment, educational, and economic opportunities found there. The community, while developed in many ways, did not have a functioning water distribution system as of 2012. Several PCVs have served in the community and the nearby area over the course of many years, but they have provided unsuccessful support for the poorly designed water system.

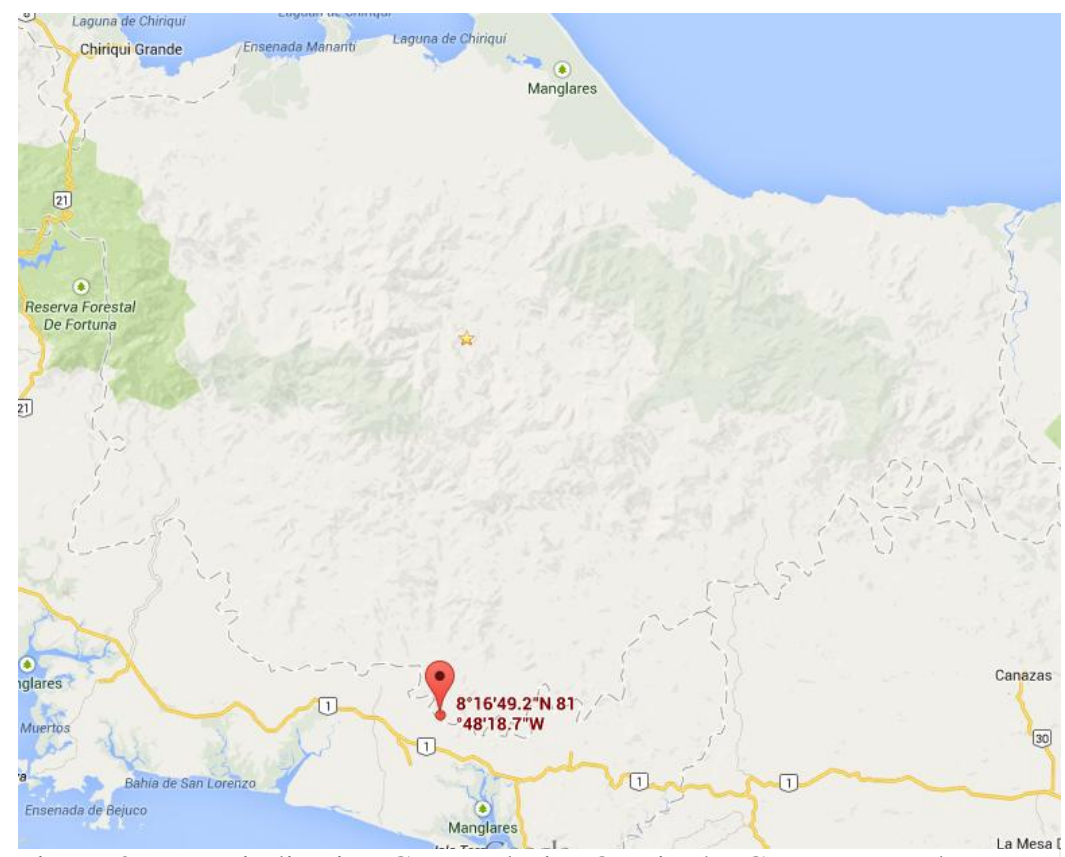

Figure 39. Map indicating Cerro Iglesias One in the Comarca NgöbeBuglé (GPS 8.280337, -81.805186) 
Without a water system, community members bathed and gathered water from various springs around the community, walking longer distances during the dry season. A primary school serves Cerro Iglesias One and provides meals for around 100 students twice daily, for which water must be carried uphill in containers from a spring to the school. Water delivered in this way is significantly more at risk for waterborne pathogens than water from a closed water system.

The infrastructure for a water system had existed in the community, as an extension from another community, Cerro Iglesias Two. Varying accounts can be found in the community of how water originally flowed downhill from the first system, then ascended a large hill, and ultimately flowed down to fill a tank just above the community. Some community members say it never flowed; some say it did and then stopped. The addition to the system, to bring water to Cerro Iglesias Two, was never surveyed for elevation, and the elevation of the water sources did not exceed the peak of a large hill. In 2013, a simple elevation survey picked out a rugged path, crossing several steep ravines, in which a transmission line would bring water from a different, separate water source. This would create a separate, independent water system for the community of Cerro Iglesias One, as shown in Figure 40.

Cerro Iglesias is a community of many resources. Even living in the community is a retired doctor who lived and worked in the United States. There is an elementary school associated with the Seventh Day Adventist Church that receives groups from the United States every year to support with church and school activities. Peace Corps has had a presence in and around the community for over ten years. So, it could be asked why no one was concerned enough in the community about the lack of water to have any motivation to do anything about it. There were community members with financial resources, educated community members, business owning community members, and frequent visits from MINSA technicians. After speaking with community members in April 2013, the author sensed a feeling of hopelessness among the people. The community had a water system, but it did not work, and there seemed to be nothing anyone could do.

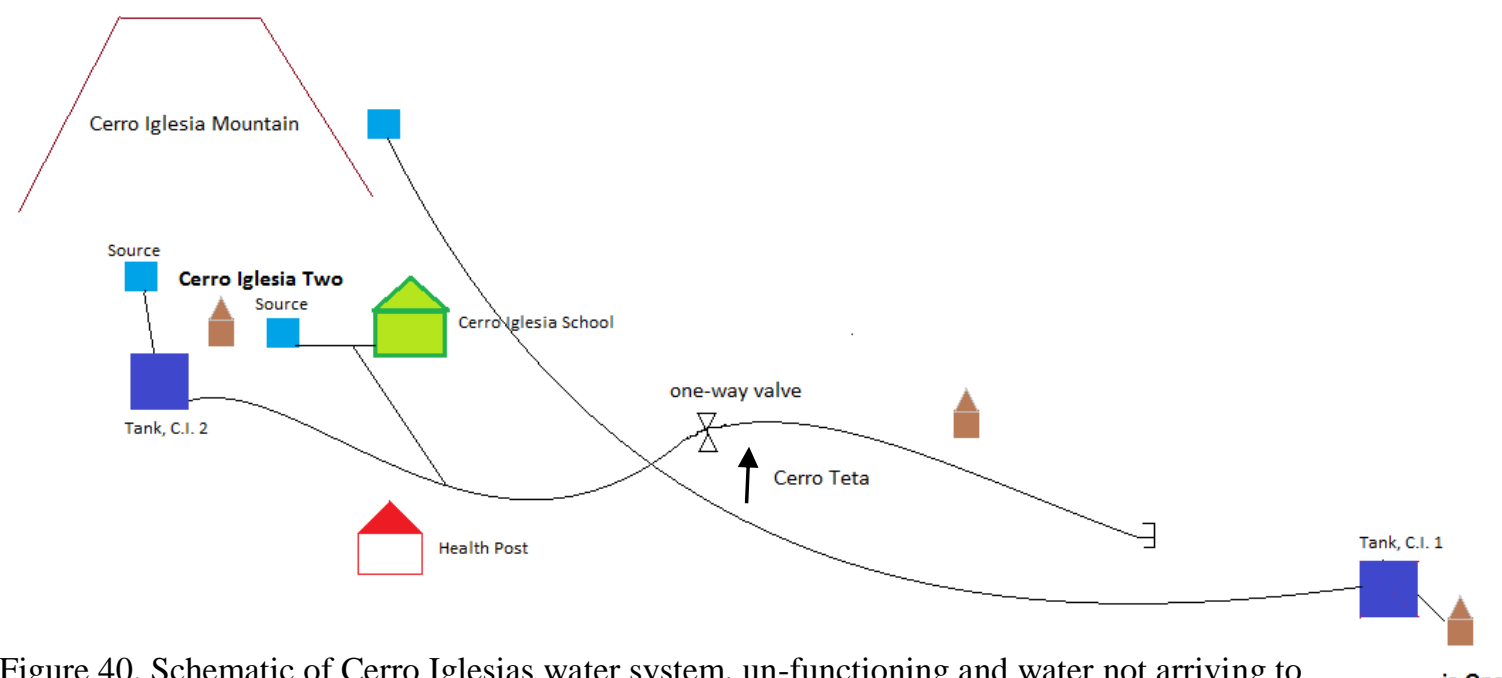

Figure 40. Schematic of Cerro Iglesias water system, un-functioning and water not arriving to community 
In May 2013, after a day of surveying in the community and the application of basic principles of gravity flow water systems, a new design was found by the author to be feasible, shown in Figure 41. The feeling of hopelessness among community members came up throughout challenges in project implementation, but the completion of the water system and the arrival of the water to the community finally quieted critics who doubted the design.

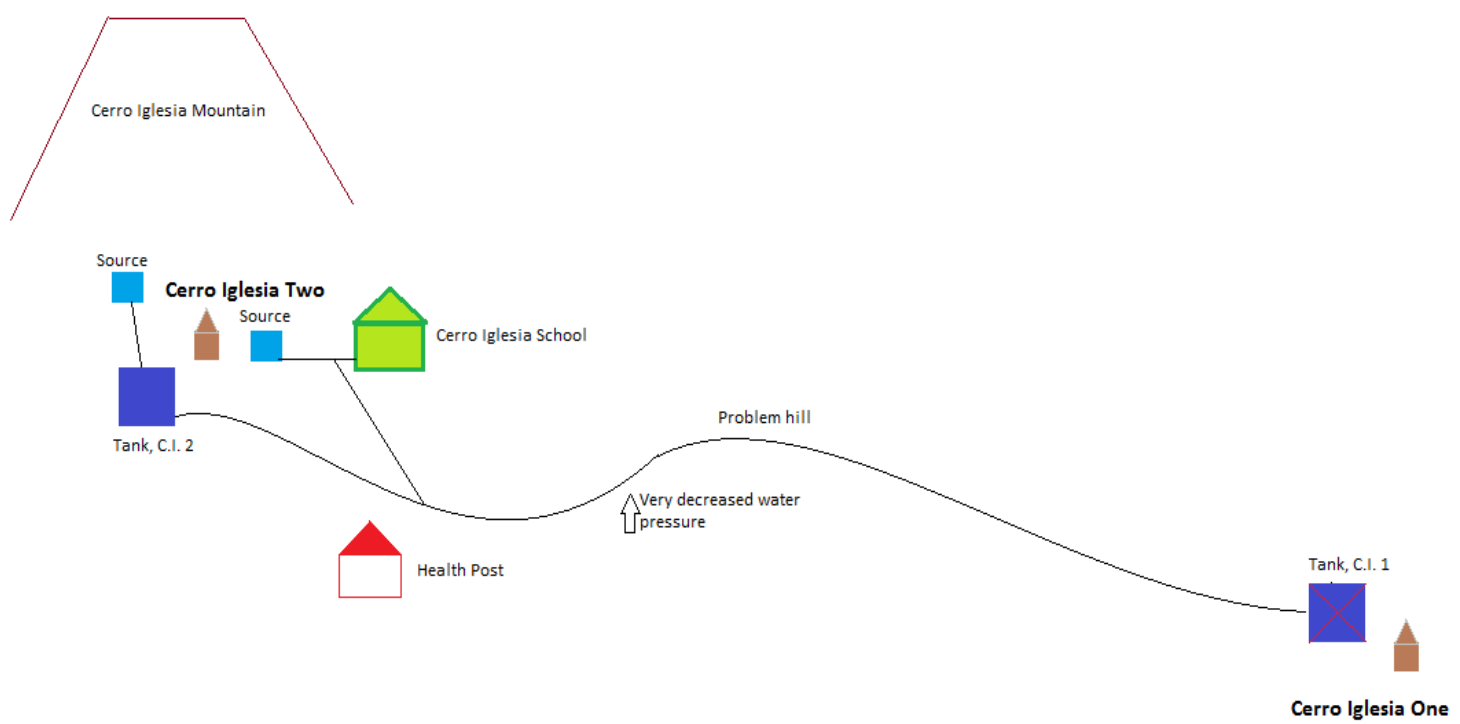

Figure 41. Schematic of Cerro Iglesias water system, improved

\subsubsection{Role of the Volunteer Circuit Rider and Community Participants}

The role of the author was primarily as motivator and facilitator of outside resources, but it was made clear that the project was that of the community. The author reiterated constantly that the project was the idea of the community, the responsibility of the community to organize, and the obligation of the community to participate in the construction. When there were problems, the author would purposefully be slow to respond in order to give the leaders in the community an opportunity to trouble shoot. At times, the author was emotional with the community when they could not resolve issues that she believed were within their power to resolve, until it was felt that proper sense of responsibility was instilled in the participating community members. The author understood from a sustainability perspective that if the community did not feel responsible for the issues that arose, then after she was no longer working in Panama the community might once again feel hopeless, having clung to the dependency that was created.

Two members of the community stood out as leaders in the project to rehabilitate the water system of Cerro Iglesias. The two were already a part of the newly formed water committee, and they believed that the lack of water infrastructure could be resolved. The author spent extra time with these two participants, building trust with them and 
encouraging them in their positions in the community. When morale was low among the community members, the author would primarily encourage the two leaders and let them recommend construction and maintenance methods.

\subsubsection{Case Study Outcomes and Conclusion}

The case study in Cerro Iglesias illustrates the ability of the Circuit Rider, while providing technical support, to motivate and empower a community towards a sense of ownership of their water system. Through leadership identification and challenging those leaders, the Circuit Rider helped the community to better understand their responsibility. Outcomes of these empowerment methods were noted in personal interactions, through more rigorous assessment methods could be used in future studies.

Overall, the sentiments of the community included an increased acknowledgement of the responsibility for maintaining the water system. While at the start of the project, community members were frequently disheartened by small issues, following the project there was a sense of capability to troubleshoot and resolve issues. The two leaders who stood out during the project also noted to the author that they would feel more comfortable in leadership positions in the future. The author felt most satisfied about the state of the community when, at the completion celebration, she received gratitude yet little recognition for the fruition of the project. It was obvious that the community took ownership of the project, and did not view it as a gift from an outside source (the author).

The observed increase in community empowerment validates the Peace Corps' approach to community development and the use of PACA tools. The effective use of PACA methods for community empowerment within the CRM is a recommendation that can be drawn from this case study. The following section summarizes recommendations for a unified Circuit Rider program based on these empowerment techniques and the resources of Peace Corps and PASAP.

\subsection{Recommendations for Panama Circuit Rider Program}

The purpose of the Peace Corps Circuit Rider program in the Comarca is to serve the monitoring and evaluation needs of Waterlines and Peace Corps projects. While this represents a significant number of water systems and a steady opportunity for a Peace Corps Response Volunteer, the CRM should be designed in Panama to allow for maximum sustainability of all water systems in the Comarca Ngäbe-Buglé, without Waterlines or Peace Corps presence. This means utilizing the system of PASAP technicians already in place and training them as Circuit Riders.

Under the Honduran model, the greatest issues are lack of social infrastructure and lack of funding. In the Comarca Ngäbe-Buglé, there are entities with economic resources already working towards water system coverage. Peace Corps gains access to economic resources through grants and NGO participation, including strong ties to Waterlines for funds. Peace 
Corps also specializes in the development of social infrastructure. What Peace Corps lacks, however, is permanent personnel to serve as Circuit Riders. This personnel infrastructure is available in the PASAP technicians.

\subsubsection{Training Circuit Riders for the Comarca Ngäbe-Buglé}

Under the current position description for the Circuit Rider Response Volunteer, the partner organization is PASAP, and the volunteer is to build a relationship with the director of that ministry. Waterlines focuses on maintenance and operations of existing water systems. Waterlines also provides funds for the Peace Corps Response Circuit Rider position in Panama, so the sustained success of the projects for which they provided initial economic support is a priority. The Circuit Rider job description, as performed by the author and by her successor, is to visit communities, provide technical support, make recommendations, and facilitate infrastructure rehabilitation projects as needed (Rios, 2013). PASAP in the Comarca Ngäbe-Buglé, in turn, has potential for being an effective monitor of water system performance. Thus, the following points should be considered for the implementation of an expanded Circuit Rider program in the Comarca Ngäbe-Buglé.

$>$ The Peace Corps Response Circuit Rider continues to maintain Peace Corps projects, making clear when working with communities that the Circuit Rider is concerned with the functionality of the water system and the training of community members; their presence in the community does not indicate an immediate economic assistance. The Circuit Rider for Waterlines should focus on training and empowerment of water committees.

Under the expanded program, the Peace Corps Response Volunteer would be responsible for coordinating with the PASAP office and its technicians for assessing the level of technical ability of each of their technicians and implementing the system similar to the one used in Honduras.

Under the guidance of the PASAP office, the designation of managerial positions would be established. For the Comarca Ngäbe-Buglé and its seven regions, one manager for each region is sufficient according to the Honduras model.

- The Circuit Rider should inventory the tools and instruments available to PASAP technicians and make recommendations for the essentials needed for monitoring and design of water systems.

$>$ A formal record keeping system should be established, with standard community visit forms and criteria for system evaluation.

PASAP technicians should be extensively trained on the MAR manual and its lesson plans. Training should also include how to organize water committee seminars, invite water committees, and work with host communities. 
$>$ New MAR manual lessons should be developed that focus on the establishment of one or more permanent water system operators within each community whose primary responsibilities are to provide solutions to immediate, non-technical water system issues; lead regular maintenance work; and work with the PASAP technician to identify and solve larger issues. PASAP would work with MINSA to establish national standards for rural water systems.

The Peace Corps Response Volunteer Circuit Rider should facilitate the growth of PASAP technicians in best practices of community integration, trust building, and community facilitation, with a strong understanding of what skills the technician already possesses. 


\section{Conclusion and Further Work}

Ensuring the sustainability of rural water systems is an evolving practice. Relevant technical, social, and economic aspects are dynamic within communities of emerging water and sanitation development. The ideas presented in this report were identified as the most relevant topics for improving the sustainability of gravity-fed water systems based on work done over two years of Peace Corps service in the Comarca Ngäbe-Buglé.

Sustainability of water systems in the Comarca Ngäbe-Buglé starts with the initial planning and continues through the operations and maintenance of the system. The improved spring capture approach was implemented in several documented cases. When applying the improved spring capture approach to the initial design of a system, spring flow measurements before and after construction demonstrate complete capture of spring flow to the benefit of the community. When the method is applied to the renovation of a traditional spring capture, spring flow measurements demonstrate a significant increase in captured water. Although flow data were not collected over multiple years, immediate results mimic flow patterns observed in historical flow and precipitation data from the area. Additional monitoring of spring capture flows would provide a more accurate analysis of the improved approach over time.

Overall, the success of the improved spring capture approach reinforced the need for the approach to be reproducible by those working on water systems in the Comarca NgäbeBuglé. The Peace Corps Panama Environmental Health program has a strong, continual presence in the Comarca Ngäbe-Buglé. A spreadsheet was developed for the design of improved spring captures, allowing all PCVs the opportunity to better understand this approach and design an improved spring capture if the need is present. This tool promises to increase the competence of volunteers and encourage them to approach water systems projects, with limited background knowledge of design and construction required.

Finally, the Circuit Rider model (CRM) promotes sustainability in two ways: the training and empowerment of community members towards better self-management of their water systems, and the availability of an experienced technician for complicated issues and recommendations. Peace Corps Panama maintains a single Circuit Rider, and the Panamanian ministry PASAP has the personnel infrastructure that could be developed into an expanded CRM. The recommendation of this report is to utilize the Peace Corps Circuit Rider to work with PASAP, and in turn help to transition their maintenance program to the CRM. This will facilitate training of technicians to improve the quality of water systems maintenance by communities of the Comarca Ngäbe-Buglé. 


\section{References}

Anderson, R. (2010). Waterlines. Our Projects Retrieved March 2, 2014, from http://waterlines.org/sub_our_projects.html

Bansal, G., Butterton, M., Caley, D., Weber, E., Ashby, A., Rogge, M., \& Majkrzak, J. (2011). El Manejo de Acueductos Rurales: Waterlines.

Brookbanks, L., Duncan, R., \& Gabster, A. (2008). Safe Water in the Ngobe Bugle Comarca, Panama: Water Quality Laboratory and Surveillance Program. Canada: University of Alberta international House.

Economic Comission for Latin America and the Caribbean. (2006). Social Problems of Latin America Indigenous peoples of Latin America: old inequities, mixed realities and new obligations for democracies in the twenty-first century. Chile: Economic Comission for Latin America and the Caribbean.

Encalada, M. (2013). PANAMA: Donaran de agua a comarcas. Retrieved Feburary 20, 2014 from http://washrural.ning.com/profiles/blog/show?id=5512694\%3ABlogPost\%3A37470\&xgs=1 \&xg_source=msg_share_post

Ferrer, N. V. (2012). Ngobe-Bugle Map [Map of the Comarca Ngobe-Bugle with Municipalities] Published 2012.

Guillen, L. V. (2012). Analysis Ambiental y Social del Programa de Agua Potable y Saneamiento Rural e Indigena en Panama (PG-G1003): Banco Interamericano de Desarrollo.

Jordan, T. D. (2006). A Handbook of Gravity-Flow Water Systems. Kathmandu, India: UNICEF.

Mau, R. (2006). Cerro Iglesia 1, Panama Implementation Trip. Cerro Iglesia, Panama Completed. Retrieved March 3, 2014, from http://ewbgreateraustin.org/projects/panama-cerro-iglesia-1-completed/

Meditz, S. W., \& Hanratty, D. M. (1987). Panama: A Country Study History. Washington: Library of Congress.

Rios, T. D. L. (2013). Peace Corps Response Volunteer Position Description. United States Peace Corps. Panama. 
Shaw, R. (1999). Running Water. More Technical Briefs on Health, Water, and Sanitation (R. Shaw Ed.): Intermediate Technology Publications.

Suzuki, R. (2010). Post-Project Asessment and Follow-Up Support for Community Managed Rural Water Systems in Panama: Michigan Technological Unviersity

Thomas, M. F. (1974). Tropical Geomorphology. U.S.A.: Halsted Press.

Toledo, E. (2014). Circuit Rider, A Method of Post Construction Support. Center for International Water and Sustainability. Desert Research Institute

United Nations. (2013). Millennium Development Goals and Beyond 2015.

United Nations. (2013). 2013 Progress chart. In MDG (Ed.), Statistics Division, Department of Economic and Social Affairs: United Nations.

U.S. Department of Agriculture. (2014). Circuit Rider - Technical Assistence for Rural Water Systems. Rural Development. Retrieved January 29, 2014, from http://www.rurdev.usda.gov/UWP-circuitrider.htm

U.S. Peace Corps. Peace Corps Volunteer Report Form. Retrieved March 2, 2014, from http://www.peacecorps.gov/vrt/

U.S. Peace Corps. (2005). PACA Vol. M0086. Using Participatory Analysis for Community Action (pp. 176).

U.S. Peace Corps. (2014a). Peace Corps Response. from http://www.peacecorps.gov/volunteer/response/

U.S. Peace Corps. (2014b). Peace Corps Standward Sector Indicator Data Sheet HE-047. Washginton, D.C.

The World Bank. (1999). Panama Poverty Assessment Priorities and Strategies for Poverty Reduction. In H. D. Department (Ed.), (Vol. 1 Main Report, pp. 20,32). Latin America and the Caribbean Region: The World Bank.

The World Bank. (2014). Panama. Data. Retrieved January 29, 2014, from http://data.worldbank.org/country/panama 


\section{Appendix A - Precipitation and Flow Data}

\begin{tabular}{|c|c|c|c|c|c|c|c|c|c|c|c|c|c|}
\hline & \multicolumn{13}{|c|}{ San Félix Precipitation $(\mathrm{mm})$} \\
\hline & 112003 & & & & & & & & & & & & \\
\hline & 1 & 2 & 3 & 4 & 5 & 6 & 7 & 8 & 9 & 10 & 11 & 12 & MES \\
\hline 1955 & N/D & N/D & N/D & N/D & N/D & N/D & N/D & N/D & N/D & N/D & N/D & N/D & N/D \\
\hline 1956 & N/D & N/D & N/D & N/D & N/D & N/D & N/D & N/D & N/D & N/D & N/D & N/D & N/D \\
\hline 1957 & N/D & N/D & N/D & N/D & N/D & N/D & N/D & N/D & N/D & N/D & N/D & N/D & N/D \\
\hline 1958 & N/D & N/D & N/D & N/D & N/D & N/D & N/D & N/D & N/D & N/D & N/D & N/D & N/D \\
\hline 1959 & N/D & N/D & N/D & N/D & N/D & N/D & N/D & N/D & N/D & N/D & N/D & N/D & N/D \\
\hline 1960 & N/D & N/D & N/D & N/D & N/D & N/D & N/D & N/D & N/D & N/D & N/D & N/D & N/D \\
\hline 1961 & N/D & N/D & N/D & N/D & N/D & N/D & N/D & N/D & N/D & N/D & N/D & N/D & N/D \\
\hline 1962 & N/D & N/D & N/D & N/D & N/D & N/D & N/D & N/D & N/D & N/D & N/D & N/D & N/D \\
\hline 1963 & N/D & N/D & N/D & N/D & N/D & N/D & N/D & N/D & N/D & N/D & N/D & N/D & N/D \\
\hline 1964 & N/D & N/D & N/D & N/D & N/D & N/D & N/D & N/D & N/D & N/D & N/D & N/D & N/D \\
\hline 1965 & N/D & N/D & N/D & N/D & N/D & N/D & N/D & N/D & N/D & N/D & N/D & N/D & N/D \\
\hline 1966 & N/D & N/D & N/D & N/D & N/D & N/D & N/D & N/D & N/D & N/D & N/D & N/D & N/D \\
\hline 1967 & N/D & N/D & N/D & N/D & N/D & N/D & N/D & N/D & N/D & N/D & N/D & N/D & N/D \\
\hline 1968 & N/D & N/D & N/D & N/D & N/D & N/D & N/D & N/D & N/D & N/D & N/D & N/D & N/D \\
\hline 1969 & N/D & N/D & N/D & N/D & N/D & N/D & N/D & N/D & N/D & N/D & N/D & N/D & N/D \\
\hline 1970 & N/D & N/D & N/D & N/D & N/D & N/D & N/D & N/D & N/D & N/D & N/D & N/D & N/D \\
\hline 1971 & N/D & N/D & N/D & N/D & N/D & N/D & N/D & N/D & 640.3 & 653.4 & 503.4 & 52.7 & $1,849.8$ \\
\hline 1972 & 170.3 & 6.5 & 13.9 & 113.7 & 343.9 & 385.1 & 183.0 & 320.6 & 753.6 & 310.4 & 420.7 & 138.5 & $3,160.2$ \\
\hline 1973 & 18.6 & 18.3 & 104.0 & 133.3 & 442.8 & 719.1 & 847.9 & 935.4 & 789.3 & 761.7 & 791.1 & 129.1 & $5,690.6$ \\
\hline 1974 & 75.2 & 7.0 & 68.2 & 35.2 & 377.8 & 971.2 & 478.4 & 512.0 & 600.9 & $1,096.5$ & 316.4 & 41.2 & $4,580.0$ \\
\hline 1975 & 0.8 & 0.0 & 8.5 & 40.8 & 687.6 & 710.6 & 364.3 & 554.1 & 587.3 & 716.9 & 859.4 & 146.6 & $4,676.9$ \\
\hline 1976 & 0.0 & 0.0 & 0.0 & 88.4 & 377.9 & 287.2 & 218.1 & 461.6 & 522.3 & 710.5 & 304.9 & 63.8 & $3,034.7$ \\
\hline 1977 & 0.0 & 0.0 & 13.0 & 34.6 & 240.0 & 430.4 & 367.7 & 699.4 & 616.9 & 639.8 & 422.3 & 75.6 & $3,539.7$ \\
\hline 1978 & 0.0 & 24.3 & 103.3 & 120.0 & 343.7 & 373.7 & 543.6 & 632.5 & 611.2 & 647.2 & 468.0 & 190.4 & $4,057.9$ \\
\hline 1979 & 0.0 & 8.1 & 74.0 & 192.8 & 658.2 & 326.6 & 464.7 & 491.9 & 770.7 & 981.2 & 528.3 & 252.6 & $4,749.1$ \\
\hline 1980 & 35.0 & 59.2 & 0.0 & 32.0 & 462.5 & 408.3 & 613.1 & 641.0 & 817.1 & 649.7 & 515.5 & 118.5 & $4,351.9$ \\
\hline 1981 & 0.0 & 0.0 & 85.8 & 264.7 & 790.1 & 733.1 & 477.3 & 739.9 & 548.1 & 709.7 & 661.8 & 232.1 & $5,242.6$ \\
\hline 1982 & 126.9 & 82.1 & 14.7 & 308.0 & 694.2 & 540.4 & 444.4 & 726.1 & 760.7 & 635.0 & 184.1 & 0.0 & $4,516.6$ \\
\hline 1983 & 0.0 & 2.3 & 85.4 & 58.0 & 248.0 & 427.2 & 223.3 & 262.4 & 612.3 & 556.7 & 392.7 & 287.9 & $3,156.2$ \\
\hline 1984 & 11.0 & 156.2 & 83.7 & 89.1 & 359.8 & 723.7 & 474.0 & 513.3 & 815.6 & 916.8 & 518.2 & 16.1 & $4,677.5$ \\
\hline 1985 & 0.0 & 0.0 & 12.8 & 64.5 & 245.1 & 421.6 & 395.6 & 472.7 & 586.8 & 663.4 & 213.0 & 112.5 & 3,188.0 \\
\hline 1986 & 0.0 & 34.3 & 28.9 & 75.3 & 283.1 & 382.5 & 179.1 & 348.4 & 300.2 & 876.3 & 317.6 & 121.7 & $2,947.4$ \\
\hline 1987 & 0.0 & 0.0 & 113.3 & 37.7 & 304.2 & 426.2 & 812.0 & 500.8 & 690.8 & 640.1 & 180.0 & 229.7 & $3,934.8$ \\
\hline 1988 & 0.0 & 5.9 & 98.3 & 69.2 & 334.9 & 643.3 & 496.1 & 445.7 & 500.8 & 692.2 & 188.3 & 94.2 & $3,568.9$ \\
\hline 1989 & 2.3 & 0.0 & 7.4 & 5.5 & 207.8 & 399.5 & 623.4 & 592.7 & 666.2 & 640.2 & 278.1 & 103.1 & $3,526.2$ \\
\hline 1990 & 8.3 & 3.6 & 0.0 & 125.3 & 513.0 & 495.2 & 542.2 & 290.8 & 562.7 & 759.8 & 517.9 & 88.4 & $3,907.2$ \\
\hline 1991 & 25.6 & 0.0 & 93.1 & 110.7 & 539.5 & 342.7 & 460.8 & 454.3 & 643.5 & 415.0 & 416.1 & 116.7 & $3,618.0$ \\
\hline 1992 & 0.0 & 0.0 & 0.0 & 81.7 & 301.6 & 338.7 & 449.8 & 551.1 & 445.4 & 508.3 & 445.3 & 70.1 & $3,192.0$ \\
\hline 1993 & 43.1 & 0.0 & 62.4 & 116.6 & 340.3 & 453.1 & 276.8 & 614.8 & 546.3 & 402.2 & 417.1 & 64.3 & $3,337.0$ \\
\hline 1994 & 0.0 & 9.0 & 6.0 & 119.8 & 415.1 & 491.4 & 335.3 & 467.8 & 567.8 & 550.5 & 262.4 & 15.8 & $3,240.9$ \\
\hline 1995 & 0.0 & 0.0 & 19.7 & 292.4 & 517.4 & 463.1 & 490.5 & 512.4 & 492.1 & 464.9 & 356.3 & 162.1 & $3,770.9$ \\
\hline 1996 & 93.4 & 0.0 & 21.0 & 73.2 & 428.3 & 507.2 & 394.3 & 490.9 & 430.9 & 549.1 & 273.7 & 26.0 & $3,288.0$ \\
\hline 1997 & 51.4 & 5.2 & 22.1 & 65.4 & 318.7 & 300.6 & 151.3 & 132.2 & 394.3 & 222.2 & 426.9 & 3.5 & $2,093.8$ \\
\hline 1998 & 0.0 & 67.3 & 0.0 & 16.2 & 512.0 & 321.2 & 543.9 & 812.0 & 531.9 & 763.4 & 445.3 & 502.5 & $4,515.7$ \\
\hline 1999 & 48.3 & 122.8 & 15.3 & 155.4 & 392.6 & 625.6 & 310.0 & 704.3 & 750.9 & 471.2 & 468.6 & 355.5 & $4,420.5$ \\
\hline 2000 & 48.0 & 10.4 & 14.5 & 84.2 & 615.3 & 473.8 & 428.9 & 605.5 & 894.9 & 561.1 & 339.0 & 49.5 & $4,125.1$ \\
\hline 2001 & 42.1 & 0.0 & 92.4 & 23.2 & 752.4 & 417.8 & 393.6 & 571.8 & 820.5 & 942.6 & 488.1 & 124.2 & $4,668.7$ \\
\hline 2002 & 11.5 & 1.3 & 22.4 & 42.9 & 469.3 & 460.1 & 401.7 & 490.4 & 831.7 & 466.4 & 293.8 & 82.0 & $3,573.5$ \\
\hline 2003 & 0.0 & 17.7 & 175.7 & 153.2 & 421.0 & 766.4 & 589.1 & 639.7 & 648.0 & 621.7 & 693.8 & 218.9 & $4,945.2$ \\
\hline 2004 & 6.1 & 4.0 & 5.0 & 144.3 & 664.5 & 381.9 & 508.2 & 705.5 & 588.3 & 875.9 & 417.0 & 92.2 & 4,392.9 \\
\hline 2005 & 15.9 & 0.0 & 285.4 & 95.2 & 580.5 & 516.4 & 564.4 & 646.2 & 685.8 & 517.7 & 809.1 & 77.3 & $4,793.9$ \\
\hline 2006 & 170.6 & 4.0 & 39.6 & 143.6 & 382.7 & 374.8 & 672.1 & 479.6 & 355.4 & $1,000.5$ & 644.5 & 224.9 & $4,492.3$ \\
\hline 2007 & 0.2 & 0.0 & 10.6 & 173.5 & 567.2 & 512.2 & 531.5 & $1,167.3$ & 557.2 & 528.3 & 523.8 & 188.3 & $4,760.1$ \\
\hline 2008 & 0.0 & 191.2 & 34.7 & 108.6 & $1,116.0$ & 545.4 & 639.7 & 491.0 & 667.3 & 918.6 & 996.6 & 70.4 & $5,779.5$ \\
\hline 2009 & 56.7 & 32.7 & 43.6 & 44.7 & 401.1 & 500.9 & 493.4 & 708.9 & 403.5 & 575.8 & 581.2 & 146.6 & $3,989.1$ \\
\hline 2010 & 43.0 & 88.1 & 68.3 & 513.9 & 445.5 & 692.5 & 807.5 & 725.5 & 608.4 & 974.4 & 649.0 & 191.7 & $5,807.8$ \\
\hline 2011 & 12.5 & 12.2 & 23.5 & 82.4 & 399.5 & 643.6 & 543.4 & 527.2 & 694.2 & 532.9 & 525.8 & 199.6 & $4,196.8$ \\
\hline 2012 & 6.1 & 0.0 & 0.0 & 260.5 & 714.5 & 376.3 & 333.4 & 476.5 & 294.6 & 736.2 & 156.7 & 55.6 & $3,410.4$ \\
\hline 2013 & 0.0 & 3.0 & 46.5 & 103.1 & 535.5 & 547.7 & 527.8 & 560.0 & 598.0 & 872.1 & 374.7 & 75.0 & $4,243.4$ \\
\hline 2014 & 24.0 & N/D & N/D & N/D & N/D & N/D & N/D & N/D & N/D & N/D & N/D & N/D & 24.0 \\
\hline
\end{tabular}


Hato Pilón Precipitation $(\mathrm{mm})$

\begin{tabular}{|c|c|c|c|c|c|c|c|c|c|c|c|c|}
\hline \\
\hline 1 & 2 & 3 & 4 & 5 & 6 & 7 & 8 & 9 & 10 & 11 & 12 & MES \\
\hline N/D & N/D & N/D & N/D & N/D & N/D & N/D & N/D & N/D & N/D & N/D & N/D & N/D \\
\hline N/D & N/D & N/D & N/D & N/D & N/D & N/D & N/D & N/D & N/D & N/D & N/D & N/D \\
\hline N/D & N/D & N/D & N/D & N/D & N/D & N/D & N/D & N/D & N/D & N/D & N/D & N/D \\
\hline N/D & N/D & N/D & N/D & N/D & N/D & N/D & N/D & N/D & N/D & N/D & N/D & N/D \\
\hline N/D & N/D & N/D & N/D & N/D & N/D & N/D & N/D & N/D & N/D & N/D & N/D & N/D \\
\hline N/D & N/D & N/D & N/D & N/D & N/D & N/D & N/D & N/D & N/D & N/D & N/D & N/D \\
\hline N/D & N/D & N/D & N/D & N/D & N/D & N/D & N/D & N/D & N/D & N/D & N/D & N/D \\
\hline N/D & N/D & N/D & N/D & N/D & N/D & N/D & N/D & N/D & N/D & N/D & N/D & N/D \\
\hline N/D & N/D & N/D & N/D & N/D & N/D & N/D & N/D & N/D & N/D & N/D & N/D & N/D \\
\hline N/D & N/D & N/D & N/D & N/D & N/D & N/D & N/D & N/D & N/D & N/D & N/D & N/D \\
\hline N/D & N/D & N/D & N/D & N/D & N/D & N/D & N/D & N/D & N/D & N/D & N/D & N/D \\
\hline N/D & N/D & N/D & N/D & N/D & N/D & N/D & N/D & N/D & N/D & N/D & N/D & N/D \\
\hline N/D & N/D & N/D & N/D & N/D & N/D & N/D & N/D & N/D & N/D & N/D & N/D & N/D \\
\hline N/D & N/D & N/D & N/D & N/D & N/D & N/D & N/D & N/D & N/D & N/D & N/D & N/D \\
\hline N/D & N/D & N/D & N/D & N/D & N/D & N/D & N/D & N/D & N/D & N/D & N/D & N/D \\
\hline N/D & N/D & N/D & N/D & N/D & N/D & N/D & N/D & N/D & N/D & N/D & N/D & N/D \\
\hline N/D & N/D & N/D & N/D & N/D & N/D & N/D & N/D & 446.0 & $1,179.5$ & 744.0 & 22.1 & $2,391.6$ \\
\hline 6.4 & 7.9 & 4.1 & 313.1 & 586.3 & 549.6 & 256.2 & 474.9 & 539.8 & 745.5 & 539.7 & 117.2 & $4,140.7$ \\
\hline 5.4 & 31.0 & 19.4 & 281.0 & 610.2 & 708.4 & 785.1 & $1,369.0$ & 982.7 & $1,635.5$ & 814.9 & 95.9 & $7,338.5$ \\
\hline 9.2 & 1.7 & 69.3 & 65.0 & 937.5 & 785.9 & 406.5 & 716.6 & 934.7 & $1,378.6$ & 154.4 & 9.7 & $5,469.1$ \\
\hline 6.3 & 30.6 & 71.0 & 28.5 & 579.5 & 377.7 & 771.9 & 590.2 & 924.5 & 989.3 & $1,250.6$ & 159.8 & $5,779.9$ \\
\hline 0.0 & 0.0 & 0.0 & 68.3 & 407.3 & 569.2 & 174.3 & 372.6 & 518.9 & 713.1 & 196.5 & 27.3 & $3,047.5$ \\
\hline 0.0 & 0.0 & 0.0 & 44.1 & 505.0 & 444.5 & 132.5 & 740.3 & 405.7 & 609.5 & 428.6 & 52.9 & 3,363.1 \\
\hline 0.0 & 43.3 & 218.9 & 203.3 & 377.9 & 521.1 & 443.0 & 539.3 & 924.5 & 961.2 & 423.6 & 44.5 & $4,700.6$ \\
\hline 0.0 & 16.0 & 51.0 & 462.4 & 647.3 & 406.1 & 528.8 & 710.5 & 942.8 & $1,392.1$ & 807.6 & 197.8 & $6,162.4$ \\
\hline 19.3 & 0.0 & 0.0 & 158.2 & 884.5 & 659.6 & 554.9 & 566.0 & 939.7 & 830.2 & 668.0 & 117.8 & $5,398.2$ \\
\hline 2.8 & 0.0 & 155.1 & 215.8 & 938.0 & 722.8 & 537.2 & 741.1 & 586.7 & $1,220.1$ & 486.8 & 112.8 & $5,719.2$ \\
\hline 19.6 & 0.0 & 18.0 & 250.7 & 964.8 & 504.2 & 204.7 & 261.5 & $1,004.2$ & $1,121.1$ & 28.6 & 36.2 & $4,413.6$ \\
\hline 1.0 & 0.0 & 61.1 & 202.4 & 284.9 & 477.1 & 288.9 & 271.9 & 789.8 & 580.7 & 423.8 & 121.9 & $3,503.5$ \\
\hline 17.5 & 76.1 & 9.4 & 247.3 & 454.5 & 501.0 & 750.8 & 471.1 & 994.3 & 742.3 & 375.2 & 30.7 & $4,670.2$ \\
\hline 0.0 & 0.0 & 0.0 & 24.7 & 224.6 & 301.5 & 464.1 & 748.6 & 992.3 & 870.0 & 378.1 & 143.1 & $4,147.0$ \\
\hline 1.1 & 51.9 & 34.4 & 6.6 & 624.5 & 485.2 & 163.8 & 367.3 & 594.1 & $1,185.9$ & 270.8 & 33.5 & $3,819.1$ \\
\hline 8.8 & 30.0 & 103.1 & 51.7 & 524.2 & 349.0 & 622.4 & 411.6 & 844.7 & 995.3 & 209.6 & 139.5 & $4,289.9$ \\
\hline 6.7 & N/D & 85.7 & 194.8 & 543.1 & $1,142.6$ & 860.8 & $1,747.3$ & $1,131.2$ & $1,672.1$ & 382.8 & 24.4 & $7,791.5$ \\
\hline 5.2 & 0.0 & 11.5 & 11.8 & 416.6 & 756.7 & 617.1 & 716.4 & $1,205.2$ & 438.8 & 435.7 & 289.2 & $4,904.2$ \\
\hline 5.2 & 2.7 & 6.9 & 199.5 & 757.0 & 446.1 & 596.6 & 451.5 & 431.1 & $1,316.3$ & 646.2 & 159.8 & $5,018.9$ \\
\hline 52.3 & 0.0 & 200.6 & 138.9 & 715.8 & 713.6 & 145.3 & 403.6 & 736.6 & 848.7 & 226.0 & 151.7 & $4,333.1$ \\
\hline 0.0 & 3.6 & 0.0 & 83.9 & 437.1 & 625.4 & 444.9 & 417.1 & 675.2 & 455.6 & 387.0 & 39.1 & $3,568.9$ \\
\hline 78.5 & 0.0 & 123.3 & 150.5 & 789.1 & 667.9 & 177.0 & 745.9 & 942.5 & 697.6 & 518.8 & 92.5 & $4,983.6$ \\
\hline 0.0 & 23.3 & 2.5 & 192.4 & 434.1 & 400.2 & 279.0 & 334.9 & 769.6 & $1,306.2$ & 482.5 & 10.3 & $4,235.0$ \\
\hline 0.0 & 0.0 & 78.3 & 354.0 & 739.5 & 628.5 & 555.3 & 985.6 & 919.3 & $1,163.0$ & 386.2 & 190.4 & $6,000.1$ \\
\hline 133.6 & 20.9 & 50.5 & 161.8 & 875.4 & 751.0 & 732.0 & 813.0 & 902.3 & $1,120.1$ & 563.7 & 152.9 & $6,277.2$ \\
\hline 191.8 & 19.8 & 38.8 & 538.4 & 368.1 & 536.8 & 178.2 & 133.6 & 582.4 & 332.0 & 904.8 & 43.8 & $3,868.5$ \\
\hline 0.0 & 80.7 & 4.0 & 57.2 & 421.3 & 698.7 & 594.2 & 754.7 & 789.1 & $1,073.2$ & 557.7 & 468.2 & $5,499.0$ \\
\hline 66.6 & 89.2 & 31.9 & 397.6 & 571.3 & $1,129.8$ & 359.1 & $1,236.5$ & $1,340.9$ & $1,239.1$ & 434.1 & 261.3 & $7,157.4$ \\
\hline 10.9 & 6.4 & 4.3 & N/D & N/D & N/D & N/D & N/D & N/D & N/D & N/D & N/D & 21.6 \\
\hline N/D & N/D & N/D & N/D & N/D & N/D & N/D & N/D & N/D & N/D & N/D & N/D & N/D \\
\hline N/D & N/D & N/D & N/D & N/D & N/D & N/D & N/D & N/D & N/D & N/D & N/D & N/D \\
\hline N/D & N/D & N/D & $\mathrm{N} / \mathrm{D}$ & N/D & N/D & N/D & N/D & N/D & N/D & N/D & N/D & N/D \\
\hline N/D & N/D & N/D & N/D & N/D & N/D & N/D & N/D & N/D & N/D & N/D & N/D & N/D \\
\hline N/D & N/D & N/D & N/D & N/D & N/D & N/D & N/D & N/D & N/D & N/D & N/D & N/D \\
\hline N/D & N/D & N/D & N/D & N/D & N/D & N/D & N/D & N/D & N/D & N/D & N/D & N/D \\
\hline N/D & N/D & N/D & N/D & N/D & N/D & N/D & N/D & N/D & N/D & N/D & N/D & N/D \\
\hline N/D & N/D & N/D & N/D & N/D & N/D & N/D & N/D & N/D & N/D & N/D & N/D & N/D \\
\hline N/D & N/D & N/D & N/D & N/D & N/D & N/D & N/D & N/D & N/D & N/D & N/D & N/D \\
\hline N/D & N/D & N/D & N/D & N/D & N/D & N/D & N/D & N/D & N/D & N/D & N/D & N/D \\
\hline N/D & N/D & N/D & N/D & N/D & N/D & N/D & N/D & N/D & N/D & N/D & N/D & N/D \\
\hline N/D & N/D & N/D & N/D & N/D & N/D & N/D & N/D & N/D & N/D & N/D & N/D & N/D \\
\hline N/D & N/D & N/D & N/D & N/D & N/D & N/D & N/D & N/D & N/D & N/D & N/D & N/D \\
\hline N/D & N/D & N/D & N/D & N/D & N/D & N/D & N/D & N/D & N/D & N/D & N/D & N/D \\
\hline
\end{tabular}




\begin{tabular}{|c|c|c|c|c|c|c|c|c|c|c|c|c|c|}
\hline & & & & $\mathrm{GE}$ & $\begin{array}{l}\text { ESA DE } \\
\text { ERENCIA }\end{array}$ & DE HID & ROMETE & ERECTRIC & $\begin{array}{l}\text { CA, S.A. } \\
\text { GIIA }\end{array}$ & & & & \\
\hline & & & & & DALES & מת & 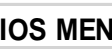 & $1-0$ & $\mathrm{~S}\left(\mathrm{~m}^{3} / \mathrm{s}\right)$ & & & & \\
\hline & & & & & & & & & & & & & \\
\hline Latitud & $08^{\circ}$ & 9'48" N & & & & & & & Número & $112-0$ & & & \\
\hline Longitl & Id: $: 82^{\circ}$ & 0'03" O & & & & & & & Provinci & : CHIRIO & & & \\
\hline Elevac & ión : 95 n & snm & & & & & & & Area de & Drenaje: & $198 \mathrm{Km}^{2}$ & & \\
\hline Informa & ación des & le : Julic & 1983 & & & & & & Tipo de & Estación : & : Cv & & \\
\hline Año & Ene & Feb & Mar & Abr & May & Jun & Jul & Ago & Sep & Oct & Nov & Dic & $\begin{array}{c}\text { Prom. } \\
\text { Anuales }\end{array}$ \\
\hline 1983 & & & & & & & & 7.621 & 38.93 & 42.89 & 37.963 & 13.765 & $5^{\prime} 28.23$ \\
\hline 1984 & 5.482 & 2.859 & 2.18 & 2.457 & 12.723 & 34.907 & 53.194 & 38.935 & 76.263 & 54.877 & 43.57 & 10.192 & 28.14 \\
\hline 1985 & 5.074 & 3.027 & 1.885 & 2.017 & 5.163 & 16.48 & 20.242 & 38.516 & 32.693 & 36.266 & 23.073 & 7.53 & $3 \quad 16.00$ \\
\hline 1986 & 2.854 & 1.666 & 1.97 & 1.313 & 9.548 & 18.13 & 16.029 & 10.175 & 37.83 & 70.471 & 14.942 & 8.12 & 216.09 \\
\hline 1987 & 4.777 & 3.122 & 2.567 & 2.086 & 2.889 & 4.884 & 13.104 & 24.477 & 33.642 & 50.508 & 17.414 & 9.435 & $5 \quad 14.08$ \\
\hline 1988 & 3.362 & 2.313 & 1.721 & 1.498 & 3.96 & 42.565 & 44.457 & 80.666 & 85.344 & 96.334 & 32.827 & 12.976 & $6 \quad 34.00$ \\
\hline 1989 & 6.492 & 3.88 & 2.567 & 1.682 & 3.44 & 15.979 & 24.021 & 21.909 & 59.444 & 25.872 & 20.246 & 21.191 & 117.23 \\
\hline 1990 & 6.144 & 3.14 & 1.876 & 1.504 & 4.862 & 10.031 & 18.036 & 14.605 & 25.969 & 75.896 & 43.138 & 16.876 & $6 \quad 18.51$ \\
\hline 1991 & 5.183 & 2.591 & 2 & 1.432 & 9.125 & 17.677 & 14.947 & 11.302 & 32.976 & 39.522 & 15.902 & 9.634 & $4 \quad 13.52$ \\
\hline 1992 & 3.438 & 1.787 & 0.63 & 1.403 & 3.161 & 12.497 & 12.759 & 14.746 & 36.577 & 28.185 & 12.139 & 13.001 & 111.69 \\
\hline 1993 & 4. & 2.402 & 2 & 2.413 & 15.556 & 27.584 & 19.601 & 28.427 & 54.762 & 61 & 77 & 11.03 & $3^{2} 20.21$ \\
\hline 1994 & 4.722 & 2 & & 1.567 & 4.745 & 61 & 14.026 & & 068 & & & 6.67 & $7 \times 16.35$ \\
\hline 1995 & 2.671 & 1.395 & 1.733 & 2.995 & 12.27 & 38.217 & 28.892 & 56.816 & 63.361 & 59.512 & 455 & 11.949 & 924.94 \\
\hline 1996 & 11.319 & 7.946 & 4.394 & 2.273 & 12.201 & 22.741 & & 41.617 & 45.127 & 79.8 & 27.543 & 3.285 & $5^{\prime} 24.39$ \\
\hline 1997 & & & & & 4.988 & 22.7 & 9.725 & 5.468 & & & 97 & 0.152 & 2 \\
\hline 1998 & 4.619 & 3.158 & 2.194 & 1.748 & 2.866 & 13.582 & 27.548 & 37.048 & 58.607 & 81 & 31.251 & & 21.95 \\
\hline 1999 & & & & 3.396 & 17.741 & 40.437 & & & 76.443 & 77.644 & & 6.248 & $8^{7} 38.65$ \\
\hline 2000 & 8.256 & 4.302 & 2.458 & 2.042 & 6.881 & 35.548 & 16.005 & 24.545 & 63.141 & 35.11 & 21.493 & 8.574 & 419.03 \\
\hline 2001 & 3.88 & 2.118 & 1.492 & 0.875 & 5.896 & 13.404 & 13.311 & 19.917 & 51.008 & 43.909 & 28.548 & 8.285 & $5^{\prime} 16.05$ \\
\hline 2002 & 4.057 & 2.25 & & & & 28.132 & 14.174 & 22.786 & 54.397 & 46.306 & 27.39 & 8.802 & 23.14 \\
\hline 2003 & 3.764 & 1.945 & 2.794 & 3.083 & 11.91 & 52.488 & 34.718 & 26.142 & 50.887 & 88.903 & & 17.885 & $5^{\prime} 26.77$ \\
\hline 2004 & 5.618 & 3.524 & 2.662 & 2.285 & 16.683 & 15.659 & 18.382 & 20.761 & 51.483 & 63.615 & 23.838 & 7.648 & $8^{\prime} 19.35$ \\
\hline 2005 & & & & & & & 27.162 & 20.07 & & 55.571 & 54.641 & & 39.36 \\
\hline 2006 & & & & & & & & 19.343 & 23.586 & 35.201 & & 9.399 & $9^{\prime} 21.88$ \\
\hline 2007 & 3.986 & 1.73 & & & & 38.602 & & & & & 31.831 & 8.448 & $8 \quad 16.92$ \\
\hline & & & & & & & & & & & & & \\
\hline & & & & & & & & & & & & & \\
\hline 2010 & & & & & & & & & & & & 14.81 & 1 14.81 \\
\hline 2011 & 3.465 & 1.13 & & & 2.239 & 11.639 & 19.634 & 20.262 & 22.088 & 935 & 8.848 & 7.641 & 12.79 \\
\hline 2012 & 2.29 & 0.654 & 0.337 & 0.907 & 5.542 & 12.215 & 19.634 & 20.262 & 22.088 & 30.935 & 8.848 & 7.641 & $1>10.95$ \\
\hline Prom. & 4.82 & 2.71 & 2.08 & 1.95 & 7.93 & 23.21 & 21.80 & 25.62 & 46.90 & 52.71 & 26.67 & 11.43 & 20.78 \\
\hline & & & & & & & & & & & & & \\
\hline ota & Valor $e$ & 010 & ung, & mple & to & $f$ & antes & & & & & & \\
\hline & Celda $\Theta$ & color & narill & in datc & & & & & & & & & \\
\hline & Valor $\mathrm{e}$ & colo & in & caud & lales est & IIITac & 年 & in & acus & & & & \\
\hline & Valor & & & & let & & - & - & te & Me & & & \\
\hline Cv & Estació & Hidron & étrica C & onvenci & onal & & & & & & & & \\
\hline
\end{tabular}




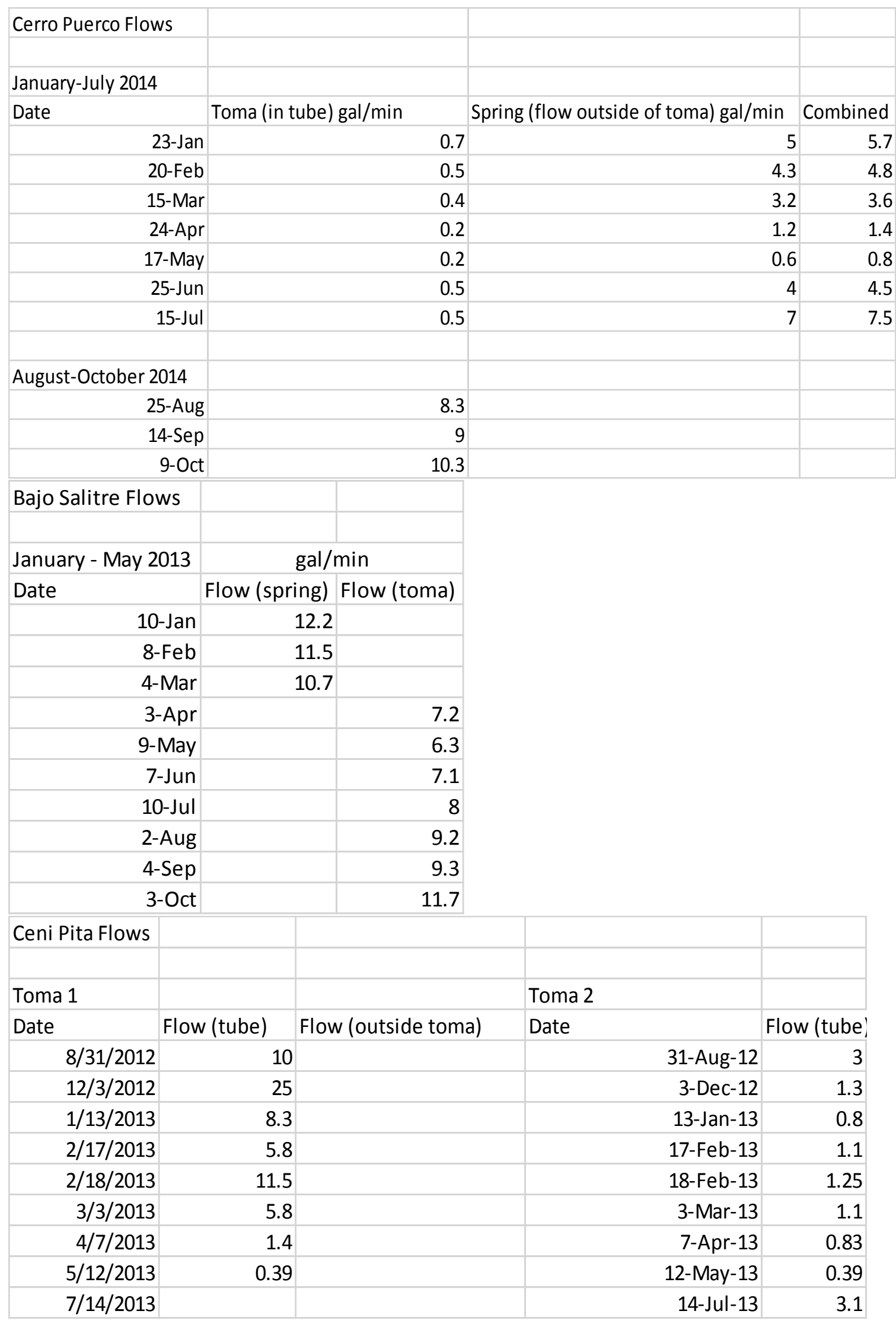

